National Public Health Institute, Department of Microbiology, Helsinki, Finland

University of Helsinki, Faculty of Medicine, Helsinki, Finland

\title{
MOLECULAR EPIDEMIOLOGY OF METHICILLIN-RESISTANT STAPHYLOCOCCUS AUREUS IN FINLAND
}

\author{
Saara Salmenlinna
}

Academic dissertation

To be publicly discussed, with permission of the Faculty of Medicine, University of Helsinki. Haartman Institute, Haartmaninkatu 3, Helsinki, November 8, 2002 at 12.00 noon 
Publications of the National Public Health Institute

KTL A20/2002

ISBN 951-740-303-8 (print)

ISBN 951-740-304-6 (pdf)

ISBN 951-740-304-4 (html)

ISSN 0359-3584

\section{Supervisor}

Docent Jaana Vuopio-Varkila, M.D, PhD.

Department of Microbiology,

National Public Health Institute, Helsinki, Finland

\section{Reviewers}

Docent Pentti Kuusela, M.D, PhD.

Department of Bacteriology and Immunology,

The Haartman Institute, University of Helsinki, Finland

Docent Mikael Skurnik, PhD.

Department of Medical Microbiology and Molecular Biology,

University of Turku, Finland

\section{Opponent}

Alex van Belkum, PhD.

Department of Medical Microbiology and Infectious Diseases, Erasmus Medical Center Rotterdam, Erasmus University,

Rotterdam, The Netherlands

\section{JULKAISIJA-UTGIVARE-PUBLISHER}

Kansanterveyslaitos

Mannerheimintie 166

00300 Helsinki

puh. (09) 47441

fax. (09) 47448238
Folkhälsoinstitutet

Mannerheimvägen 166

00300 Helsinki

tel. (09) 47441

fax. (09) 47448238
National Public Health Institute

Mannerheimintie 166

00300 Helsinki

phone. +358-0-47441

fax. $+358-0-47448238$ 
To my family 


\section{Contents}

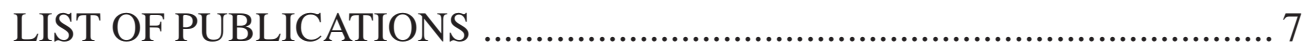

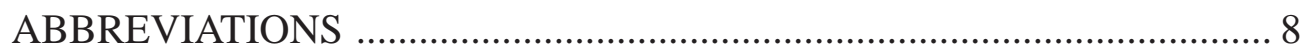

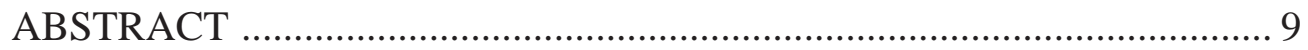

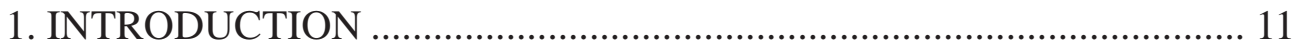

2. REVIEW OF THE LITERATURE ........................................................ 14

2.1 Staphylococcus aureus ................................................................ 14

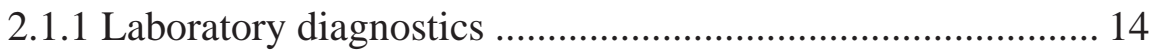

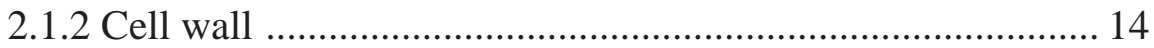

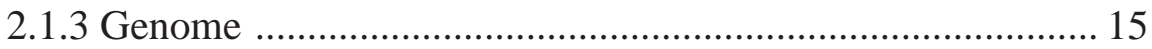

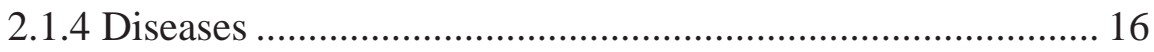

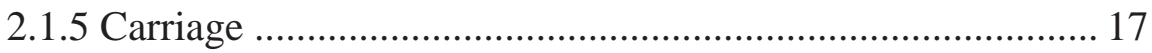

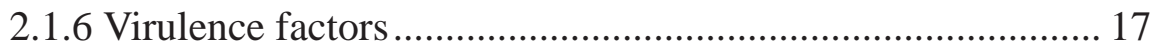

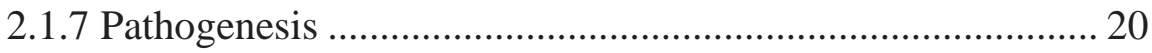

2.2 Methicillin-resistant

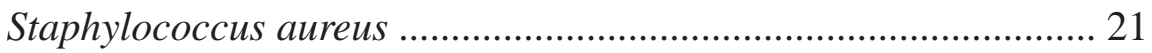

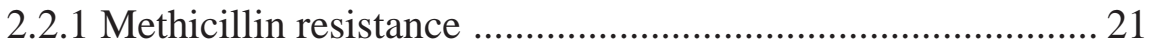

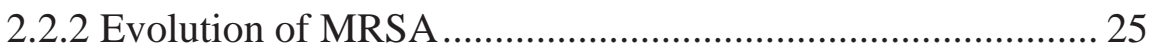

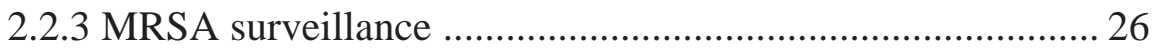

2.2.4 MRSA in health care facilities .............................................. 27

2.2.5 Community-acquired MRSA …………............................... 29

2.2.6 Molecular typing of MRSA ….............................................. 30

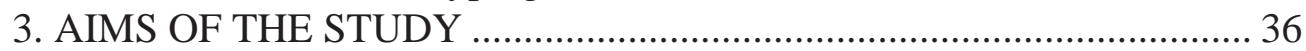

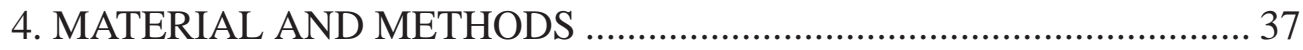

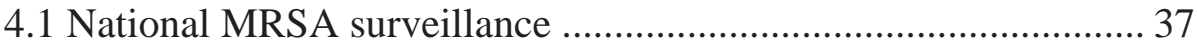

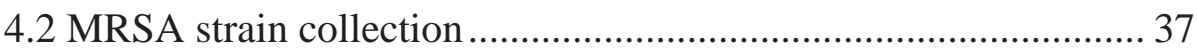

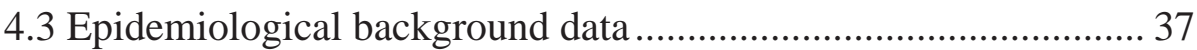

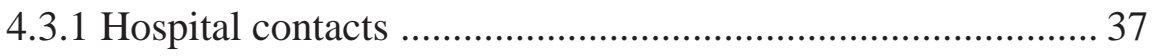

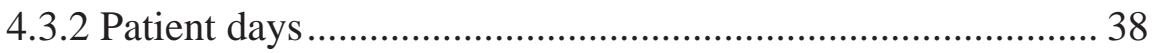

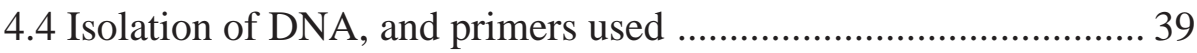

4.5 Identification and antimicrobial

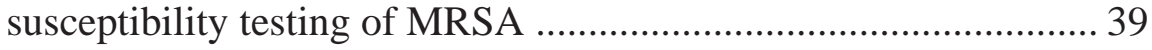

4.5.1 Antimicrobial susceptibility testing …….............................. 39

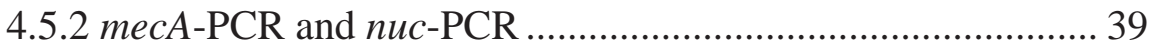

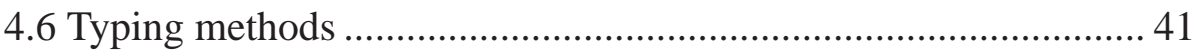

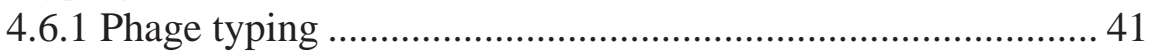

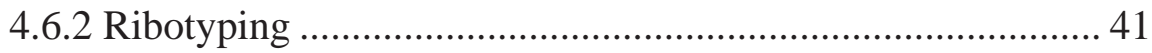

4.6.3 Pulsed field gel electrophoresis (PFGE) ............................... 41

4.6.4 Hypervariable region (HVR) hybridization ......................... 42

4.6.5 Multilocus sequence typing ............................................... 42 


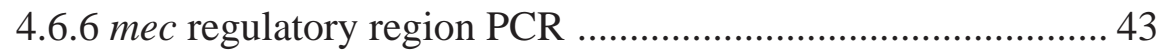

4.6.7 mec hypervariable region sequencing ................................. 43

4.6.8 Computer-assisted analysis of typing data ........................... 43

4.7 Definitions and nomenclature of strains ....................................... 43

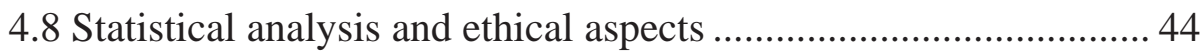

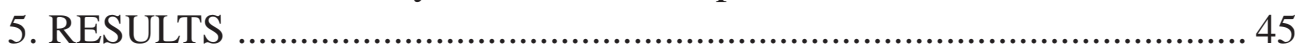

5.1 Elaboration of MRSA verification and typing (I, II, III, IV) ........ 45

5.2 MRSA trends and epidemic strains (I, II, III, IV) ......................... 46

5.3 Molecular traits linked to epidemic spread (II) .............................. 49

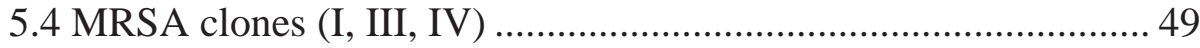

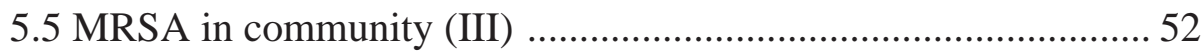

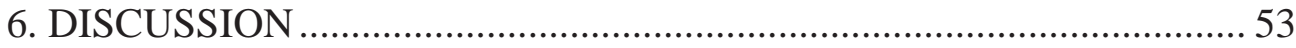

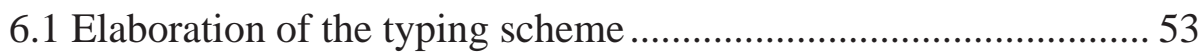

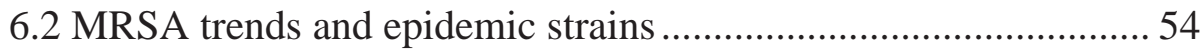

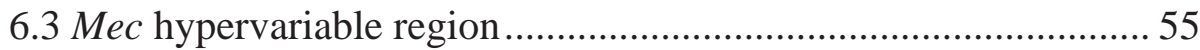

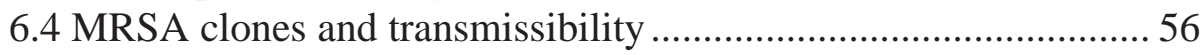

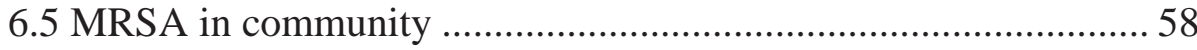

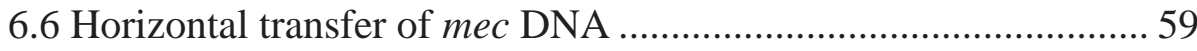

7. CONCLUSIONS AND CONSIDERATIONS

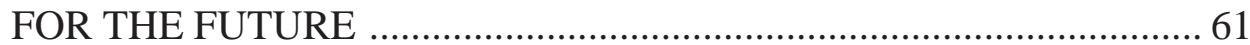

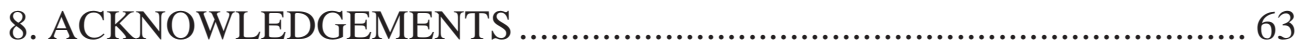

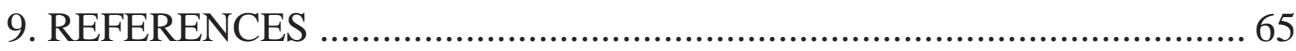

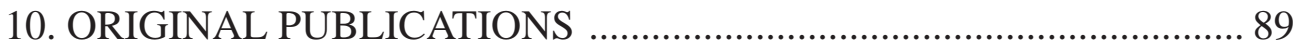




\section{LIST OF PUBLICATIONS}

This thesis is based on the following articles, which are referred to in the text by Roman numerals.

I. Salmenlinna S, Lyytikäinen O, Kotilainen P, Scotford R, Siren E, Vuopio-Varkila J. Molecular Epidemiology of methicillin-resistant Staphylococcus aureus in Finland. Eur J Clin Microbiol Infect Dis 2000;19:101-7.

II. Salmenlinna S and Vuopio-Varkila J. Recognition of two groups of methicillin-resistant Staphylococcus aureus strains based on epidemiology, antimicrobial susceptibility, hypervariable-region type, and ribotype in Finland. J Clin Microbiol 2001;39:2243-7.

III. Salmenlinna S, Lyytikäinen O, Vuopio-Varkila J. Community-acquired methicillin-resistant Staphylococcus aureus, Finland. Emerg Inf Dis 2002;8:602-7.

IV. Salmenlinna S, Vehkaoja L, Vuopio-Varkila J. Analysis of genetic background of predominant methicillin-resistant Staphylococcus aureus in Finland. Submitted for publication.

In addition, some unpublished results are included. 


\section{ABBREVIATIONS}

AFLP

$a g r$

aux

AP-PCR

BORSA

EARSS

FAME

fem

HELICS

ICU

Ig

IL

MIC

MRSA

GlcNAc

MurNAc

NCCLS

NINSS

NNIS

MHC

MLEE

MLST

MSCRAMM

ORF

PAGE

PBP

PCR

PFGE

PVL

RAPD

RFLP

sar

SCCmec

slv

ST

TSST 1 amplified fragment length polymorphism

accessory gene regulator

auxilliary factors for methicillin resistance

arbitrarily primed PCR

borderline resistant Staphylococcus aureus

European Antibiotic Resistance Surveillance System

fatty acid modifying enzyme

factors essential for methicillin resistance

Hospitals in Europe Link for Infection Control through Surveillance

intensive care unit

immunoglobulin

interleukin

minimal inhibitory concentration

methicillin-resistant Staphylococcus aureus

$\mathrm{N}$-acetylglucosamine

$\mathrm{N}$-acetylmuramic acid

National Committee for Clinical Laboratory Standards

Nosocomial Infection National Surveillance Scheme (UK)

National Nosocomial Infections Surveillance System(USA)

major histocompatibility complex

multilocus enzyme electrophoresis

multilocus sequence typing

microbial surface components recognizing adhesive matrix

molecules

open reading frame

polyacrylamide gel electrophoresis

penicillin binding protein

polymerase chain reaction

pulsed field gel electrophoresis

Penton-Valentine leucosidin

randomly amplified polymorphic DNA

restriction fragment length polymorphism

staphylococcal accessory gene regulator

staphylococcal casette chromosome mec

single locus variant

sequence type

toxic shock syndrome toxin 1 


\section{ABSTRACT}

Methicillin-resistant Staphylococcus aureus (MRSA) is a major cause of nosocomial infections worldwide, and hospital outbreaks caused by MRSA are common. Unless outbreaks are controlled, MRSA may reside permanently in a hospital environment. Such endemic MRSA are difficult to eradicate, and they most likely further increase the number of infections, the costs, and the length of hospital stays. MRSA strains are commmonly resistant to multiple antimicrobials, which narrows treatment possibilities and changes the spectrum of antibiotics prescribed in hospitals.

This study was performed to analyze comprehensively the Finnish MRSA isolates collected through a nationwide surveillance program since 1992 by various molecular methods. We describe the elaboration of a typing scheme suitable for continuous national surveillance in a country with a low prevalence of MRSA, and analyze the overall trends of MRSA, as well as the proportion of communityacquired MRSA. We especially focus on the characterization of predominant MRSA strains linked to interhospital epidemics and local intrahospital outbreaks. We assess clonality, evolution, association with community acquisition, and molecular traits linked to increased transmissibility.

The baseline number of annual MRSA remained stable in the 1980 s and early 1990s. After a peak caused by extensive hospital epidemics in
1994, an increasing trend has been observed. The incidence of MRSA increased from 1.7 in 1995 to 5.0 in 2000 per population of 100,000 . Between 1997 and 1999, one fifth of all MRSA isolates were from persons who had not been hospitalized within two years before the date of the MRSA isolation. It was suspected that these isolates had been acquired in a community setting.

A total of 38 epidemic or local outbreak strains were identified between 1992 and 2001. By phage typing, ribotyping, pulsed field gel electophoresis, and multilocus sequence typing, 31 of these strains clustered into eight different clones. Representatives of six clones had multilocus sequence types identical to international MRSA clones, the Brazilian, Iberian, UK EMRSA-16, UK EMRSA-15, New York, and Berlin clones. Together, these clones accounted for $35 \%$ of all MRSA isolates in 19971999. The remaining two clones, named Joensuu and Mikkeli, showed a molecular epidemiology different from that of the pandemic MRSA clones. The multilocus sequence type of Joensuu is commonly found among international methicillin sensitive $S$. aureus strains, and the Mikkeli sequence type is a single locus variant of another, apparently rare, MRSA type. The Mikkeli clone was the most prevalent MRSA clone in Finland between 1997 and 2001.

Phage typing, ribotyping, and pulsed field gel electrophoresis revealed that three strains were associated with community acquisition. 
These strains belonged to the Mikkeli and Joensuu clones, and the third was a triple allele multilocus sequence variant of the Joensuu clone.

Search for epidemicity markers revealed two different populations of MRSA strains. One group contained strains showing mec hypervariable region hybridization pattern A combined with a variety of ribotypes and resistance to beta lactam antibiotics only. The majority of these strains were sporadic by nature. The other group contained strains with mec hypervariable region hybridization pattern $\mathrm{B}$ or $\mathrm{C}$ in association with two ribotypes, and resistance to other antibiotic groups in addition to beta lactams. This group contained both epidemic and sporadic strains.

Taken together, these results suggest that two epidemiologically and evolutionarily distinct MRSA populations exist in Finland: 1) global clonally disseminated, often multiresistant strains, and 2) strains sensitive to multiple antibiotics with genetic backgrounds related to methicillin-sensitive $S$. aureus strains. Some strains of the latter population may have recently acquired the mec DNA through horizontal transfer, and this may have occured in a community setting as well. 


\section{INTRODUCTION}

Nosocomial infections cause a substantial burden for health and economics worldwide. A nosocomial infection is defined as an infection acquired in hospital, and which is not in the incubation phase on the patient's admission to hospital. However, a nosocomial infection may be caused by a colonizing organism which the patient carried before hospital admission (84). Such endogenous, sporadic infections account for the majority of all nosocomial infections $(136,290,302)$. Cross-transmission may lead to epidemics, i.e. an increased number of infections and/or colonizations.

Any microbial group, bacteria, viruses, fungi, or parasites can cause a nosocomial infection, but bacteria are the most prevalent organisms. Among gram positive bacteria, common nosocomial agents include staphylococci, enterococci, streptococci, and Clostridium difficile, and among gram negatives, Escherichia coli, Klebsiella sp, Enterobacter, Proteus, Serratia, Pseudomonas aeruginosa, Stenotrophomonas maltophilia, Acinetobacter spp, and Haemophilus spp. An additional concern is the emergence and dissemination of nosocomial organisms with increased resistance to antimicrobial agents. Such microbes include methicillin-resistant S. epidermidis and $S$. aureus, vancomycin-resistant enterococci, multiresistant and extended-spectrum beta-lactamaseproducing gram negative bacteria.

By extrapolating studies performed in Sweden, Norway, and the USA, it has been estimated that approximately 50,000 nosocomial infections occur annually in Finland, and about 1000 persons without a serious underlying disease die of nosocomial infections $(2,17,99,155)$. A recent study showed that the overall rate of nosocomial bloodstream infections in Finland is similar to the rates in England and in the USA, but S. aureus, enterococci and fungi are less common as causative agents in Finland (69, 157). The most common bloodstream pathogens in Finland are coagulase negative staphylococci (31\%), Escherichia coli (11\%), and S. aureus (11\%). Comparison of the number of nosocomial infections between hospitals and countries is difficult for several reasons. First, although definitions of different types of nosocomial infections exist, they may be interpreted in different ways by individual reseachers. Second, comprehensive reporting of nosocomial infections may be difficult to achieve without a substantial resource input. Third, denominator data should be suitable, and gathered in a uniform way $(30,155)$

Because of inevitable risk factors related to treatment or to patients, nosocomial infections cannot be totally eradicated. Invasive operations and devices create opportunities for microbes to invade the host tissue, and ingreasingly ill and compromised patients can be treated by evolving techniques and equipment. Risk factors most likely to result in colonization or infection with multiresistant species include advanced age, severity of ill- 
ness, inter-institutional transfer, prolonged hospital stay, gastrointestinal surgery, transplantation, exposure to medical devices, and exposure to broad-spectrum antibiotics (236). However, some of nosocomial infections are avoidable, namely those arisen through cross-transmission.

One of the most important pathogens causing considerable morbidity and mortality in hospitals is methicillin-resistant $S$. aureus (MRSA). Owing to expression of an additional penicillin binding protein, PBP2a, with decreased affinity to betalactam agents, MRSA is resistant to all beta-lactam antibiotics, including cephalosporins and staphylococcal penicillins (15). Many isolates of MRSA are also resistant to several other antimicrobial groups. Between 1997 and 1998, the SENTRY antimicrobial surveillance program gathered a total of 3981 monthly consequtive bacterial specimens from several types of infections: bloodstream, pneumonia, respiratory tract, skin and soft tissue, and urinary tract infections. Twenty-five European intensive care units were involved. The most prominent organism was S. aureus, and $39 \%$ of the isolates were resistant to methicillin (76).

The epidemiology of MRSA is changing constantly. Two new stages of MRSA evolution have occurred during recent years: emergence of MRSA strains with reduced susceptibility or with resistance to glycopeptide antibiotics (GISA or GRSA strains, respectively) (31), and com- munity-acquisition of MRSA by persons without known risk factors (29).

The first GISA strain was reported in 1997 in Japan, and thus far about two dozen strains of this type have been reported in different parts of world. The resistance mechanism involves thickening of cell wall peptidoglycan, which walls off vancomycin from the target (110). In July 2002, the first GRSA was reported in the USA in a catheter exit site in a patient with several underlying diseases and multiple courses of antimicrobial therapy. This strain showed minimal inhibitory concentration (MIC) of vancomycin and teicoplanin of $>128 \mu \mathrm{g} /$ $\mathrm{ml}$ and $32 \mu \mathrm{g} / \mathrm{ml}$, respectively, and contained the enterococcal vanA gene (31).

Community-acquired MRSA have been isolated from persons with risk factors for MRSA, such as intravenous drug use or previous hospital stays. However, between 1997 and 1999, community-acquired MRSA caused fatal infections in four children without any known risk factors for MRSA (29). Although it is not known whether the community-acquired isolates were originally hospital born, it seems that transmission of MRSA may occasionally occur in the community, and serious infections may develop in previously healthy persons.

This study focuses on molecular epidemiology of MRSA in Finland by analyzing, by various typing methods, the MRSA strain collection gathered by nationwide MRSA surveillance between 1992 and 2001. 
The resulting molecular information allows the development of a hypothesis on the evolution of different populations of MRSA, and examined together with epidemiological background information, the characterization of strains associated with community acquisition. 
2. REVIEW OF THE LITERATURE

\subsection{STAPHYLOCOCCUS AUREUS}

\subsubsection{Laboratory diagnostics}

S. aureus is a gram positive, catalase positive aerobic or anaerobic coccus showing hemolytic and large yellow colonies. The laboratory diagnostics is based on culture and biochemical tests: typical morphology, positive coagulase reaction, fermentation of mannitol and trehalose, and production of heat stabile nuclease (thermonuclease). The ability of coagulase to clot plasma is the most widely used method for identification. A four-hour tube coagulase test with reconsituted plasma is definitive, and a slide test for bound coagulase is a means of rapid screening for species identification (130). Latex agglutination tests, such as Slidex Staph Plus (Biomérieux, France) and Staphaurex Plus (Murex Biotech, England), consist of latex particles coated with IgG (bound by protein A), fibrinogen (bound by clumping factor), and $\operatorname{IgG}$ for $S$. $a u$ reus specific antigens. The thermonuclease can be detected using a metachromatic agar diffusion procedure and DNA toluidine blue agar (143).

\subsubsection{Cell wall}

The outermost layers of pathogens are important in the infection process (6). Most $S$. aureus isolates are covered by a polysaccharide capsule. Capsular polysaccharides can be classified into eleven different serotypes. Beneath the capsule $S$. aureus harbors a typical gram positive cell wall (86). The gram positive cell wall differs from that of gram negative bacteria in two major characteristics: a gram positive cell wall has a thicker and highly crosslinked peptidoglycan layer, and it lacks the outer membrane $(12,18$, 220, 287) (Figure 1).

Figure 1. Schematic presentation of $S$. aureus cell wall.

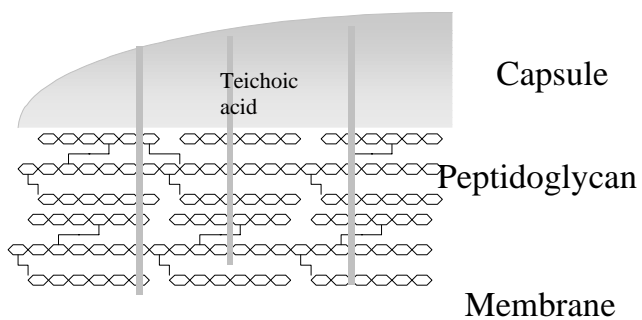

Membrane

The peptidoglycan consists of glycan strands of $\mathrm{N}$-acetylglucosamine-N-acetylmuramic acid (GlcNAc-MurNAc) disaccarides, crosslinked by tetrapeptides consisting of L-alanine, D-glutamine, Llysine, and D-alanine (86). In S. aureus, a pentaglysine inter-bridge links the tetrapeptide units of adjacent glycan strands. $S$. aureus produces four penicillin-binding proteins, PBP1-4, involved in the cell wall peptidoglycan assembly (141). The biological activity of these native PBPs is similar to that of serineproteases, and they act as transpeptidases in the crosslinking of the glycan chains $(181,299)$. PBP2 
is a bifunctional protein which, in addition to transpeptidase activity, also acts as transglycosylase (91). PBPs bind effectively to beta-lactam antibiotics, and in the presens of these agents, the cell wall assembly is discontinued.

Another common feature in the gram positive cell wall is teichoic acid, a carbohydrate-phosphate polymer covalently linked to MurNAc (12). Teichoic acids bind divalent cations and possess antigenic properties (146).

\subsubsection{Genome}

The genomic positions of various genetic markers of S.aureus have been localized by creating physical maps of the genome. The development of $S$. aureus chromosomal maps began through definition of three linkage groups consisting of nine auxotrophic markers and a novobiocin resistance marker on S. aureus NCTC 8325 (211). By inclusion of a large number of additional markers, and the use of pulsed field gel electrophoresis (PFGE) and subsequent hybridization with available probes, the physical map of S. aureus NCTC 8325 continued to be more and more precise (116, 210, 295) (Figure 2). However, until data from genome sequencing became available, the mutual distances between genetic markers within each PFGE fragment were unknown.

Figure 2. S.aureus NCTC 8325 physical map. Adapted from (205). SmaI restriction fragments A-P, their sizes in kilobase pairs, and examples of identified genetic markers.

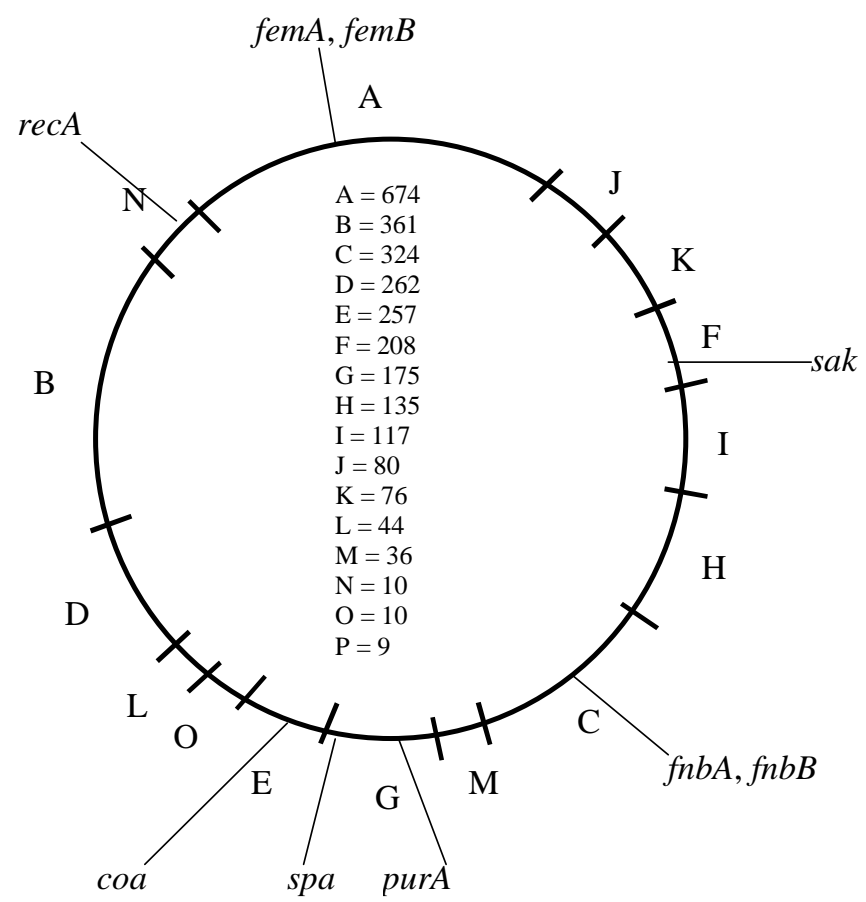


Knowledge of bacterial structures and functions has increased and will further increase owing to recent advances in genome sequencing and in other genome-wide analysis. To date, genomes of seven $S$. aureus strains have been elucidated or are soon to be completed, COL, NCTC 8325, N315, Mu50, MW2, UK EMRSA-16, and MSSA 476, (http:// www.sanger.ac.uk/Projects/S_aureus, http://www.tigr.org/tigr-scripts/ CMR2/CMRHomePage.spl, http:// www.genome.ou.edu/staph.html) (11, 139). Half of all predicted proteins of strain N315 were similar to those of Bacillus subtilis or Bacillus halodurans, and these proteins mostly coded for essential functions such as DNA replication, protein synthesis, and carbohydrate metabolism. Nearly $40 \%$ of all predicted proteins were similar to as yet unknown proteins, or showed no sequence similarity in global databases. Furthermore, some of the open reading frames (ORFs) were similar to those of taxonomically distant organisms, but not all of them differed in GC content or codon usage. However, the first sextant of the chromosome showed accumulation of ORFs with unusual codon composition. It has been suggested that this region contains exogenous genes recently acquired through lateral transfer (139).

\subsubsection{Diseases}

Staphylococcus aureus causes a wide variety of diseases, from mild skin infections to severe life threatening systemic infections (297). It is a common cause of skin and subcutaneus infections, including folliculitis, furunculosis, cellulitis, mastitis, and impetigo. Recurrent abscesses of the skin and the subcutaneous tissue may be difficult to treat. The preferable tratment for folliculitis and local abscesses is surgical drainage, whereas cellulitis is usually treated with antimicrobials. Impetigo can range from mild, recurrent infections to a more severe bullous form and to the potentially life-threatening scalded skin syndrome (144). S. aureus is also commonly associated with postoperative wound infections, catheter-related infections, toxic shock syndrome (TSS), and food poisoning. TSS and food poisoning are toxin-mediated diseases. The common, self-limiting, food poisoning is caused by enterotoxins present in contaminated food, and is characterized by nausea, vomiting, headache, and sometimes diarrhea. The symptoms start four to five hours after consumption of contaminated food $(112,304)$. TSS, caused by TSST-1, is a potentially fatal condition, most commonly associated with the use of highly absorbent tampons, but also known in non-invasive $S$. aureus infections in children. The symptoms include high fever, rash, desquamation of skin one to two weeks after onset, hypotension, and involvement of multiple organ systems $(63,247,268)$

Serious $S$. aureus infections include osteomyelitis, pneumonia, sepsis, acute endocarditis, myocarditis, pericarditis, cerebritis, meningitis, scalded skin syndrome, and sterile site 
abscesses (297). S. aureus pneumonia is rare in a community setting, but fairly common in a hospital setting, especially as a consequence of influenza in elderly patients (154). Acute osteomyelitis primarily affects long bones in children, whereas chronic (duration of infection $>6$ months) osteomyelitis is more common in adults after bacteremia, or as a complication of penetrating wounds (298). S. aureus sepsis most often originates in a local infection focus such as cellulitis, pneumonia, or a wound, or is related to an intravascular device (301). Complicated sepsis may hematogenously spread the infection to other organs, such as heart, bone, and joints. Annually, $S$. aureus causes 700-900 septic infections in Finland, and is the third most common causative agent of nosocomial sepsis (157). S. aureus endocarditis can present as right-sided endocarditis, often among intravenous drug users, as left-sided native valve infection, or as prosthetic valve endocarditis (120)

\subsubsection{Carriage}

Nasal carriage of $S$. aureus is one of the major risk factors for $S$. aureus infection (131). Although $S$. aureus can be found in different parts of the body, anterior nares is the primary ecological niche in humans $(65,227)$. In the healthy population $10-35 \%$ of individuals carry $S$. aureus persistently, $20-75 \%$ intermittently, and $5-50 \%$ never carry $S$. aureus in the nose. Proportions of nasal carriage patterns differ, depending on the study design and definitions for persistant-, intermittent-, and non-carrier (192). Other risk factors for $S$. aureus infection include age, dialysis, repeated rupture of the skin, and underlying conditions, such as renal or liver disease and diabetes.

\subsubsection{Virulence factors}

S. aureus harbors an extensive arsenal of virulence factors contributing to its ability to propagate and spread within the human host. The form and severity of the disease result from a complex interplay between the host defense and the activities of the virulence factor repetoire of the infecting strain. Considerable knowledge exists on the contribution of several virulence factors to specific diseases. Much less is known of the conserted action of these factors, their interaction with the host, and the relative importance of each factor in infection. One virulence factor may be indispensable in some infections, but insignificant in others. According to their biological function, the virulence factors can be divided into three groups: those involved in adhesion, in host defense evasion, and in tissue penetration (Table 1). One factor can serve in one or more of these activities, and different factors are produced in different growth phases.

Most clinical $S$. aureus strains produce capsular polysaccaride of serotype 5 or 8 . The capsule may inhibit binding of antibodies and thereby opsonization, and phagocytosis (264, 266). In addition, capsular polysaccharide may have a role in bacterial ad- 
Table 1. Examples of Stapylococcus aureus virulence factors. $\uparrow=$ upregulation, $\downarrow=$ downregulation. Adapted from (223), table 3-1, and from (193), table 1. n.d, not determined or not reported in the literature.

\begin{tabular}{|c|c|c|c|c|c|}
\hline Virulence factor & Gene & Regulation system & $\begin{array}{l}\text { Production } \\
\text { phase }\end{array}$ & $\begin{array}{l}\text { Proposed virulence } \\
\text { function }\end{array}$ & Reference \\
\hline Clumping factor & clfA & sar & Exponential & Attachment & $(41,175)$ \\
\hline Fibrinogen binding protein $\mathrm{A}$ & $f b a A$ & agr, sar & Exponential & Attachment & $(40)$ \\
\hline Fibronecting binding protein $\mathrm{B}$ & $f n b B$ & agr, sar & Exponential & Attachment, invasion & $\begin{array}{l}(45,127,173, \\
252)\end{array}$ \\
\hline Collagen binding protein & cna & sar & Exponential & Attachment & (21) \\
\hline Coagulase & coa & agr, sae & Exponential & Attachment & $(87,226)$ \\
\hline Protein A & spa & $\begin{array}{l}\text { agr, sarA, } \\
\text { sarS, sae }\end{array}$ & Exponential & $\begin{array}{l}\text { Host defence evasion, } \\
\text { attachment }\end{array}$ & $(42,87,104)$ \\
\hline Enterotoxin A & entA & agr & All & Host defence evasion & (63) \\
\hline Enterotoxins B-E, G-J & ent $B-E$, ent $G-J$ & agr & Postexponential & Host defence evasion & (63) \\
\hline Toxic shoc syndrome toxin & tst & agr , sar & Postexponential & Host defence evasion & (63) \\
\hline Exfoliative toxin & eta, etb & agr & Postexponential & Host defence evasion & (144) \\
\hline Lipase & geh & agr, sar & Postexponential & Host defence evasion & (21) \\
\hline Serine protease & $\operatorname{spr}$ & agr, sar & Postexponential & Host defence evasion & $(224)$ \\
\hline V8 protease & $\operatorname{sas} P, \operatorname{ssp} A$ & agr, sar & Postexponential & Host defence evasion & $(8,127)$ \\
\hline $\begin{array}{l}\text { Fatty acid metabolizing } \\
\text { enzyme }\end{array}$ & n.d. & agr , sar & Postexponential & Host defence evasion & $(33,178)$ \\
\hline Penton-Valentine leucosidin & $\begin{array}{l}l u k F-P V, \text { lukS- } \\
P V\end{array}$ & n.d. & Postexponential & Host defence evasion & \\
\hline Leucosidin R & $l u k F-R, l u k S-R$ & agr & n.d. & Host defence evasion & \\
\hline Capsular polysaccarides & cap1-8 locus & agr & Postexponential & Host defence evasion & $(156)$ \\
\hline Staphylokinase & sak & agr & n.d. & Host defence evasion & (8) \\
\hline Hemolysins , & hla, hlb, hld & agr, sarA & Postexponential & Tissue penetration & (226) \\
\hline Hemolysin & hlg & agr & Postexponential & Tissue penetration & (8) \\
\hline Phospholipase C & plc & agr & n.d. & Tissue penetration & (8) \\
\hline Metalloprotease & aur & agr & n.d. & Tissue penetration & (8) \\
\hline Hyaluronidase & hysA, hal & agr & Postexponential & Tissue penetration & $(8)$ \\
\hline
\end{tabular}


hesion to polymer surfaces in medical devices (180).

The role of free coagulase in the virulence of $S$. aureus is uncertain. However, since it is produced by the majority of strains and has biological function as a prothrombin activator, it is considered a probable virulence factor. The cell wall bound clumping factor, another fibrinogen binding protein, shares a significant sequence similarity with coagulase, and its role in adherence is clearer than that of coagulase $(61,175,250)$.

Surface proteins needed in attachment to host tissue are expressed in the logarithmic growth phase during cell wall synthesis. These microbial surface components recognizing adhesive matrix molecules (MSCRAMMs) (212) include fibronectin binding protein, fibrinogen binding protein, collagen binding protein, and clumping factor. Protein A, another surface protein also produced during cell wall synthesis, may have a role in host defense evasion, since its biological function is to bind the IgG Fc-domaine (277). The surface proteins of gram positive bacteria have a common overall structure. An aminoterminal secretory signal peptide directs the export of the protein, and it is then cleaved off. The hydrophobic carboxyterminal remains within the cell membrane, and just outside of the cell membrane the protein is then cleaved between threonine and glycine residues in a well-conserved LPXTG motive. In staphylococci, the protein is anchored to the pentaglycine cross- bridge in the cell wall peptidoglycan. A proline-rich area spans the cell wall, and the extracellular amino-terminus contains a unique sequence that recognizes the target molecule in its environment (77).

$S$. aureus produces a wide variety of exoproteins, most of them during the postexponential growth phase. These proteins degrade the host tissue to nutrients required for the growth of the bacteria, and/or allow the bacteria to penetrate deeper into the host tissue (63). The majority of strains produce hemolysins, nucleases, proteases, lipases, hyaluronidase, and collagenase. Alpha-hemolysin (or alphatoxin) is dermonecrotic, neurotoxic, and lyses mammalian cells, especially red blood cells, by forming a pore in the target membrane (19). Betahemolysin acts as sphingomyelinase, gamma-hemolysin has leucocytolytic activity, and it has been suggested that delta-hemolysin has surfactant or channel forming properties (63). Staphylokinase is a plasminogen activator (145). Hyaluronidase digests hyaluronic acid present in the skin, bone, umbilical cord, vitreous body of the eye, and synovial fluid. Some $S$. aureus strains produce additional exoproteins, which may have host defense evasion as their major function in vivo. One serine protease has the ability to cleave and inactivate $\mathrm{IgG}$ antibodies (224). Another function of proteases may include protection against antimicrobial peptides. It has been proposed that a fatty acid modifying enzyme (FAME) detoxifies bactericidal 
fatty acids (178). Penton-Valentine leucocidin (PVL) has leucocytolytic activity. Exfoliative toxin, TSST 1, and enterotoxins A-E and G-J are potent superantigens $(63,144)$.

Genes for $S$. aureus virulence factors may reside in plasmids, bacteriophages, transposons, or pathogenicity islands of the chromosome. Recent sequencing of two $S$. aureus strains revealed three new classes of pathogenicity islands: TSST family islands, exotoxin islands, and enterotoxin islands. A considerable number of new putative virulence genes were also identified (139).

The genes coding for virulence factors are not essential for cell-division and growth, but are useful in certain situations and environments. Constitutive expression of these genes would be an unnecessary waste of energy. Instead, many virulence factors are concomitantly upregulated, whereas others, not needed at that point in time, are down-regulated (Table 1). Two major global regulator systems have been identified: accessory gene regulator $(a g r)$ and staphylococcal accessory gene regulator (sar) (8). Other regulatory genes and operons, such as $s a e, \operatorname{sig} B, s s r A$-ssrB , and $\operatorname{arl} S$-srlR $(78,87,138,310)$, as well as environmental factors (172), also affect the regulation of virulence factors.

The agr regulation turns off the surface protein expression in the late exponential phase of growth, and turns on the synthesis of secreted proteins for a relatively short time period. The swich-off mechanism of the secreted proteins' expression is unknown. Two distinct $a g r$ gene products, generated from promoter $\mathrm{P} 2$, form a classical signal transduction pathway, which is activated by an autoinduction protein also translated from the same promoter. Signal transduction leads to activation of a response regulator AgrA (195). AgrA acts together with another accessory transcription factor, SarA, to further upregulate promoter $\mathrm{P} 2$ and another agr promotor, P3 (43). The transcript from the latter, RNAIII, is the actual effector in the agr-regulation (195). RNAIII primarily acts at the transcription level, probably through one or more regulatory proteins. It has also been shown that RNAIII forms a specific complex with leader sequences of some of the upregulated genes (177). SarA, coded for by the sar locus, regulates the expression of certain exoprotein genes directly, without agr-activity. Many such genes, as well as the intergenic region between $\mathrm{P} 2$ and $\mathrm{P} 3$ of the agr operon, contain an AT-rich sequence recognized by SarA (43).

\subsubsection{Pathogenesis}

Staphylococcal pathogenesis results from various bacterial activities mediated by virulence factors, and from the immunological response by the host. It is commonly thought that bacterial adherence to host tissue is a prerequisite for colonization and infection. This is achieved by the MSCRAMMs (212). Subsequent survival, growth, and establishment of infection depend on the ability of the bacterium to circumvent host defense. The primary host response is mediat- 
ed by polymorphonuclear leucocytes (288), which are attracted by expression of adhesion molecules on endothelial cells. The cell wall components, peptidoglycan and teichoic acids, trigger signaling pathways leading to the release of cytokines $(70,106)$. Leucocytes and other host cellular factors can be destructed by locally acting bacterial toxins. Anti-inflammatory response is also achieved by the staphylococcal extracellular adherence protein, Eap, which inhibits the recruitment of host leucocytes by direct interaction with the host adhesive proteins ICAM-1, fibrinogen, and vitronectin (39). If not attenuated enough, however, the robust local inflammatory response may lead to the formation of an abscess. Inside an abscess, the bacteria gradually fall into a state of nutritional stress as the density of bacteria increases. At this point the autoinduction of secreted virulence factors could enable the bacteria to break out and spread to new locations (194).

In toxin mediated diseases, superantigens bind non-specifically to the major histocompatibility complex II (MHC II) and crosslink it to the variable beta chain of T-lymphocyte. Since the normal route of internalization, processing, and antigen presentation is bypassed, this unspecific binding leads to massive expansion of T-lymphocytes and production of cytokines. Superantigens also induce endotoxin hypersensitivity and bind directly to endothelial surfaces, probably causing capillary leakage through endothelial cell death or intercellular gap formation.

In invasive diseases, such as sepsis and endocarditis, staphylococci must interact with the endothelium. By using MSCRAMMs, the bacteria can adhere to damaged areas of the endothelium, or directly to the endothelial cell via the adhesin-receptor mechanism or via bridging ligands (122). The bacteria may then be phagocytized into endothelial cells $(102,196)$ and/or reach the underlining tissue (154). Both endothelial phagocytosis and tissue invasion elicit an inflammatory response leading to the relase of IL $-1,-6,-8$, tumor necrosis factor (TNF), and subsequently interferongamma. Leucocytes adhere to endothelial cells and increase vascular permeability.

Although $S$. aureus is primarily an extracellular pathogen, it may sometimes survive inside non-professional phagocytes, such as fibroblasts, renal cells, and osteoblasts. Intracellular survival may explain the persistent and recurrent nature of certain staphylococcal infections (222). Intracellular staphylococci often appear as small colony variants which have mutations affecting electron transport (170), and show slowly growing, nonpigmented colonies with reduced production of virulence factors (291).

\subsection{METHICILLIN-RESISTANT STAPHYLOCOCCUS AUREUS}

\subsubsection{Methicillin resistance}

Methicillin-resistant strains of $S$. $a u$ reus are able to grow in the presence of beta-lactams and its derivatives, 21 
including cephalosporins and staphylococcal penicillins. Low-level methicillin resistance can result from the production of large amounts of betalactamases, or increased production and/or modified penicillin-binding capacity of normal PBPs $(168,269)$. Such borderline resistant $S$. aureus strains (BORSA) seldom have minimal inhibitory concentrations (MIC) of methicillin exceeding $16 \mu \mathrm{g} / \mathrm{ml}$, and their clinical significance is thought to be limited. The challence is to differentiate BORSA strains from the true methicillin-resistant Staphylococcus aureus (MRSA) strains (35).

The most clinically relevant and the most prevalent form of methicillin resistance is characterized by production of an additional penicillin binding protein, PBP2a (or PBP2') $(26,228,275)$. PBP2a has probably evolved by recombination of a penicillinase gene and a PBP gene similar to PBP2 and PBP3 of Escherichia coli (255). PBP2a has an unusually low binding affinity for all beta-lactam antibiotics, substituting the native PBPs and allowing continuous cell wall assembly $(36,228)$. However, the production of PBP2a alone is not sufficient for optimal expression of methicillin resistance (216). Native PBP2 provides the transglycosylase function of glycan chain elongation in spite of the presence of beta-lactams, and $\mathrm{PBP} 2 \mathrm{a}$ is required for the transpeptidase function (215).

The PBP2a is inducible and coded by the mecA gene, which is part of an additional DNA region, staphylo- coccal casette chromosome mec (SC$\mathrm{Cmec}$ ), found in methicillin-resistant strains, but not in methicillin-susceptible strains $(14,128,167)$. SCCmec is always located in the same region in the $S$. aureus chromosome, between spa and purA $(137,209)$. The sequence of the chromosomal region where SCCmec is integrated seems to be highly homologous among different strains. Four structurally different SCCmec types (SCCmec I-IV) and a few variants have been identified (Figure 3.) $(117,158,198)$. All SCCmec types contain common features, including the mecA gene and part of its regulatory region, and $c c r A$ and $c c r B$ genes. The mecRl-and mecl-genes code for the regulatory proteins of the $m e c A, \operatorname{Mec} \mathrm{R} 1$ is a signal transducing protein with a penicillin binding domain and a transmembrane domain, and MecI is a repressor protein of the mecA gene (140, 248, 263). ccrA and $c c r B$ code for recombinases CcrA and $\mathrm{CcrB}$ of the resolvase-invertase family. CcrA and $\mathrm{CcrB}$ are required for site and orientation specific integration and excision of the SCCmec (118, 128).

Other genetic and environmental factors independent of SCCmec also have influence on methicillin resistance $(15,16,34,56,57,235)$. Insertional inactivation studies have identified several normal staphylococcal genes necessary for methicillin resistance. Mutations in these fem (factors essential for methicillin resistance) or aux (auxilliary) factors inhibit the peptodoglycan precursor for- 
Figure 3. SCCmec types according to published sequences, accession numbers AB033763 (SCCmec I), AB063172 (SCCmec IV), D86934 (SCCmec II), and AB037671 (SCCmec III).

\footnotetext{
$\square$ Casette chromosome recombinase $(\operatorname{ccr} A, \operatorname{ccr} B)$

Penicillin binding protein 2' (mecA)

Two componen regulator of $m e c A$ ( $m e c I$ and $m e c R l$ )

Insertion sequence (IS431 or IS1272)

Transposon, plasmid (Tn554, Tn554\%, pUB110)

Other elements (genes)
}

SCCmecI, 34kbp

IS 1272

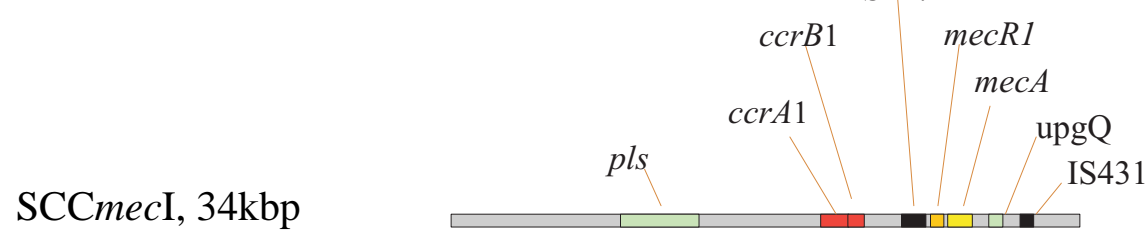

SCCmecIV, 24kbp

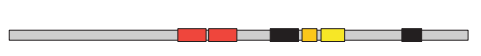

SCCmecII, 53kbp $k d p$ operon $\quad T$ Tn554 pUB110

SCCmecIII, 67kbp $\quad x y l r \quad$ repC $\quad$ mer operon

mation (Figure 4). FemA, FemB, and FemX (or FmhB) add glycine recidues in the pentaglycine interbridge between peptidoglycan strains (230, 256). Amidation of glutamate in the stem peptide is inhibited in $\mathrm{femC}$ (or $g \ln R$ ) mutants $(97,257)$, glucosamine1-phosphate formation is inhibited in femD (or femR or glmM) mutants (124), and precursor formation is blocked at the lysine addition step in femF mutants (202). Other factors that may have influence on methicillin resistance include global regulators sar and $\operatorname{agr}(217)$, ilm gene coding for a lipophilic membrane protein, and genes coding for murein hydrolases.

The expression of methicillin resistance varies among strains (107, 166, 234). Strains with intact mecI$m e c R 1$ regulon are phenotypically methicillin sensitive, since mecA is effectively repressed by MecI (260). Constitutive expression of methicillin 
Figure 4. Factors affecting peptidoglycan assembly and methicillin resistance.

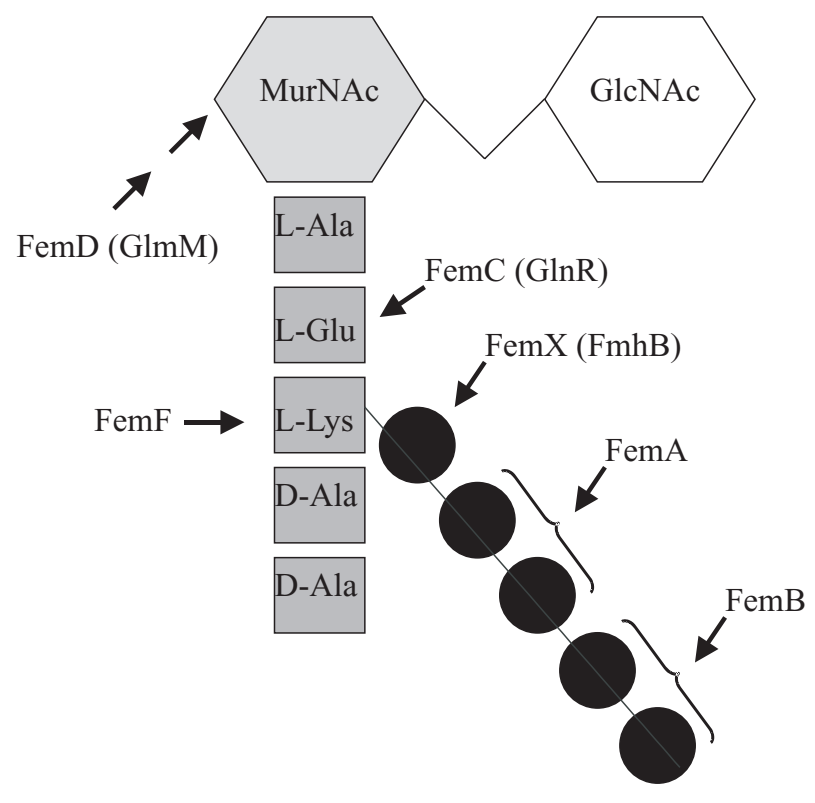

resistance requires alterations in regulatory genes and absence of beta-lactamase regulatory genes (blaI and blaR 1), which are also able to repress mecA (98). Clinical MRSA isolates show deletions in mecI and some $m e c R l$ regions, or mutations in mecI or in the promoter region of mecA $(133,260)$. Some strains express methicillin resistance heterogeneously; only a small subset of the population $\left(10^{-3}-10^{-7}\right)$ is resistant to high methicillin concentrations. Others are homogeneously resistant, i.e. each bacterium of the population shows uniform high-level resistance (107). Strains with eagle-type resistance are sensitive in low concentrations of methicillin, but resistant in high concentrations. This type of resistance is achieved by exposing strains with intact mecA regulon to a high methicillin concentration. The expression of eagle-type resistance and the conversion of heterogeneous resistance to homogeneous resistance are thought to result from the same genetic factor independent of SCCmec and fem factors $(134,234)$.

Methicillin-resistant strains of $S$. aureus are often resistant to other antibiotic groups in addition to beta lactams. The SCCmec itself may carry several resistance genes generally located in integrated plasmids or transposons. Macrolide-lincosamine-streptogramin (MLS) resistance resides within Tn554, and has been linked to SCCmec types II, III, and IIIA (44, 265). Tetracycline resistance gene lies in pT181 in SCCmec type III (129). Aminoglygoside resistance genes are located either within pUB110 (aadD, tobramycin resistance) (28) found in SCCmec types IA and II or in pG01 (gentamycin resistance), which also 24 
contains a gene for trimetoprim resistance (179). Fluoroquinolone resistance often forms during treatment because of mutation in the topoisomerase IV gene ( $g r l A)$, the primary target of these agents in staphylococci, and high-level resistance arises through an additional mutation in the DNA gyrase gene $(126,189)$. Rifampin and mupirocin resistance occur because of a point mutation in target enzymes, RNA polymerase and isoleucyl-t-RNA synthethases, respectively $(9,300)$. High-level resistance to mupirocin arises through acquisition of a plasmid containing an additional isoleucyl-t-RNA-synthethase gene (276), but other mechanisms may also be involved (241). Strains intermediately resistant to glycopeptides (GISA) have been described in different geographic locations $(110,162$, $219,232,253)$. The molecular mechanism of resistance has not been fully elucidated. However, thickening of the cell wall through accumulation of excess peptidoglycan, either by increased synthesis or by decreased turnover, seems to be common to all GISA strains $(52,103,108)$. This results in the trapping of glycopeptide molecules in the cell wall, and the blocking of the access to the major target of glycopeptide antibiotics, D-ala-D-ala residue on the $\mathrm{N}$-acetyl-muramicacid precursor in the cytoplasm (108). Recently, a truly glycopeptide resistant strain (GRSA) was isolated. This strain had the vanA gene of glycopeptide resistant enterococci. A vancomycin-resistant enterococcus was also isolated from the same infection site, suggesting that a van gene transfer from enterococci to staphylococci may have occurred (31).

Primary diagnosis of methicillin resistance can be performed through antimicrobial susceptibility testing recommended by National Committee for Clinical Laboratory Standards (NCCLS). The test methods are based either on diffusion of oxacillin from commercially prepared filter paper disks into the agar or on serial twofold dilution of oxacillin in an agar or broth base $(187,188)$. A commercially available MIC test, E-test (AB Biodisk, Sweden), is widely used in Finland. Heterogeneously resistant MRSA strains grow more slowly than do homogeneously resistant strains, and may be more difficult to detect. Addition of $\mathrm{NaCl}$ to the growth medium, an incubation temperature of $30{ }^{\circ} \mathrm{C}$, and an incubation time of $48 \mathrm{~h}$ aid detection. Automated antimicrobial susceptibility testing systems are widely used in the USA, but not in Finland. A commercial agglutination test (MRSA Screen, Denka Seiken, Japan) based on the detection of PBP2a, and commercial agar plates with oxacillin supplements, are available for the screening for methicillin resistance (132). Definitive diagnosis is achieved using the detection of the mecA gene by PCR (182), hybridization, or a commercially available fluorescence test.

\subsubsection{Evolution of MRSA}

First MRSA strains were described in 1961 (121), in the same time period 
when methicillin was introduced into clinical use. The origin of the mecA gene and SCCmec is unknown, but the $m e c A$ gene and the flanking regions have also been detected in other staphylococcal species. One possible source is Staphylococcus sciuri, since one series of studies suggested that $m e c A$ is a native element in S. sciuri; a mecA gene, showing $88 \%$ overall similarity with mecA of MRSA, was present in each of more than 100 independent isolates from different ecological sources and representing a wide variety of genotypes (49). However, the majority of these isolates showed no resistance to methicillin. The isolates which were resistant to methicillin had a further copy of mecA, identical to that of MRSA isolates (46, 309).

The mode of transfer of the $m e c A$ gene from an unknown donor to $S$. aureus has been subject to a debate. Initially, all MRSA strains were thought to be descendants of a single common ancestor, since they showed pigmentation different from MSSA strains, invariable survival capacity, and a typical resistance profile (142). Later, their clonality was studied in a more precise way by using a MRSA strain collection of 472 isolates from different geographic areas, and DNA probes to the mecA region and staphylococcal transposon Tn554. Twentynine Tn554 patterns and six different temporally ordered mecA patterns were found. Each Tn554 pattern associated with only one mecA pattern, suggesting that $\mathrm{Tn} 554$ polymorphism had arisen after mecA integration into the S.aureus chromosome (135). However, another study suggested that $m e c A$ had integrated into different $S$. aureus lineages as evidenced by size differences in the evolutionary wellconserved housekeeping proteins (183). The same protein profiles were also found in common MSSA strains. When a set of MRSA strains with these protein profiles were recently analyzed using microarrays comprising $96 \%$ of the S.aureus COL genome, it became evident that SCCmec had integrated into at least five MRSA lineages, which were highly different in their overall gene content (75). It seems, however, that the horizontal transfer of SCCmec is a relatively rare event, although horizontal transfer of genetic material othervise plays a major role in the evolution of $S$. aureus $(75,139)$

\subsubsection{MRSA surveillance}

The trends of MRSA numbers and the characteristics of isolates (e.g. antimicrobial resistance) can be followed by surveillance systems (13). The surveillance may be ongoing, restricted to certain defined areas (e.g. high risk units or operations) and performed at several levels (local, national, international), and should always include feedback information to the instances which provided the data. The surveillance aims at recognizing outbreaks, monitoring the success of infection control methods, and ultimately reducing the number of MRSA and costs attributable to MRSA infections. In- 
dividual hospitals often report the total number of MRSA strains isolated within a certain time period. Comparison of these reports may be difficult owing to differences or lack of denominator data. National MRSA data may be gathered as part of nosocomial infections surveillance systems, and some countries additionally require MRSA cases to be reported to national infectious diseases registers (http:// www.ktl.fi/ttr/). The Nosocomial Infection National Surveillance Scheme (NINSS) in the UK involves monitoring blood stream infections and surgical site infections of more than 100 hospitals (http://www.phls.co.uk/services/nisu.htm). The National Nosocomial Infections Surveillance (NNIS) System in the USA is based on voluntary participation of 315 acute-care general hospitals (http:// www.cdc.gov/ncidod/hip/surveill/ nnis.htm). International initiatives include HELICS (Hospitals in Europe Link for Infection Control through Surveillance), one of whose tasks is to define and validate a methodology for pooling and analyzing nosocomial infection data from intensive care and surgery units, collected in European networks (http://helics.univlyon1.fr/index.htm). EARSS (European Antibiotic Resistance Surveillance System) collects antimicrobial resistance data in a standardized manner, allowing analysis of temporal and geographical resistance trends (http:// www.ears.rivm.nl) (90). The SENTRY Antimicrobial Surveillance Program monitors the predominant patho- gens and antimicrobial resistance of nosocomial and community-acquired infections through global sentinel hospitals. The objects covered by SENTRY include bacteremia, fungemia, outpatient respiratory infections, wound infections, and urinary infections (62).

\subsubsection{MRSA in health care facili- $\underline{\text { ties }}$}

S. aureus is one of the major causative agents of nosocomial bacteremia (69), postoperative wound infection (190, 213), and catheter related infections (71). Most nosocomial S. aureus infections are endogenous, caused by the patient's own carriage strain (136). Susceptibility information on $S$. $a u$ reus bacteremias, gathered by the EARSS, indicate that the proportion of methicillin resistant strains in Europe varies from country to country, and reaches $40-50 \%$ in several areas (Figure 5). The Nordic countries and

Figure 5. Proportion (\%) of S. aureus resistant to methicillin in European countries in 1999-2001. Den, Denmark; Ger, Germany; Bel, Belgium; UK, United Kingdom; Ita, Italy. Source: EARSS (http://www.earss.rivm.nl/ index.html).

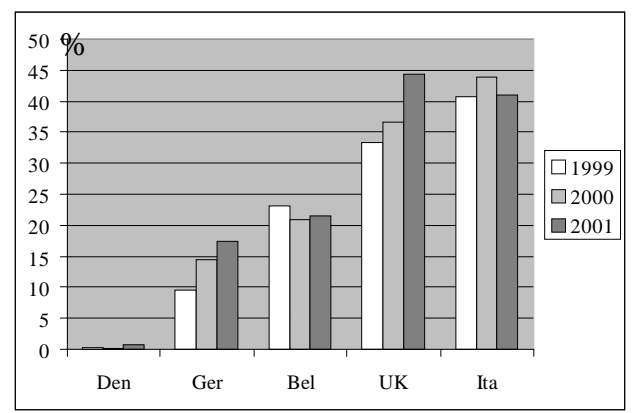


the Netherlands still have low proportions of MRSA in $S$. aureus bacteremias, from 0 to $2.5 \%$ in 1999 through 2001 (http://www.earss.rivm.nl/ index.html). A recent study revealed that the proportion of MRSA among $S$. aureus blood isolates rose from 18.1 to $26.1 \%$ in San Francisco County between 1996 and 1999 (113). The US National Nosocomial Infections Surveillance System (NNIS) reported a $55.3 \%$ methicillin resistance rate among $S$. aureus strains from 5070 ICU patients in 2000, indicating an increase of $29 \%$ compared with the previous five years (1), (http:// www.cdc.gov).

Prevalence studies show that MRSA is a major cause of nosocomial infections worldwide, and may account for up to $20-40 \%$ of all S. aureus infections $(258,293)$. In the USA, the prevalence of MRSA in hospitals increased from $2.4 \%$ in 1975 to $29 \%$ in 1991 (205). Similar trends have been reported in Europe. In central Europe, the prevalence of MRSA increased from $1.7 \%$ in 1990 to $8.7 \%$ in 1995 (307). In Australia, MRSA has attained endemic levels of $20-40 \%$ in the eastern cities, Sydney, Melbourne, and Brisbane, during the past decade. Other major Australian cities, Perth, Darwin, Adelaide, and Camberra, had lower rates of MRSA in the beginning of the 1990s. Recently, proportions of MRSA in these latter cities have been approaching to those of Sydney (272). Data on MRSA prevalence in Asia and Africa are scarce, but sporadic reports suggest a rapid increase of methicil- lin resistance among $S$. aureus: from $2 \%$ in 1988 to $33 \%$ in 1998 in two Saudi-Arabian tertiary-care hospitals (159), from $26.7 \%$ in 1990 to $70.9 \%$ in 1997 in one hospital in Taiwan (37), and from $9.8 \%$ in 1992 to $45.4 \%$ in 1998 in India, according to a surveillance study on $S$. aureus strains submitted for typing (171). Prevalence studies of short time periods revealed $27.5 \%$ and $30.5 \%$ methicillin resistance among $S$. aureus isolates in Sri Lanka and Ethiopia, respectively (85, 267)

The proportion of methicillin resistance of S.aureus varies among hospitals of individual countries. This variation has previously been correlated with the number of hospital ICU beds, total beds, annual admissions, or annual length of stay $(100,119,205)$. Recently, this correlation has become less evident (113). Extensive use of antibiotics within a hospital may partly explain differences among hospitals in transmission rates of resistant organisms (249).

The main reservoir of MRSA in hospitals consists of infected or colonized patients. The spread of MRSA from one patient to another occurs mainly through contaminated hands of health care personnel (254). The MRSA prevention methods in non-endemic countries, such as Finland, include careful hand desinfection after each patient contact, wearing gloves and a gown when caring for MRSA patients, treatment of colonized patients, and isolation of MRSA patients and suspected MRSA positive patients 
until three negative MRSA cultures have been obtained. $(289,294)$. In Finland, a patient is suspected to be a MRSA carrier if the patient has previously been MRSA positive, has shared a room with a MRSA positive patient, has been hospitalized outside the Nordic countries within the past six months, or has been transferred from a hospital with an ongoing MRSA epidemic (294). Countries with endemic MRSA focus their screening and isolation resources on high risk departments where the impact of MRSA spread is most pronounced (67).

The primary route of nosocomial MRSA spread between hospitals and countries is clonal dissemination of relatively few international epidemic clones. In the UK, the first epidemic MRSA (UK EMRSA-1) seemed to be similar to the epidemic strain in eastern Australia (270). This strain was later superceded by a series of other MRSA strains (UK EMRSA-2$14)$, and in the 1990s by UK EMRSA-15 and -16 $(163,174)$. UK EMRSA-15 and-16 gradually spread throughout the country, and they have also been identified elsewhere in Europe. In Germany, six different epidemic strains have gradually disseminated throughout the country (306). The Iberian and Pediatric clones, originally identified in Spain and Portugal, respectively, have subsequently been identified in several countries in Europe, Latin America, and in the USA $(58,93,165,229)$. The New York strain has spread widely in the USA and a similar strain also exists in Japan (7). Why these particular clones have been so successful in spreading remains to be elucidated.

\subsubsection{Community-acquired} MRSA

MRSA strains of nosocomial origin may be transmitted in the community through discharged patients or health care workers. Another possibility is that MRSA strains arise de novo through acquisition of SCCmec into the genomes of previously susceptible S.aureus strains.

Long-term care facilities, such as nursing homes, have been suspected as being reservoirs of MRSA. Recent studies suggest that, in the USA, long-term care residents commonly harbor antibiotic-resistant organisms, and MRSA is the most common organism found $(184,271)$. The rates of MRSA colonization in the nares and in wounds range from 8-53\%, and 30$82 \%$, respectively (23). European studies from the UK and Ireland suggest that the rates of MRSA colonization in long term care residents are lower, from $0.81 \%$ to $17 \%(50,79$, $186,204)$. Even if MRSA colonization rates are high in long-term care facilities, infections of MRSA may occur infrequently. It has been suggested that facilities with endemic MRSA should perform routine surveillance of MRSA infections and uphold basic infection control practices to prevent transmission. Knowledge of the MRSA colonization status of residents is not so necessary. Only when a certain threshold of MRSA 
infections is reached, should more intensive prevention measures, such as screening and isolation, be implemented until the chain of transmission is disrupted $(203,204)$. Prevention measures for long-term care facilities with non-endemic MRSA have not been suggested. Some studies indicate that MRSA strains isolated from long-term care residents originate in the referring hospitals, since the strains show phage types similar to hospital strains (79).

Community acquisition of MRSA has been described in rural communities with a low socio-economic status, e.g. among Australian aboriginees, American Indians, and in certain areas in New Zealand, Tonga, and Samoa (72, 95, 160, 272). Outbreaks of community MRSA have been described among intravenous drug users, members of a sports group, and families $(150,152,239)$. One outbreak of gastroenteritis has also been attributed to a community MRSA (125). The overall prevalence of community MRSA among urban homeless and marginally housed adults, subjected to crowded living conditions with poor access to sanitation facilities, was $2.4 \%$. However, the urban poor who did not have known MRSA risk factors had an MRSA prevalence similar to that of the general population (38). Household pets may also carry MRSA (151), and transmission to humans has been suspected (32). Reports on MRSA in the community are conflicting. MRSA colonization in healthy individuals without MRSA risk factors and health-care facility contacts seem to be rare $(4,237,249,259)$. On the other hand, MRSA caused the deaths of four healthy children without any known risk factors (29), and certain patient groups are commonly colonized with MRSA prior to hospital admission $(72,147,238)$. These observations warrant wider investigations on the frequency of, and risk factors specific for, community acquisition of MRSA. In contrast to MRSA strains found in long-term care residents, other community-acquired MRSA usually show antibiotic resistance patterns and genotypes differing from those of hospital isolates $(3,95)$.

\subsubsection{Molecular typing of MRSA}

Molecular typing through phenotypic or genotypic methods aims at defining whether a group of strains of a single species is clonal, i.e. arises from a common precursor. For MRSA, this information is needed for various purposes. In an outbreak investigation, an increased number of spacially and temporally related strains are typed in order to identify whether the outbreak is due to the spread of a single strain. Molecular typing provides information on changes in the MRSA population during long-term surveillance, after implementation of infection control measures, or after a change in antibiotic prescribing policy. Typing is also used to deduce evolution and global spread of MRSA strains. A large number of typing methods have been developed over the past decades. The choice of the typing method depends 


\begin{tabular}{|l|l|l|l|}
\hline Method & Target & Principle & Outcome \\
\hline Phage typing & $\begin{array}{l}\text { Cell surface } \\
\text { components }\end{array}$ & $\begin{array}{l}\text { Infection of strains with phages, } \\
\text { differentiation by ability of } \\
\text { phages to lyse distinct strains }\end{array}$ & $\begin{array}{l}\text { Lytic plaques on bacterial lawn on } \\
\text { plate }\end{array}$ \\
\hline $\begin{array}{l}\text { Pulsed field gel } \\
\text { electrophoresis }\end{array}$ & Whole genome & $\begin{array}{l}\text { Total genomic digestion with } \\
\text { infrequent cutters, followed by } \\
\text { electrophoresis with periodic } \\
\text { changes in the orientation of } \\
\text { electric field }\end{array}$ & $\begin{array}{l}\text { Restriction fragment length } \\
\text { polymorphism of total genomic } \\
\text { DNA }\end{array}$ \\
\hline Ribotyping & rRNA genes & $\begin{array}{l}\text { Total genomic digestion, } \\
\text { followed by Southern } \\
\text { hybridization with rDNA probe }\end{array}$ & $\begin{array}{l}\text { Restriction fragment length } \\
\text { polymorphism based on the size } \\
\text { and number of fragments that } \\
\text { contain rRNA genes }\end{array}$ \\
\hline HVR-hybridization & $\begin{array}{l}\text { Hypervariable } \\
\text { region within mec } \\
\text { DNA }\end{array}$ & $\begin{array}{l}\text { Total genomic digestion, } \\
\text { followed by Southern } \\
\text { hybridization with probes } \\
\text { recognizing the hypervariable } \\
\text { region }\end{array}$ & $\begin{array}{l}\text { Restriction fragment length } \\
\text { polymorphism based on the size } \\
\text { and number of fragments that } \\
\text { contain HVR-sequence }\end{array}$ \\
\hline $\begin{array}{l}\text { Multilocus } \\
\text { sequence typing }\end{array}$ & $\begin{array}{l}\text { Seven } \\
\text { housekeeping } \\
\text { genes }\end{array}$ & Sequencing of each gene & Nucleotide sequence \\
\hline
\end{tabular}


on the purpose of the analysis (outbreak investigation, surveillance, evolution studies), and on the biological performance and technical efficiency of the method (283) (Table 2). An optimal method for all purposes of typing should show high typeability, technical reproducibility, ease of interpretation of results, and low cost. For outbreak investigations the general availability of the method and ease of performance are of practical importance. The discriminatory power should be high for outbreak investigations, but less high for population studies, otherwise the clonal relationships may remain obscure (74). Reproducibility is particularly important if the typing results are (electronically) stored and later compared with new results.

Phenotypic typing methods characterize the strain relations indirectly through the expression of different genes. The results are often influenced by environmental factors. Therefore phenotypic identity or similarity is not always due to genomic identity, and genomic identity is not always reflected phenotypically.

Phage typing is one of the oldest methods used for discrimination of MRSA strains; the first set of phages was established over 50 years ago (208), and phage type data on historical $S$. aureus strains are available (82, 303). Phage typing is based on variable capabilities of different bacteriophages to lyse different MRSA strains (207). Although an international set of phages for S. aureus and an additional set for MRSA have been established, and standardization has been attempted, this method shows considerable inter-laboratory variation and variable typeability, and requires technical expertise $(10,164)$. However, it is rapid and usually sufficiently discriminative for short-term outbreak investigations.

Antimicrobial sensitivity testing has been a useful adjunct to MRSA typing in short outbreaks caused by multiresistant strains, since the antibiogram is often the first typing result available (231). Different patterns predict different sources of infection. However, the antimicrobial susceptibility pattern of an individual strain may change during treatment (126), or because of antibiotic selection pressure in hospitals.

Multilocus enzyme electrophoresis (MLEE) is based on electrophoretic mobility of several proteins essential for cell viability and growth (245). This method is not sufficiently discriminative for outbreak investigations, but instead provides information on population studies. Other phenotypic typing methods, such as biotyping, serotyping, polyacrylamide gel electrophoresis (PAGE) analysis of released or cell wall bound proteins, and immunoblotting, can be used as additional methods $(244,261)$. However, these methods are not often used because of lack of appropriate reproducibility or discriminatory power.

Genotypic typing is based on the analysis of a chromosome or extrachromosomal DNA, allowing direct comparison of genotypes between 
strains. Analysis of plasmid profiles or restriction fragment analysis of plasmids has been used in outbreak investigations. Although the method is technically simple and feasible in most laboratories, its use is restricted because of its variable typeability and discriminatory power.

The restriction of chromosomal DNA with frequently cutting enzymes and subsequent agarose gel electrophoresis provides a discriminative fingerprint of the whole chromosome. Owing to the large number of fragments, the interpretation may be subjective and therefore non-reproducible. The interpretation can be improved by Southern blotting the DNA fragments to membrane and by highlighting a subset of the fragments with specific probes (278). The probes must include both conservative (to provide typeability) and variable (to retain discrimination) sequence areas. Preferably the target sequence should occur in multiple locations within the chromosome. DNA sequences meeting these criteria among MRSA strains include ribosomal RNA operons, Tn554, IS256, and IS 257/IS431. Individual hybridization with multiple probes, each recognizing a single-copy gene, such as those for most virulence factors, can also be used, but this approach is fairly laborious.

Several typing methods based on polymerase chain reaction (PCR) have been developed. Specific genes with polymorphic repeat regions, such as coa- and spa genes, have been used as targets for PCR amplification (80,
111). Additional discrimination can be achieved by subsequent restriction fragment length polymorphism (RFLP) analysis. PCR amplification of a tandem repeat region of the extracellular part of staphylococcal coagulase, and subsequent AluI digestion, results in moderate discrimination of strains $(92,261)$. The variation in the protein A repeat units is also a target for typing. Changes in the protein A repeat region may, however, occur more rapidly than the entire genome evolves, and thus be an unsuitable target for purposes other than outbreak investigation (280). The ribosomal RNA sequences and the spacer sequence between $16 \mathrm{~S}$ and 23S rDNA have also been targets for PCR-based typing. Another approach is to use as PCR targets polymorphic non-coding repetitive (ERIC or REP) sequences scattered around bacterial genomes (59). Arbitrarily primed PCR (APPCR) and randomly amplified polymorphic DNA analysis (RAPD) are based on short primers and low-stringency amplification conditions. Amplification of random sequences forms a PCR-pattern shared by identical strains. Low-stringency PCR conditions may reduce the reproducibility of this method, and it is seldom suitable for ongoing epidemiological surveillance, unless sophisticated equipment, high techical skills, and means for computerized data storage and interpretation are available (201). Amplified fragment length polymorphism (AFLP) is a PCR-typing method recently adapted for discrimination of 
bacteria (292). In this method, chromosomal DNA is first digested with frequent cutters, specific adapters are then linked to the resulting fragments, and a subset of the fragments is selectively amplified using primers recognizing the adapter sequence and extending the original fragment by one to three selective bases. The large number of fluorecently labeled amplicons is finally separated by electrophoresis.

Binary typing is based on differential hybridization of up to 12 selected probes with different MRSA strains. For each strain analyzed, 12 "yes" or "no" (1 or 0$)$ results are obtained (284). The suitable probes, hybridizing only with a subset of characterized MRSA strains, were initially identified by RAPD (285). The method has proved to be useful in the characterization of the genetic diversity of MRSA clone, as well as in detecting nationwide spread of one MRSA clone $(282,286)$.

Pulsed field gel electrophoresis (PFGE), introduced in 1984 (243), is regarded as the "gold standard" method for distinguishing MRSA strains. In this method, chromosomal DNA is digested with infrequently cutting enzymes having recognition sequences of six to eight bases in length. The digestion yields large fragments of DNA (20-800kb), which cannot be separated in conventional agarose gel electrophoresis. In PFGE, the direction of the electric field periodically changes, which allows separation of DNA fragments of up to $10 \mathrm{Mb}$ in size. The separation is primarily based on the time needed for reorientation, longer for larger than for smaller fragments, instead of the speed of migration.

Comparison of whole genome sequences would be the ultimate and the most stringent typing method for any bacterium. However, for the purposes described above, whole genome sequencing is not feasible. Instead, identification of regions with both conservative and variable sequencs is needed. The degree of variation depends again on the purpose of typing. For population analysis of MRSA, multilocus sequence typing (MLST) has been used successfully (161). MLST is based on the sequencing of seven "housekeeping" genes. A distinct number is assigned to each different sequence of the same allele, and the allelic profile of the seven genes defines a sequence type (ST). Isolates with identical sequence types are considered clonal with a high degree of accuracy (74). For outbreak investigations, sequencing a single discriminatory locus, such as short sequence repeats (SSR) in spa or coa genes (80), may be more convenient and less costly.

Data storage and interpretation issues are essential as massive volumes of genotypic and phenotypic data may be generated in both shortterm and long-term approaches. In addition, international comparison of MRSA strains has become increasingly relevant because of the pandemic spread of MRSA strains. Despite established interpretation criteria (262), availability of sophisticated software 
packages, and several inter-laboratory standardization initiatives for PFGE $(46,281)$, inter-laboratory reproducibility is difficult to achieve. Although software which transform bands mathematically to numerical values do exist, PFGE and other banding pattern based methods are prone to bias due to manual selection of bands. Therefore, databases based on binary output or sequence of numbers or letters would facilitate international comparison of strains. 


\section{AIMS OF THE STUDY}

The purpose of this study was to investigate the molecular epidemiology of methicillin-resistant Staphylococus aureus in a low-prevalence country. The phenotypic and genotypic characteristics of Finnish MRSA isolates were analyzed in order to gain new insights into the short-term and longterm evolution of MRSA. The specific aims were:

1. To elaborate a MRSA typing scheme suitable for continuous nationwide MRSA surveillance in Finland.

2. To analyze trends of MRSA occurrence in Finland in the 1990s and to analyze molecular characteristics of isolates in order to identify those linked to epidemics.

3. To estimate the proportion of isolates of community-acquired MRSA in Finland, and to determine if any molecular type associates with community acquisition.

4. To recognize internationally spread MRSA clones in Finland, to search for molecular traits linked to the epidemic spread of MRSA, and to analyze the clonality of the most common MRSA strains encountered in Finland. 


\section{MATERIAL AND METHODS}

\subsection{NATIONAL MRSA SUR- VEILLANCE}

Until 1995, data on the annual numbers of MRSA isolations were collected voluntarily on a weekly basis and were available from the major microbiology laboratories, which included those of all central and university hospitals, as well as the major private laboratories. Since 1995, microbiology laboratories have reported MRSA isolations, as well as all blood and cerebrospinal fluid isolations of $S$. aureus, to the National Infectious Disease Register at the National Public Health Institute (KTL). In this register, the time interval within which $S$. aureus isolates from the same person are interpreted as one case is 36 months. The following data concerning each isolate are reported to the register: age and gender of the patient, health care institution, date of isolation, and source of positive culture.

\subsection{MRSA STRAIN COLLEC- TION}

Since 1992, all microbiology laboratories have been asked to send all MRSA isolates to the Laboratory of Hospital Bacteriology at KTL. The present study reports the analysis of this population-based MRSA collection from 1992 to 2001 (Table 3). Eighteen internationally characterized epidemic MRSA strains were used as controls. These strains were obtained from the Harmony group (http://
www.phls.org.uk/International/Harmony/Harmony.htm), and included type strains for Belgium EC-1 (97S96), Belgium EC-2 (97S99), Belgium EC-3 (97S101), France A (162), France B (97121), France C (10828), Greece 1 (3680), Spain E1 (5), N. German I (134/93), Hannover III (1000/ 93), Berlin IV (825/96), UK EMRSA1 (NCTC 11939), UK EMRSA-3 (M307), UK EMRSA-15 (90/10685), UK EMRSA-16 (96/32010), Pediatric clone (HDE288), Brazilian clone (HSJ216), and Iberian clone (HPV 107).

\subsection{EPIDEMIOLOGICAL BACKGROUND DATA}

\subsubsection{Hospital contacts}

For publication III, the data on previous hospitalization periods of MRSA positive persons were retrieved from the National Hospital Discharge Register (HILMO) at the National Research and Development Centre for Welfare and Health (STAKES). HILMO is a civil register comprising comprehensive health-care records provided by all hospitals and healthcare centers in Finland, including outpatient surgery. Each report to the register includes patient identity information, admission and discharge dates, the code of the health-care provider, the type of service, speciality, the place (home or institution) from which the patient came to the institution, and the date of the surgical procedures.

For MRSA positive persons regarding whom no HILMO reports 
Table 3. MRSA isolates and methods used in the study.

\begin{tabular}{|c|c|c|c|}
\hline $\begin{array}{l}\text { Public } \\
\text {-ation }\end{array}$ & Focus of study & $\begin{array}{l}\text { Selection criteria for } \\
\text { Finnish isolates } \\
\text { (number of isolates } \\
\text { studied) }\end{array}$ & Methods used \\
\hline I & $\begin{array}{l}\text { MRSA trends } \\
\text { and } \\
\text { identification of } \\
\text { epidemic } \\
\text { strains }\end{array}$ & $\begin{array}{l}\text { All isolates, one per } \\
\text { person, isolated in 1992- } \\
1997(891)\end{array}$ & $\begin{array}{ll}\text { - } & \text { Antimicrobial } \\
\text { susceptibility } \\
\text { - } & \text { Phage typing } \\
\text { - } & \text { PFGE and ribotyping for } \\
& \text { a subset of strains }\end{array}$ \\
\hline II & $\begin{array}{l}\text { Molecular traits } \\
\text { for epidemic } \\
\text { spread }\end{array}$ & $\begin{array}{l}\text { All sporadic isolates } \\
\text { from year 1995 (47), } \\
\text { and representatives of } \\
\text { intra- and interhospitally } \\
\text { spread strains (25) from } \\
1992-1999\end{array}$ & $\begin{array}{ll}\text { - } & \text { Ribotyping } \\
\text { - } & \text { Phage typing } \\
\text { - } & \text { Antimicrobial } \\
\text { susceptibility } \\
\text { - HVR hybridization for } \\
\text { representatives of each } \\
\text { ribotype }\end{array}$ \\
\hline III & $\begin{array}{l}\text { Community- } \\
\text { acquired } \\
\text { MRSA }\end{array}$ & $\begin{array}{l}\text { All isolates, one per } \\
\text { person, from 1997-1999 } \\
(526)\end{array}$ & $\begin{array}{ll}\text { - } & \text { PFGE } \\
\text { - } & \text { subset of strains } \\
\text { - } & \text { Phage typing } \\
\text { - } & \text { Antimicrobial } \\
\text { susceptibility } \\
\text { - Search for } \\
\text { hospitalization periods } \\
\text { from the hospital } \\
\text { discharge register } \\
\text { (HILMO) and by a } \\
\text { questionnaire }\end{array}$ \\
\hline IV & $\begin{array}{l}\text { Clonality and } \\
\text { evolution of } \\
\text { MRSA }\end{array}$ & $\begin{array}{l}\text { Representatives of the } \\
\text { most common strains in } \\
1997-1999(14)\end{array}$ & $\begin{array}{ll}\text { - } & \text { MLST } \\
\text { - } & \text { Mec regulatory region- } \\
& \text { PCR } \\
\text { - } & \text { HVR sequencing }\end{array}$ \\
\hline
\end{tabular}

could be found, additional background information was collected by sending questionnaires to infection-control nurses at the relevant health-care facilities. The information collected included: 1) whether the MRSA-positive person was a patient or a staff member, 2) whether the specimen was taken on a clinical or a screening basis, and 3) whether the screening sample was taken because of a hospital contact abroad or because of an epidemic situation.

\subsubsection{Patient days}

Annual patient days in health care were retrieved from public HILMO (Net-HILMO, http://info.stakes.fi/nettihilmo), with no access to client specific information. A patient day was defined as $24 \mathrm{~h}$ during which a patient occupied a bed in a health-care institute. The admission and discharge days together counted as one patient day. 


\subsection{ISOLATION OF DNA, AND PRIMERS USED}

Total genomic DNA was prepared for all PCR-methods, ribotyping, hypervariable region hybridization, and MLST. DNA was purified using a guanidium isothiocyanate method (218) (Publication I-III), a Qiagen Tissue Purification Kit (Qiagen, Germany), or a method using phenol chloroform elution (101) (Publication IV).

The primers used in the study (Table 4) were purchased from Amersham Pharmacia Biotech, England.

\subsection{IDENTIFICATION AND ANTIMICROBIAL SUSCEPTI- BILITY TESTING OF MRSA}

On reception at the Laboratory of Hospital Bacteriology, all isolates suspected of being MRSA were verified for oxacillin resistance by disk diffusion and MIC-tests (see 4.5.1) and/or by $m e c A$-PCR (see 4.5.2). Initially, $S$. aureus species identification was verified only if the species identification was suspected of being incorrect: an atypical or mixed culture, or nontypable by $S$. aureus phages. The identification methods included Slidex agglutination test (BioMérieux, France), nuc-PCR (see 4.5.2), coagulase test (130), API Staph (BioMérieux, France), API ID 32 Staph (BioMérieux, France), and biochemical tests. Since 2000, all isolates have been tested routinely for correct species identification and methicillin resistance by $n u c$ - and $m e c A$-PCRs, respectively.
4.5.1 Antimicrobial susceptibility testing

The antimicrobial susceptibilities were tested by the disk diffusion method after overnight incubation at $37^{\circ} \mathrm{C}$ on Muller-Hinton agar plates according to the guidelines recommended by the NCCLS. The antimicrobials tested included gentamicin, tobramycin, erythromycin, clindamycin, chloramphenicol, ciprofloxacin, rifampin, fucidic acid, trimethoprim-sulfamethoxazole, tetracycline, mupirocin, and vancomycin. Oxacillin resistance was determined by the disk diffusion method after $24-48 \mathrm{~h}$ growth at $30^{\circ} \mathrm{C}$. MIC of oxacillin was determined by the E-test according to the manufacturer's instructions (AB Biodisk, Sweden).

\subsection{2 mecA-PCR and nuc-PCR} $m e c A-P C R$ and nuc-PCR were performed either separately as described earlier $(24,182)$ or as a multiplex application. A $50 \mu \mathrm{l}$ volume of PCR reaction mixture contained $1 \mu \mathrm{l}$ of purified genomic DNA, 50 pmol of each of the $n u c$ - and $m e c A$-primers, $0.2 \mathrm{mM}$ of dNTP, $1 \mathrm{U}$ of DynaZyme polymerase (Finzymes, Finland), and $5 \mu \mathrm{l}$ of 10x buffer containing $15 \mathrm{mM}$ of $\mathrm{MgCl}_{2}$. The PCR amplification protocol included initial denaturation at $96^{\circ} \mathrm{C}$ for $10 \mathrm{~min}$, followed by $40 \mathrm{cy}-$ cles of denaturation at $96^{\circ} \mathrm{C}$ for $30 \mathrm{~s}$, annealing at $46^{\circ} \mathrm{C}$ for $30 \mathrm{~s}$, and extension at $72^{\circ} \mathrm{C}$ for $2 \mathrm{~min}$, and final extension at $72^{\circ} \mathrm{C}$ for $5 \mathrm{~min}$. The resulting amplicons were run in a $1.5 \%$ Sea Kem agarose gel (BMA, USA) at $90 \mathrm{~V}$ for $1 \mathrm{~h}$. 
Table 4. Primers used in the study

\begin{tabular}{|l|l|l|}
\hline Primer & Sequence 5' $\rightarrow$ 3' & Reference \\
\hline mecA, forward & AAAATCGATGGTAAAGGTTGGC & $(182)$ \\
mecA, reverse & AGTTCTGCAGTACCGGATTTGC & \\
\hline nuc, forward & GCGATTGATGGTGATACGGTT & $(24)$ \\
nuc, reverse & AGCCAAGCCTTGACGAACTAAAGC & \\
\hline arcC-Up & TTGATTCACCAGCGCGTATTGTC & $(73)$ \\
arc-Dn & AGGTATCTGCTTCAATCAGCG & \\
aroE-up & ATCGGAAATCCTATTTCACATTC & \\
aroE-Dn & GGTGTTGTATTAATAACGATATC & \\
glpF-Up & CTAGGAACTGCAATCTTAATCC & \\
glpF-Dn & TGGTAAAATCGCATGTCCAATTC & \\
gmk-Up & ATCGTTTTATCGGGACCATC & \\
gmk-Dn & TCATTAACTACAACGTAATCGTA & \\
pta-Up & GTTAAAATCGTATTACCTGAAGG & \\
pta-Dn & GACCCTTTTGTTGAAAAGCTTAA & \\
tpi-Up & TCGTTCATTCTGAACGTCGTGAA & \\
tpi-Dn & TTTGCACCTTCTAACAATTGTAC & \\
yqiL-Up & CAGCATACAGGACACCTATTGGC & \\
yqiL-Dn & CGTTGAGGAATCGATACTGGAAC & \\
\hline mecI forward & AATGGCGAAAAAGCACAACA & $(260)$ \\
mecI reverse & GACTTGATTGTTTCCTCTGTT & \\
mecR1 penicillin binding domaine, forward & GTCTCCACGTTAATTCCATT & \\
mecR1 penicillin binding domaine, reverse & GTCGTTCATTAAGATATGACG & \\
mecR1 transmembrane domaine, forward & CAGGGAATGAAAATTATTGGA & \\
mecR1 transmembrane domaine, reverse & CGCTCAGAAATTTGTTGTGC & \\
\hline Druforward & TCTGAAGCAGCTTTAAATGATG & Publication IV \\
\hline ISP3TT & TTACTTTAGCCATTGCTACCTT & $(200)$ \\
\hline
\end{tabular}




\subsection{TYPING METHODS}

\subsubsection{Phage typing}

Phage typing was performed with an international set of phages (207), purchased from Statens Serum Institut, Copenhagen, Denmark, at $1 \mathrm{x}$ and $100 x$ routine test dilutions, both with and without heat treatment, $55^{\circ} \mathrm{C}$ for $3 \mathrm{~min}$, of the bacteria (53). The phage pattern was defined on the basis of the weakest test dilution that produced clear lytic reactions. A minimum of 20 lytic plaques (++ reaction) was required to define a positive reaction for each phage.

All isolates included in this study were typed by phages. In publication I, the identification of epidemic strains was primarily based on phage typing.

\subsubsection{Ribotyping}

Ribotyping was performed as described in publication I. Briefly, genomic DNA was digested separately with one to three restriction enzymes, HindIII, EcoRI, and ClaI (Boehringer Mannheim, Germany). DNA fragments were separated by electrophoresis, transferred to nylon membrane (Boehringer Mannheim), and hybridized with digoxygenin labeled plasmid pKK3535 containing the $r r n$ operon of Escherichia coli (25). Digoxygenin labeled DNA marker III (Boehringer Mannheim, Germany) or MluI digested Citrobacter koseri (94) was used as the molecular weight standard. A difference of one band in a ribotype, as detected by visual analysis, was considered to represent a new type. An arbitrary identification letter was assigned to each ribotype obtained by different enzymes.

In publication I, ribotyping was used to characterize further the isolates suspected of being linked to epidemics, and those nontypable by phages. In publication II, ribotyping by EcoRI was used for genomic characterization of all isolates with unique phage patterns (sporadic isolates) from the year 1995. In publication III, ribotyping was used to verify the relatedness of isolates from the years 1997-1999 if results from PFGE and phage typing were ambiguous.

\subsubsection{Pulsed field gel electro- phoresis (PFGE)}

The genomic DNA was prepared in agarose blocks as described previously $(89,209)$ with slight modifications described in publication I. Briefly, a $0.5 \mathrm{ml}$ volume of logaritmic phase cells and an equal volume of $2 \%$ SeaPlaque agarose (FMC Bioproducts, USA) were mixed and solidified. The DNA purification protocol included lysostaphin and proteinase $\mathrm{K}$ treament, followed by washing steps with phenylmethylsulfonyl fluoride and TE buffer $(10 \mathrm{mM}$ Tris and $1 \mathrm{mM}$ EDTA, $\mathrm{pH}$ 8.0). Restriction fragment length polymorphism following SmaI-digestion was detected with Chef DR III, Chef Navigator, or Chef Mapper (BioRad, USA) for $24 \mathrm{~h}$, on $1 \%$ SeaKem agarose gel (FMC BioProducts, USA) at $6 \mathrm{~V} / \mathrm{cm}$ with initial and final switching times of $10 \mathrm{~s}$ and $60 \mathrm{~s}$, respectively. A Lambda Ladder PFG marker (New England BioLabs, USA) was 
used as the molecular weight standard. Since 2001, the Harmony PFGE protocol has also been used for analysis. In the Harmony protocol the chromosomal DNA fragments are separated by two phases: phase 1 for $10 \mathrm{~h}$, with the initial and final switching times of $5 \mathrm{~s}$ to $15 \mathrm{~s}$; and phase 2 for $13 \mathrm{~h}$, with $15 \mathrm{~s}$ to $60 \mathrm{~s}$, respectively. The molecular weight standard in the Harmony protocol is $S$. aureus NCTC 8325. Otherwise the method was performed as above. PFGE profiles differing by fewer than four bands were interpreted as identical or closely related (262)

In publication I, PFGE was used to characterize further the suspected epidemic strains and the isolates nontypable by phages. In publication III, all isolates from the years 1997-1999, showing differences in phage typing, were typed by PFGE.

\subsubsection{Hypervariable region (HVR) hybridization}

The genomic DNA was digested with $E c o$ RI and $B g l$ II restiction enzymes, and hybridized with two probes prepared from plasmid pBBB30 (233). HVR probe $\mathrm{I}$ is a $3.6-\mathrm{kb}$ fragment that recognizes the HVR of the mec DNA, starting within the mecA gene and reaching up to IS431 mec. HVR probe II is a $1.5-\mathrm{kb}$ fragment digested with Hind III from the 3.6-kb fragment. This probe recognizes the direct repeat unit (dru) -region and an E. coli ugpQ-like sequence within the mec DNA. The digoxigenin-labeling of the probes, eletrophoresis and blotting to nylon membrane of genomic DNA frag- ments, and hybridization were performed as described in publication II. Digoxygenin-labeled molecular weight marker III (Boehringer Mannheim, Germany) or Citrobacter koseri (94) was used as the molecular weight marker.

The HVR-hybridization was performed on representatives of different ribotypes identified in sporadic isolates from the year 1995, as well as on all epidemic and local outbreak strains identified before the year 2000 (publication II). Equally, the HVR-hybridization with HVR probe I was performed on all representatives of the most common MRSA strains from the years 1997-1999 (publication III).

\subsubsection{Multilocus sequence typing} Multilocus sequence typing was performed as previously described (73). Internal fragments of seven housekeeping genes [carbamate kinase $(\operatorname{arc} C)$, shikimate dehydrogenase (aroE), glycerol kinase ( $\mathrm{glpF}$ ), guanylate kinase $(g m k)$, phosphate acetyltransferase (pta), triosephosphate isomerase (tpi), and acetyl coenzyme A acetyltransferase (yqiL)] were amplified by PCR. The PCR products were purified, and the sequences of both strands (or occasionally of one strand only) were determined by ABI Prism 310 Genetic Analyzer using the BigDye fluorecent terminator chemistry (Applied Biosystems, UK). The forward and reverse sequencing primers for each gene fragment were the same as those used for the initial PCR. The allele numbers were assigned to 
each loci by the MLST database (http:/ /www.mlst.net) and allelic profiles, defining the sequence types (STs) for each strain, were compared with those available in the database and with those found in the literature.

The MLST was used to delineate the clonality and evolution of the most common Finnish MRSA strains identified during 1997-1999 (publication IV)

\subsection{6 mec regulatory region $\mathrm{PCR}$}

Using primers and a PCR protocol described earlier (260), three different fragments within the mec regulatory region were separately amplified. The fragments were: 1) almost the entire mecI gene, 2) the penicillin binding domaine of the mecRl gene, and 3) the membrane spanning domaine of the $m e c R l$ gene. The resulting amplicons were run and detected in agarose gel.

\subsection{7 mec hypervariable region sequencing}

The direct repeat region $(d r u)$ between the glycerophosphoryl diester phosphodiesterase (ugpQ)-like sequence and IS431 was amplified by using primers Druforward and ISP3TT. The Druforward primer was designed on the basis of mec sequence data in the EMBL database (accession no. Y14051), and the ISP3TT primer was modified from an ISP3 primer described previously (200). The purified amplicons were sequenced by $\mathrm{ABI}$ 310 by using BigDye fluorescent terminator chemistry (Applied Biosystems, Warrington, UK). The sequenc- ing primers were the same as those for the initial PCR.

4.6.8 Computer-assisted analysis of typing data

Computer-assisted analysis of PFGE types and ribotypes was performed by BioNumerics, version 1.0 or 2.0 (Applied Maths, Belgium), using Dice coefficient and UPGMA (unweighted pair group method using arithmetic averages).

\subsection{DEFINITIONS AND NO- MENCLATURE OF STRAINS}

Strain types were identified on the basis of the phage pattern (publications I and II), ribotype (publications II and III), and PFGE type (publication III). The strain types of two isolates were considered to be the same if the phage types were similar and the ribotypes were identical and/or the PFGE types differed by fewer than four bands. Multiresistance was defined as resistance to more than three antimicrobial groups other than betalactams, and multisensitivity as resistance up to three antimicrobial groups other than beta-lactams.

A sporadic strain of MRSA was defined as a strain isolated from one person only and displaying a unique antimicrobial susceptibility and/or strain type (publications I-IV). MRSA isolates sharing the same strain types and isolated from two or more persons in the same hospital were defined as representatives of local outbreak strains (publications I and II). MRSA isolates sharing the same strain type 
and isolated from two or more persons at two or more hospitals were defined as representatives of an epidemic MRSA strain (publications I and II).

In this study, a clone was defined as a group of MRSA strains the members of which are most probably descendants of a single ancestor. To be classified as members of the same clone, isolates had to have identical or single locus variant MLST profiles, or ribotypes differing by fewer than four bands, and PFGE patterns differing by less than seven bands (publications III and IV). Clone assignment by PFGE was not performed if more than seven band differences occured. A clone may contain different epidemic or local outbreak strains.

Unless an international name for a strain was known, each epidemic strain and clone was named according to the city/region where the strain was first isolated or suspected of having been imported from. For international communication, an identification code number was given to each local outbreak strain and epidemic strain.

An MRSA isolate was defined as community acquired if the MRSApositive specimen was obtained outside hospital settings or within 2 days of hospital admission, and if it was from a person who had not been hospitalized within 2 years before the date of the MRSA isolation (publication III).

\subsection{STATISTICAL ANALYSIS AND ETHICAL ASPECTS}

For categorigal variables, proportions were compared by the chi-square test with Yates' correction or by Fisher's exact test, as appropriate. The means and medians of the continuous variables were compared by Student's $t$ test or Mann-Whitney $U$ test, depending on the sample distribution.

On the approval of the Finnish Ministery of Social Affairs and Health and of the data protection authority, the National Research and Development Centre for Welfare and Health gave us permission to use the data from the HILMO register. 


\section{RESULTS}

\subsection{ELABORATION OF MRSA VERIFICATION AND TYPING (I, II, III, IV)}

Table 5 shows the methods used for the verification and typing of MRSA isolates at the KTL Laboratory of Hospital Bacteriology during the years 1992-2002. The current scheme includes species verification and methicillin-resistance verification by multiplex mecA-nuc-PCR, antimicrobial sensitivity testing, and typing by ph- ages and by PFGE. Ribotyping is used in cases of ambiguity between PFGE and phage typing results (Figure 6). MLST is available for identifying the genetic background of emerging epidemic strains.

Results of MRSA verification and typing are reported to the referring laboratory and to the infection control nurse of the relevant healthcare facility. Reception of notification at the National Infectious Disease Register of each confirmed MRSA is concurrently verified.

Table 5. Elaboration of the MRSA verification and typing at the Laboratory of Hospital Bacteriology, KTL.

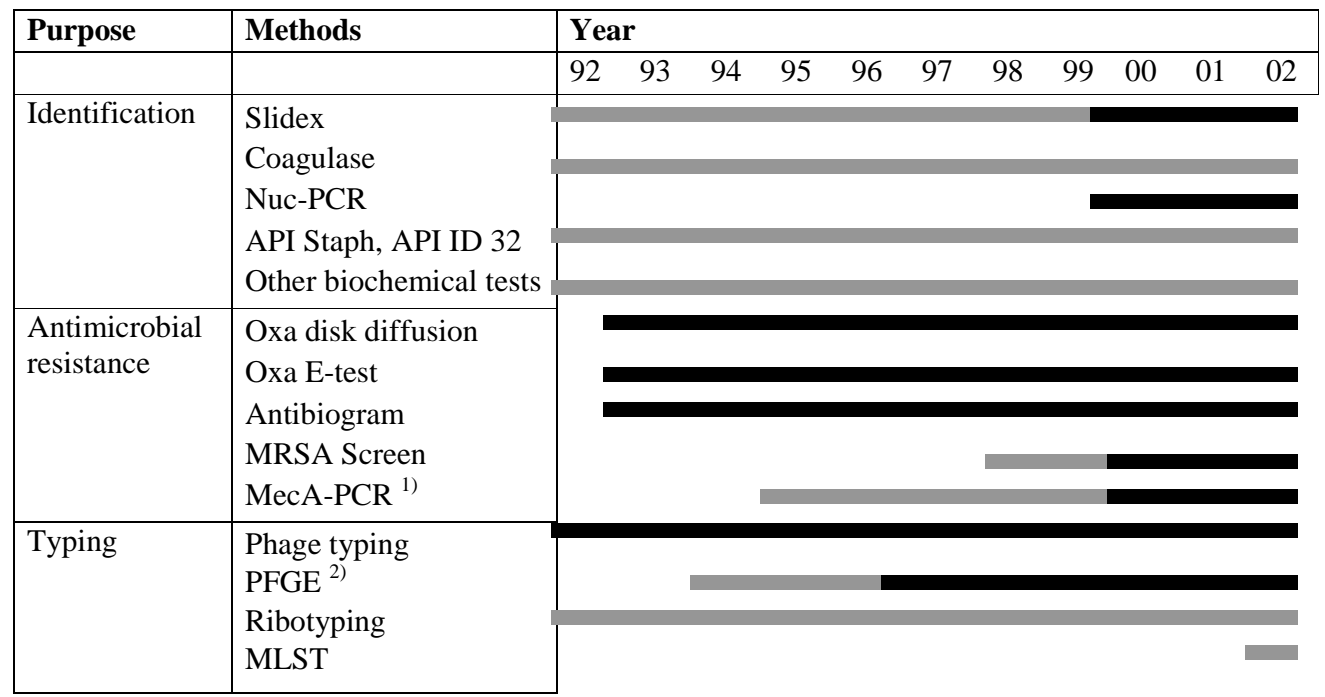
on all isolates. 1) Until 1997, and between 1997 and 1999, mecA-PCR was performed on isolates having an oxacillin MIC of $1-6 \mu \mathrm{g} / \mathrm{ml}$, and $\leq 64 \mu \mathrm{g} / \mathrm{ml}$, respectively. 2) PFGE was performed retrospectively in 1997-1999. 
Figure 6. MRSA verification and typing scheme at KTL, and the system of reporting to laboratories.

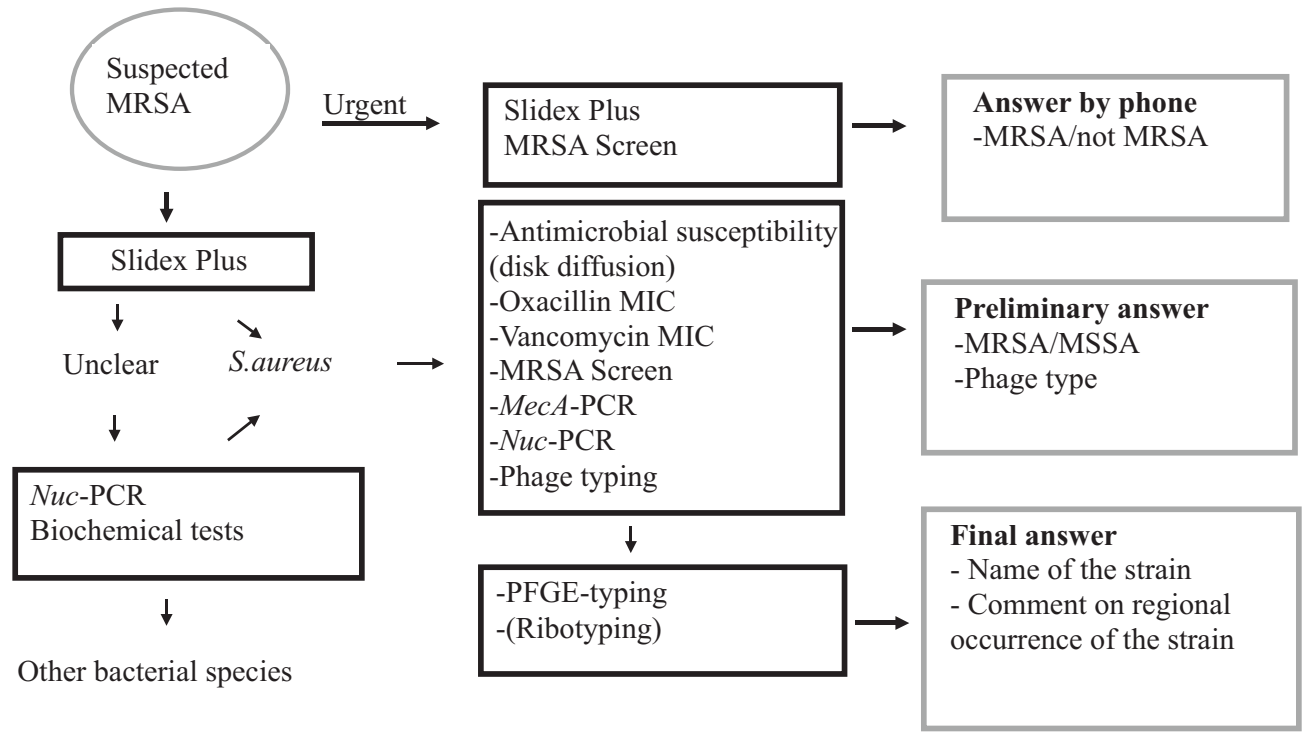

5.2 MRSA TRENDS AND EPIDEMIC STRAINS (I, II, III, IV)

On the basis of the data received from major microbiology laboratories, the number of isolates received for typing in the Laboratory of Hospital Bacteriology, and the MRSA notifications to the National Infectious Disease
Register, the annual number of MRSA isolations ranged from 89 to 340 during 1981-2001 (Figure 7).

Between 1995 and 2001, 1322 MRSA isolations were reported to the National Infectious Disease Register. The median age of MRSA positive persons was 58 years (range <1-98), and $51 \%$ (674) were male. Fourty-four

Figure 7. Number of MRSA isolations in Finland during 1981-2001.

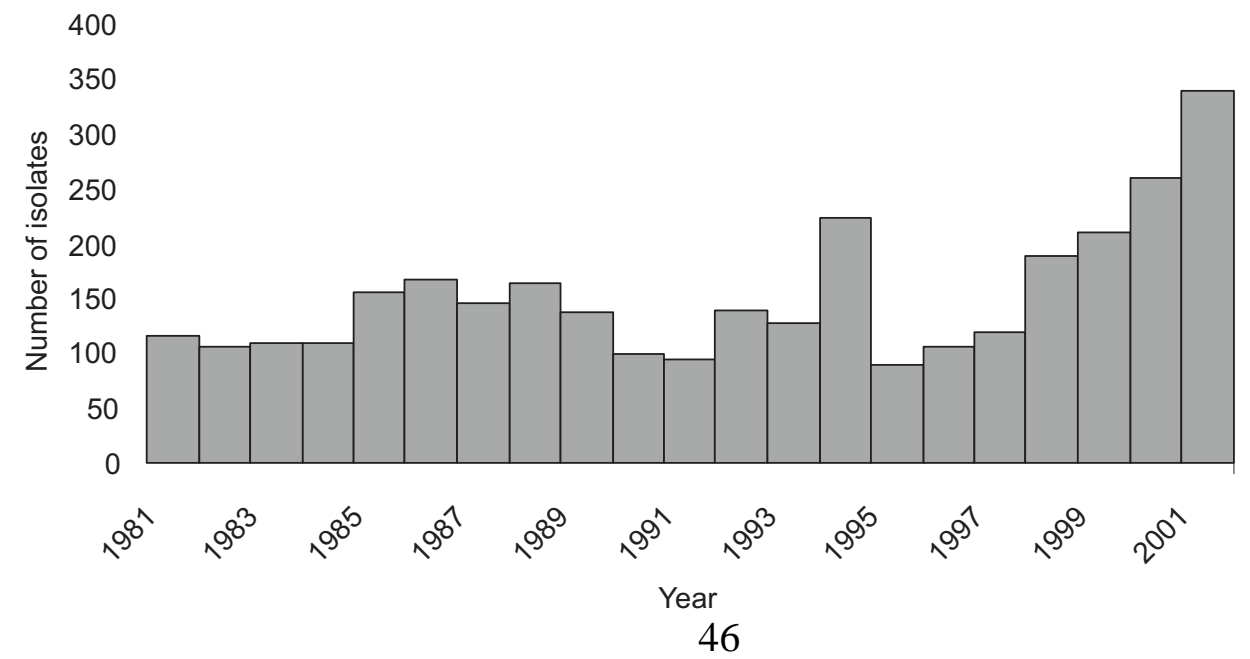


$\%$ (577) of the isolations were from persons of 60 years of age or older, and $10 \%$ (131) were from children under the age of 16 . The incidence of MRSA ranged from 1.7 per population of 100,000 in 1995 to 5.0 in 2000 (Table 6). In 1995, 70\% (69/89) of all notifications were received from the Helsinki metropolitan area, and 11 of
21 hospital districts reported no MRSA isolations. By 2001, all but two hospital districts reported MRSA, and the majority of notifications were outside the Helsinki metropolitan area (Figure 8). During 1995-2001, the proportion of methicillin resistance among $S$. aureus blood isolates remained at a level of $1 \%$ or less.

Table 6. Incidence and age distribution of MRSA cases in1995 through 2001

\begin{tabular}{|c|c|c|c|c|c|c|}
\hline Year & $\begin{array}{l}\text { Number of } \\
\text { MRSA } \\
\text { notifications }\end{array}$ & $\begin{array}{l}\text { MRSA } \\
\text { incidence per } \\
\text { population of } \\
100,000\end{array}$ & $\begin{array}{l}\text { MRSA } \\
\text { incidence } \\
\text { per } 100,000 \\
\text { patient days }\end{array}$ & $\begin{array}{l}\text { Median } \\
\text { age, } \\
\text { years }\end{array}$ & $\begin{array}{l}\text { Number of } \\
\text { persons } \\
<16 \text { years } \\
(\%)\end{array}$ & $\begin{array}{l}\text { Number of } \\
\text { persons } \\
65 \text { years } \\
(\%)\end{array}$ \\
\hline 1995 & 89 & 1.7 & NA & 65 & $6(7)$ & $47(53)$ \\
\hline 1996 & 108 & 2.1 & 7.11 & 63 & $10(10)$ & $52(48)$ \\
\hline 1997 & 120 & 2.3 & 8.10 & 52 & $13(11)$ & $49(41)$ \\
\hline 1998 & 189 & 3.7 & 12.93 & 51 & $20(11)$ & $54(29)$ \\
\hline 1999 & 211 & 4.1 & 14.77 & 57 & $23(11)$ & $87(41)$ \\
\hline 2000 & 261 & 5.0 & 18.47 & 61 & $25(10)$ & $122(47)$ \\
\hline 2001 & 344 & NA & NA & 63 & $34(10)$ & $166(48)$ \\
\hline
\end{tabular}

NA. Not applicable, since denominator data were not available.

Figure 8. Number of annual MRSA isolations by hospital district in 1995 through 2001. Number of MRSA isolations: $\square=0, \quad \square=1-10, \quad \square>10$.

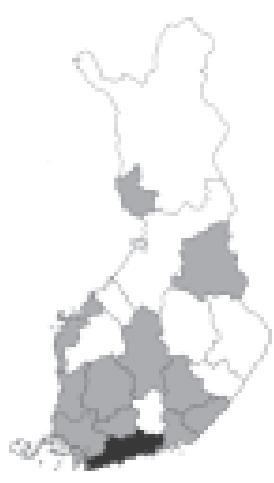

1995

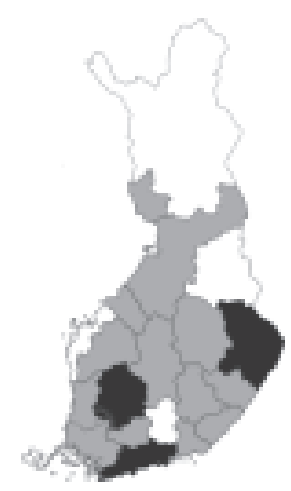

1998

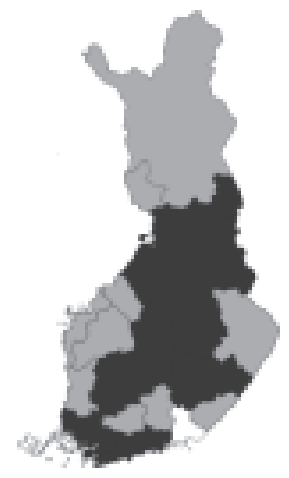

2001 
During the period of this study, from 1992 to 2001, a total of 1847 S.aureus isolates were verified as MRSA and typed. Of all isolates, 79\% (1457 of 1847) were classified as epidemic or local outbreak strains. The proportion of sporadic isolates during the periods 1992-1997 and 1997-1999 were $46 \%(345 / 748)$ on the basis of phage typing, and $11 \%(56 / 526)$ on the basis of phage typing and PFGE, respectively.

During 1992-2001, a total of 26 different epidemic and 12 local outbreak strains were identified (Table 7). Fourteen $(54 \%)$ of the epidemic strains and $5(41 \%)$ of the local outbreak strains were multiresistant, i.e. resistant to more than three antimicrobial groups other than beta lactams. Ribotyping by HindIII, EcoRI, and ClaI divided the strains into 20,18 , and 15 different types, respectively, and a combined analysis yielded 23 ribotypes. PFGE differentiated the strains into 29 distinct types and into 9 subtypes with no more than four band differences. Computer-assisted analysis of the PFGE types of the epidemic and outbreak strains revealed 8 clusters of strains with similarity values of at least $75 \%$.

Two epidemic strains were isolated from more than 200 persons, and another seven strains caused epidemics involving 50-100 persons. The largest epidemic, caused by the strain Helsinki I, occurred in Southern Finland and involved 270 persons. The epidemics started in 1992, peaked in 1994, and declined within a few years. However, this strain is still isolated oc- casionally, although most of the current isolates exhibit subtype level variation, or 4 to 7 band differences in PFGE as compared with the original epidemic strain. The other highly prevalent epidemic strain, Mikkeli II, emerged in several hospitals simultaneously in 1997. The detection of its emergence was delayed, since the isolates from different parts of the country exhibited wide variation in phage types, and no epidemiological linkage between isolates from different areas was apparent. Along with comprehensive, but retrospective, PFGE analysis of isolates from 1997 to 1999, the genomic relatedness among these epidemiologically unrelated isolates was detected.

Hypervariable region hybridization with HVR probe I differentiated the epidemic and local outbreak strains into 4 types: A, B, C, and D, each of which consisted of two bands. The HVR probe II recognized one of these two bands, showing the position of $d r u$ and flanking sequences. Multisensitive strains had the mec HVR hybridization pattern A. The only exception to this was the strain Helsinki III, which was multiresistant and still had HVR-type A. HVR types B, C, and D were found in multiresistant strains. A single multisensitive strain (Turku IV) with HVR-type $\mathrm{C}$ was identified. Strains showing HVR type A and B were negative in mecI-PCR. Sequencing of the $d r u$ region within HVR was performed on representatives of HVR types A, B, C, and D. Sequencing confirmed that HVR types B and D had a deletion of about $1000 \mathrm{~kb}$ as compared 48 
with strains with other HVR types. The $d r u$ sequences were highly similar within each HVR type and within HVR types B and D together.

\subsection{MOLECULAR TRAITS LINKED TO EPIDEMIC SPREAD (II)}

Ribotyping, with EcoRI restriction enzyme, of 72 strains, including all sporadic MRSA isolates from the year 1995 and the local outbreak and epidemic strains identified during 19921999, revealed 18 different ribotypes. The two most prevalent types, differing from each other by one band, made up $49 \%(35 / 72)$ of all strains. Of the sporadic strains, $45 \%$ (21/47) showed either of these types. Corresponding figures for epidemic and local outbreak strains were 64\% (9/14) and $45 \%(5 / 11)$, respectively.

Hypervariable region hybridization with HVR probe I differentiated the 72 strains into 7 types: A, B, C, D, $\mathrm{E}, \mathrm{F}$, and G. Most of the sporadic isolates were either of HVR type A (22/ $47,47 \%)$ or HVR type C (16/47, $34 \%)$. The epidemic strains were mostly of HVR type B $(4 / 14,29 \%)$ or type $\mathrm{C}(6 / 14,43 \%)$. Of the local outbreak strains, 7 (64\%) were of HVR type A.

Of the sporadic strains, 30\% (14/ 47) were multiresistant, whereas for the epidemic, and the local outbreak strains the corresponding figures were

$79 \%(11 / 14)$ and $45 \%$ (5/11), respectively. Multiresistance was more common among epidemic than among non-epidemic strains (11/14 vs. 19/58, $\mathrm{p}<0.005$ )

In a combined analysis of antibiotic susceptibility and genotype, the MRSA strains clustered into two main groups. One group included strains showing mec HVR hybridization pattern A combined with a variety of ribotypes and resistance to beta lactam antibiotics only. The majority of these strains were sporadic by nature. The other group included strains with mec HVR hybridization patterns $\mathrm{B}$ or $\mathrm{C}$ in association with the two major ribotypes. This group included both epidemic and sporadic strains.

\subsection{MRSA CLONES (I, III, IV)}

Of all 38 local outbreak and epidemic strains, genotyping classified 31 strains into 8 clones (Table 7). On the basis of MLST, representatives of seven of these clones were found to be identical with the internationally known $S$. aureus clones: ST 247, ST 239, ST 36, ST 22, ST 5, ST 45, and ST 12. The first six clones are also known as the Iberian, Brazilian, UK EMRSA-16, UK EMRSA-15, New York (or Pediatric), and Berlin clones. The ST12 clone was named Joensuu clone in Finland. On the basis of ribotypes and/or clustering by PFGE, six of the remaining seven strains also belong to either the Brazilian clone or to the Iberian clone. Finally, the Helsinki VIII strain was a triple allele MLST variant of Joensuu II, and may thus belong to the Joensuu clone, although the definition for a clone used in this study (see section 4.7), would 


\begin{tabular}{|c|c|c|c|c|c|c|c|c|c|c|c|}
\hline Clone & $\begin{array}{l}\text { Strain } \\
\text { identification }\end{array}$ & & $\begin{array}{l}\text { Number } \\
\text { of } \\
\text { isolates }\end{array}$ & $\begin{array}{l}\text { Year of } \\
\text { first } \\
\text { isolation } \\
\text { in } \\
\text { Finland }\end{array}$ & $\begin{array}{l}\text { Geographical } \\
\text { occurrence in } \\
\text { Finland }\end{array}$ & 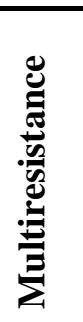 & 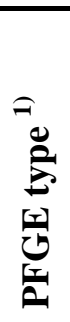 & 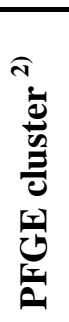 & 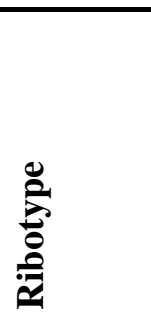 & $\sum^{\stackrel{n}{a}}$ & $\sqrt[n]{n}^{\infty}$ \\
\hline & Name & Id. no & & & & & & & & & \\
\hline \multirow[t]{5}{*}{ Brazilian } & Helsinki VI & E19 & 15 & 1998 & South & Yes & 1 & I & B.b:d & $\mathrm{C}$ & 239 \\
\hline & Helsinki VII & E20 & 12 & 1998 & South & Yes & 2 & - & C:a:e & $\mathrm{C}$ & 239 \\
\hline & Lohja & E24 & 62 & 1998 & South & Yes & 3 & III & $\mathrm{B}: \mathrm{b}: \mathrm{d}$ & $\mathrm{C}$ & $241,239 \mathrm{slv}$ \\
\hline & Kokkola & E27 & 78 & 1997 & Many regions & No & 4 & II & A:a:e & A & $8,239 \mathrm{slv}$ \\
\hline & Pori II & O16 & 3 & 1993 & West & No & $4 \mathrm{~b}$ & II & AN:a:e & $\mathrm{A}$ & \\
\hline \multirow[t]{6}{*}{ Iberian } & Turku I & E6 & 40 & 1991 & West & Yes & 5 & III & A:a:e & $\mathrm{B}$ & \\
\hline & Turku II & E7 & 62 & 1992 & West & Yes & $5 b$ & III & $\mathrm{B}: \mathrm{b}: \mathrm{d}$ & B & 247 \\
\hline & Turku III & O8 & 2 & 1992 & West & Yes & $5 \mathrm{c}$ & III & $\mathrm{B}: \mathrm{b}: \mathrm{d}$ & B & \\
\hline & Kotka & E10 & 32 & 1992 & East & Yes & $5 d$ & III & $\mathrm{B}: \mathrm{b}: \mathrm{d}$ & B & \\
\hline & Kerimäki & $\mathrm{O} 29$ & 34 & 2000 & East & No & 6 & III & A:a:e & $\mathrm{B}$ & \\
\hline & Tampere III & $\mathrm{O} 25$ & 15 & 1998 & Central & Yes & 7 & - & A.a:e & & $247 \mathrm{slv}$ \\
\hline \multirow{5}{*}{$\begin{array}{l}\text { New York } \\
\text { (or Pediatric) }\end{array}$} & Helsinki I & E1 & 270 & 1992 & South & Yes & 8 & IV & I:g:e & $\mathrm{D}$ & 5 \\
\hline & Koskela & $\mathrm{O} 26$ & 5 & 1999 & South & Yes & 9 & IV & I:g:e & $\mathrm{D}$ & \\
\hline & Bel EC-3 & E34 & 33 & 2001 & Many regions & Yes & 10 & IV & $\mathrm{CH}: \mathrm{cb}: \mathrm{e}$ & & \\
\hline & Moscow & E32 & 3 & 2000 & Many regions & Yes & 11 & IV & A:a:e & & \\
\hline & Helsinki III & $\mathrm{O} 3$ & 6 & 1994 & South & Yes & 12 & - & $\mathrm{F}: \mathrm{g}: \mathrm{e}$ & A & \\
\hline
\end{tabular}




\begin{tabular}{|c|c|c|c|c|c|c|c|c|c|c|c|}
\hline \multirow[t]{2}{*}{ UK EMRSA-16 } & Helsinki V & E5 & 75 & 1995 & South & Yes & 13 & $\mathrm{~V}$ & AR:af:q & $\mathrm{C}$ & 36 \\
\hline & Pori I & E15 & 32 & 1993 & Many regions & No & $13 b$ & V & AF:j:y & A & $30,36 \mathrm{slv}$ \\
\hline \multirow[t]{4}{*}{ Mikkeli } & Tampere I & E12 & 54 & 1994 & Central & No & 14 & VI & AP:ad:c & $\mathrm{A}$ & \\
\hline & Mikkeli I & O11 & 51 & 1993 & East & No & $14 \mathrm{~b}$ & VI & AP:ad:c & A & \\
\hline & Mikkeli II & $\mathrm{E} 23$ & 241 & 1997 & Many regions & No & $14 \mathrm{c}$ & VI & AP:ad:c & A & $59 \mathrm{slv}$ \\
\hline & Karkkila & O37 & 7 & 2000 & South & No & 15 & - & AP:ad:c & & \\
\hline \multirow[t]{5}{*}{ Berlin } & Kemi & E17 & 50 & 1996 & Many regions & No & 16 & VII & AG:aa:r & A & 45 \\
\hline & Kajaani & $\mathrm{O} 18$ & 11 & 1997 & North & No & $16 b$ & VII & BB:g:r & A & \\
\hline & Joensuu I & E21 & 8 & 1996 & East & No & $16 \mathrm{c}$ & VII & AW:bo:n & A & \\
\hline & Pello & E28 & 35 & 2000 & Many regions & No & 17 & VII & CC:bs:ax & & \\
\hline & Berlin IV & E38 & 13 & 1998 & Many regions & No & 18 & VII & CG::aa:r & & \\
\hline \multirow[t]{3}{*}{ Joensuu } & Joensuu II & E22 & 20 & 1998 & Many regions & No & 19 & VIII & AH:z:v & $\mathrm{A}$ & 12 \\
\hline & Nurmes & E36 & 2 & 2001 & East, South & No & 20 & VIII & CJ:ch:h & & \\
\hline & Vaalijala & O33 & 32 & 2001 & East & No & 21 & VIII & AH:ci:e & & \\
\hline \multirow{7}{*}{$\begin{array}{l}\text { UK EMRSA-15 } \\
\text { Undefined } \\
\text { (Iberia or Brazil) }\end{array}$} & UK EMRSA-15 & E30 & 44 & 1997 & Many regions & No & 22 & - & CB:br:al & $\mathrm{A}$ & 22 \\
\hline & Helsinki II & E2 & 36 & 1993 & South & Yes & 23 & - & $A: a: j$ & $\mathrm{~B}$ & \\
\hline & Helsinki IV & $\mathrm{O} 4$ & 3 & 1994 & South & Yes & 24 & I & A:a:z & $\mathrm{C}$ & \\
\hline & Lithuania & E35 & 4 & 2000 & South, East & Yes & 25 & I & A:a:e & & \\
\hline & Seinäjoki & E14 & 5 & 1992 & West & Yes & 26 & I & B:b:d & $\mathrm{C}$ & \\
\hline & Tampere II & E13 & 19 & 1994 & Central & Yes & 27 & - & B:b:d & $\mathrm{C}$ & \\
\hline & Turku IV & O9 & 25 & 1993 & West & No & 28 & - & A:b:d & $\mathrm{C}$ & \\
\hline Undefined & Helsinki VIII & E31 & 18 & 1997 & Many regions & No & 29 & - & Bz:ax:h & $\mathrm{A}$ & New \\
\hline
\end{tabular}

1) PFGE types and subtypes, $\leq 4$ bands difference

2) Cluster of strains with $\geq 75 \%$ similarity level by Bionumerics (dice coefficient, UPGMA, tolerance 1-2\%)

3) Blank, not determined 
not allow this assignment. For four clones (Iberian, Brazilian, New York, and Berlin), other strain types showing four to seven PFGE band differences as compared with epidemic and local outbreak strains have been identified.

Within one and the same clone, antimicrobial resistance patterns of different strains were mostly similar. A few exceptions were found: 1) Kokkola, Pori I, and Kerimäki strains, which showed multisensitive patterns in contrast to multiresistant patterns of all other members of the corresponding clones, 2) Pello strain, which showed two patterns, multiresistant and multisensitive, and 3) Helsinki V and Pori I strains, which constituted one clone, but showed different antimicrobial resistance patterns. Strains repeatedly isolated during long time periods (Helsinki I, Helsinki V, Kemi) showed changes in their antimicrobial resistance patterns.

\subsection{MRSA IN COMMUNITY (III)}

In 1997-1999, MRSA was isolated from 526 persons. Their median age was 51 years (range 0-96), and 291 $(55 \%)$ were male. Of all 526 persons, $108(21 \%)$ did not have any verified link to health-care facilities within two years before the MRSA isolation date. Their MRSA isolates were classified as community acquired. The HILMO register and the questionnaire survey showed 418 (79\%) persons who had at least one contact with a hospital, and their MRSA isolates were classified as hospital acquired. The median age of the persons who did not have any contact with a health-care facility was lower than that of the persons who did (34 vs. 58 years, $\mathrm{p}<0.01$ ).

Among the 526 MRSA isolates, the typing scheme showed 84 strain types, 56 of which were sporadic and 28 were shared by at least two persons. The distributions of sporadic (in total $56 / 526,11 \%$ ) and shared (in total $470 /$ $526,89 \%)$ strain types was similar in persons with $(43 / 418,10 \%)$ and without $(13 / 108,12 \%)$ connections to health-care facilities.

Fourteen strain types, each of which was isolated from ten or more persons, represented $80 \%(421 / 526)$ of all MRSA isolations. Three of the 14 common strain types were more likely to be found in persons who did not have a contact with a health-care facility than in those who did have such a contact: Mikkeli clone, Helsinki VIII, and Joensuu II. Of all strains isolated from persons who had no hospital contact, $94 \%$ were multisensitive. Of the 56 sporadic strains, $41 \%$ were multisensitive. 


\section{DISCUSSION}

\subsection{ELABORATION OF THE TYPING SCHEME}

Comprehensive typing of all MRSA isolates, or any particular nosocomial pathogen, has been considered unnecessary or even useless: "At best, such an expenditure of time, effort, and money provides some degree of information on the baseline genotypes of organisms in nosocomial environment. At the worst, the result is a mountain of data, which is difficult to interpret in the absence of clear driving epidemiological question" (88). However, we describe a typing scheme suitable for assisting in continuous nationwide MRSA surveillance. In addition to providing baseline information on genotypes for the whole country, and assistance in local outbreak investigations, this scheme has brought new information on the evolution and clonality of the Finnish MRSA. It is possible to conduct such intensive typing only in countries with low MRSA prevalence, and naturally this scheme needs to be subjected to constant evaluation and revision as new methods become available.

It was estimated that the proportion of sporadic strains was higher during 1992-1997 than during 19971999. This difference may not be real, since for the first period the sporadicity was mostly determined on the basis of phage typing. The reproducibility of phage typing is not sufficient for long-term surveillance, since, as shown by a recent study, fewer than one half of the same isolates typed on different days show identical reactions, or show reactions differing in strength only (10). The value of phage typing results for individual laboratories is also questionable. Since only strong reactions (++ or greater) are reported, a difference merely in the strength of the reactions of a group of strains may lead to incorrect interpretation. Therefore, the use of phage typing for surveillance purposes should be reconsidered. However, since phage typing performs well in short outbreak investigations (208), and is available only at KTL in Finland, it continues to be part of our routine typing scheme.

A more reliable identification of strains with similar genetic backgrounds was achieved by inclusion of PFGE in the routine typing scheme. The current widely accepted guidelines for interpreting PFGE patterns are restricted to outbreak investigations within a limited time frame (262). Our decision to use PFGE and the same guidelines also for continuous MRSA surveillance was based on several reasons: 1) PFGE was regarded as a gold standard method for the typing of MRSA; 2) the same method could be used for both outbreak investigations and surveillance; 3) computer-assisted analysis, storage of data, and comparison functions were available; 4) long-term reproducibility of other DNA-based typing methods, such as RAPD, might be more difficult to achieve (273); and 5) a less dis- 
criminative method, ribotyping, was available for isolates showing PFGE patterns difficult to interpret.

MLST is not sufficiently discriminative for local outbreak investigations, where the question is whether patient-to-patient transmission has occurred. In addition, MLST is too laborious and time consuming for intensive surveillance in which every new MRSA isolate is typed. However, when a new epidemic strain emerges, MLST is a powerful tool for determining whether the same clone has been encountered previously elsewhere, and for investigating the evolutionary origin of the emerging strain. In order to optimize the global comparison of pathogenic isolates, essential information, such as geographical prevalence and distribution, virulence properties, and antimicrobial resistance data for each pathogen, should be provided. This process has already begun for MRSA, Neisseria meningitidis, and antibiotic-resistant pneumococci (161, 169).

The current typing scheme does not include any method for typing mec DNA. However, according to the present study and recent reports (107, 198, 199), comprehensive assignment of MRSA lineages requires identification of both the genetic bacground of the strain and the structural type of the associated mec DNA. A multiplex PCR method (197), recently developed for rapid identification of the structural types of mec DNA, should be evaluated, using the Finnish MRSA strain collection, for its potential inclusion in the routine typing scheme.

\subsection{MRSA TRENDS AND EPI- DEMIC STRAINS}

Until 1997 the number of MRSA isolations remained stable, with a baseline of 100-150 annual isolations. A peak in 1994 (225 isolations) was due to the spread of the Helsinki I epidemic strain in the Helsinki metropolitan area. Some uncertainty remains about the data collected prior to 1995 , since the diagnostic criteria for detecting methicillin resistance and the guidelines for weekly reporting of MRSA were not well described. Since the establishment of the National Infectious Disease Register in 1995, a continuous increase in MRSA numbers has been detected. The MRSA numbers of the first three years of the National Infectious Disease Register (19951997) remained within the baseline of the previous decade, but has exceeded that since 1998. This increase may be partly due to enhanced diagnostics and a general awareness of MRSA. In 1995, MRSA isolations were mostly reported from the hospital districts with the highest population densities. By 2001, MRSA isolations were reported from all over the country.

A reliable comparison of MRSA trends with other countries is difficult, since proper denominator data are rarely available for analyses. According to one year's nationwide surveillance in Switzerland, this country and Finland had a similar incidence of MRSA in 1997, $9.3 v s .8 .1$ per 100,000 patient days, respectively (20). In Canada, the incidence of MRSA during the period 1996 to 1999 was higher than 
in Finland, but both countries experienced a similar rate of increase. In Canada, the number increased from 12.7 per 100,000 patient days in 1996 to 22.6 per 100,000 patient days in 1999 (251). The corresponding figures in Finland were 7.1 in 1996 and 18.1 in 1999. The median age of MRSA positive persons was lower in Finland than in Canada, 58 vs. 71, respectively. However, there are differences between the Canadian and the Finnish surveillance systems. The Canadian surveillance is conducted through sentinel hospitals, most of which are tertiary-care teaching hospitals (251), whereas in Finland, all clinical microbiology laboratories report MRSA isolations. A national MRSA survey in Ireland in 1995 revealed a two-week periodical MRSA prevalence of 12.7 per 100,000 population (123). This figure is more than five-fold as compared with that of Finland for the whole year, 2.3 per 100,000 population in 1997.

Despite a reasonably good MRSA situation on the national level in Finland, numerous strains causing local intrahospital outbreaks or interhospital epidemics were identified. New strains emerged throughout the study period, and twelve strains have continually been isolated since their first appearance, although the numbers of specific strains tend to decline by time. Genetic alterations, as detected by PFGE subtype variation, were occasionally observed in strains that reappeared after the first outbreak had been successfully controlled.
Approximately one third of all MRSA strains in Finland are multisensitive. This is in contrast to elsewhere in Europe, where only $13 \%$ of MRSA isolates, collected from 25 university hospitals in 15 countries through the SENTRY study, were multisensitive (76).

\subsection{MEC HYPERVARIABLE REGION}

The mec determinants of the 38 epidemic and outbreak strains were divided into four different types according to their hypervariable region hybridization profiles. An analysis of sporadic strains from the year 1995 revealed only three additional HVRtypes, each encountered in only one strain. Previous studies have shown that hypervariable region analysis by PCR and sequencing can be used to distinguish different mec DNA types (191, 233, 308). Five to eighteen different HVR-types have been identified in collections of 24-254 strains on the basis of differences in either the number or the sequence of $d r u$ repeats $(185,191,242,246,308)$. Consistently with the present study, the same HVRtype was often found in different genotypes. It is also possible that strains with identical genotypes harbor differences in HVR types. Five different subclones were identified among 50 isolates representing one epidemic strain in Germany (308). In the present study, the HVR types were mostly analyzed for one representative of each strain type, and therefore no conclusion can be drawn regarding the 
variety of HVR types within different strain types.

\subsection{MRSA CLONES AND TRANSMISSIBILITY}

Two major groups of MRSA were identified on the basis of antimicrobial susceptibility testing, ribotyping, and hybridization analysis of the mec hypervariable region of 72 epidemic, local outbreak, and sporadic MRSA strains. One group contained mainly sporadic strains showing mec HVR type A, multisensitivity, and a variety of ribotypes. The other group contained strains with mec HVR type B or $\mathrm{C}$ in association with two common ribotypes, and resistance to other antibiotic groups in addition to beta lactams. The latter group contained both epidemic and sporadic strains. Although two major groups with distinct genotypic and phenotypic traits were identified, none of the characteristics were associated directly with epidemicity or sporadicity. The failure to find such an association may be due to incorrect assignment of sporadic strains. Any strain isolated from one person only and showing a unique phage type and/or antimicrobial susceptibility pattern was defined as a sporadic strain. A classification of strain types on the basis of phage typing alone was later shown to be inadequate. In addition, an MLST analysis of the most common Finnish isolates from 1997-1999 showed that, although showing variable PFGE patterns, many of the previously identified epidemic and local outbreak strains ac- tually descended from a common ancestor. Some of the MRSA isolates originally classified as sporadic may also have belonged to these clones.

By a combination of several typing methods (phage typing, ribotyping, PFGE, and MLST), this study identified eight clones of MRSA in Finland. Six of the clones contained strains showing major MLST sequence types recently identified among MRSA strains from several different countries (74). Of a total of twelve international MRSA sequence types identified in a collection of 359 international MRSA isolates, nine (ST 5, 36, 347, 239, 241, 8, 22, 45, and $30)$ occurred in ten of the fourteen Finnish MRSA strains analyzed: Helsinki I, Helsinki V, Turku II, Helsinki VI, Helsinki VII, Lohja, Kokkola, UK EMRSA-15, Kemi, and Pori I. In addition, one strain, Tampere III, was a single locus variant of ST 247.

Two of the eight MRSA clones (Joensuu and Mikkeli) encountered in Finland contained strains showing different molecular epidemiology. Although these two clones were abundant among MRSA strains in Finland, the MLST sequence type ST 12 of Joensuu II is commonly found among international MSSA, but not among MRSA strains (http://www.mlst.net), (74), and ST 59, the slv of the Mikkeli clone has been thus far reported in one MRSA carrier and in few MSSA strains (http://www.mlst.net).

Patient-to-patient transmission of MRSA depends on many factors. Patients colonized or infected with 
MRSA are the major reservoir in hospitals. Patient risk factors for MRSA colonization and infection include previous hospitalization, pressure sores, indwelling devices, underlying disease, and recent antibiotic use $(47,64$, 236). Other factors promoting the spread of MRSA include care in highrisk departments such as burns unit or intensive care unit $(47,225)$, staff shortage (96), frequent patient transfer between wards and hospitals (60, 68), and antibiotic selection (249). MRSA dissemination may be reduced by appropriate infection control measures and antibiotic policies (96). However, the identification of a relatively small number of global MRSA clones among the large diversity of $S$. aureus clones suggests that strain characteristics also influence the dissemination of MRSA (http://mlst.net), (51, $54,74)$. The majority of the globally successful clones were also identified in Finland. Success in transmissibility seems not to be exclusively due to SCCmec, since 4 of the 12 recognized MRSA STs (ST 5, 8, 22, and 45) in Finland were common among European MSSA strains from the $1990 \mathrm{~s}$ (74), (http://www.mlst.net).

The reasons for superior transmissibility of some clones still remain unclear, although several mechanisms have been suggested. Two epidemic strains have been shown to possess better environmental survival than have three sporadic strains. The recovery capacity of all five strains declined gradually, but the epidemic strains survived three months longer, in up to approximately 1000 -fold higher quantities $(\mathrm{cfu} / \mathrm{ml})$, than did the sporadic strains (296). For some strains, enhanced transmissibility may result from better colonization at the expense of reduced virulence (153), as suggested for the Canadian epidemic strain CMRSA-3 (206). CMRSA-3 exhibited significantly higher fibronectingbinding and coagulase titers than did another epidemic strain, CMRSA-1, and sporadic strains. In the case of CMRSA-3, the balance towards enhanced colonization factor production may be explained by reduced and delayed RNAIII production by the global agr regulator (206). CMRSA-1 did not produce alpha toxin and proteases, and had a limited profile of secreted proteins but a normal level of RNAIII production. The predominant subtype of CMRSA-1 expressed a high molecular weight glycoprotein known to prevent bacterial adhesion to fibronecting, fibrinogen, and $\mathrm{IgG}$ (240). However, this protein may confer novel adhesion functions, such as those related to biofilm formation, and adherence to cellular lipids $(114,115)$. It has also been suggested that a high number of repeats $(\geq 7)$ in the polymorphic X-region of the protein A gene would predict an epidemic nature of MRSA strains. A longer X-region in epidemic strains may result in a better exposition of the Fc-binding region of protein A (81). Another study did not support this hypothesis, since no correlation was found between the length of the protein A gene repeats and the persistence of $S$. aureus colonization 
(279). In the light of the present and previous studies and the fact that $S$. aureus colonization and virulence result from a complicated interplay of numerous factors, it seems that no single mechanism is responsible for the successful transmission of certain clones. Instead, these clones may harbor a wide range of mechanisms affecting transmissibility, and the mechanisms may vary between different clones and even between subtypes of individual strains (206).

Reliable distinguishing of sporadic strains from strains with evident capacity to spread is crucial in the search for molecular markers or mechanisms for enhanced transmissibility. This requires representative population-based strain collections and careful characterization of isolates. Such material is available in Finland because of the national reporting and typing systems.

\subsection{MRSA IN COMMUNITY}

Our study showed that, from 1997 to 1999, one fifth of all Finnish MRSA isolates came from persons who had had no contact with health-care facilities, suggesting that these MRSA isolates may be community-acquired. This unexpectedly high proportion of community-acquired isolates was identified despite a stringent definition for community acquisition (22), i.e. a 2-year time period without health-care facility contact before the MRSA isolation. However, a possibility remains that some of the MRSA-positive persons may have had health-care facili- ty contacts before the 2-year cut-off period, and their MRSA isolates had been acquired in hospital and had persisted ever since.

Risk factors other than previous hospital stays were not analyzed in this study. Further information should be collected to develop a hypothesis on risk factors specific for community acquisition. Intravenous drug use, previous antibiotic use, and underlying diseases have previously been associated with community acquisition of MRSA $(147,176)$. A recent study covering 30 months identified a similar proportion $(22 \%, 20 / 92)$ of community-acquired MRSA in a university hospital. Thirteen $(65 \%)$ persons with community-acquired MRSA lacked the known risk factors (27). A known risk factor was defined as a previous hospitalization within 12 months, an underlying chronic disease, the presence of an indwelling catheter, a history of surgical procedures, previous antimicrobial therapy, intravenous drug use, or a household contact with an identified MRSA carrier.

Community-acquired MRSA can be classified into four categories: 1) discharged hospital patients and hospital staff members with MRSA; 2) nursing-home residents with MRSA; 3) MRSA transmitted to nonhospitalized patients; and 4) MRSA arising de novo in community (48). Our study focused on the last two categories by first identifying nonhospitalized MRSA-positive persons, and thereafter comparing their isolates with those from hospitalized patients 
Of all MRSA strain types isolated from ten or more persons during 1997-1999, three were associated with community acquisition: Mikkeli, Joensuu, and Helsinki VIII. Coincidentally, all these strain types showed related MLST sequence types previously encountered mostly among successful MSSA clones, but not among MRSA clones (74). In addition, three other strain types were also frequently found among persons without health-care facility contacts: Kemi, Kokkola, and Pori. All these strain types were characterized by multisensitivity and HVR type A. Preliminary PFGE studies indicate that the strain types similar to Mikkeli, Joensuu, Kemi, and Pori were also prevalent among contemporary MSSA isolates in Finland (unpublished data). In contrast, the multiresistant strain types, representing the globally spread MRSA clones (Brazilian, Iberian, New York, and the UK EMRSA16), were almost exclusively found in persons who had health-care facility contacts.

Recent sequencing of a virulent community-MRSA strain, MW2, which caused the deaths of four children without risk factors (29), suggested that different factors may be needed for competitive survival in different environments (11). Multiresistance may be biologically costly to maintain, and provides no additional fitness in an environment where the antibiotic selection pressure is low (5). The highly prevalent and virulent communityMRSA, MW2, grows faster, and has fewer transposons and insertion se- quences than have strains adapted to the hospital environment. In addition, MW2 harbors virulence factors not found in other MRSA genomes whose complete sequences are available (139). The superantigen enterotoxin $\mathrm{H}$, the penton-valentine leucocidin, a bacteriocin, and a collagen-adhesin were suggested as being partly responsible for the observed virulence (11). The virulence factors of the identified community-MRSA strains in Finland have not yet been assessed in any way. However, most of the community-acquired MRSA were multisensitive, and children were more likely to have a community-acquired than a hospital-acquired MRSA. These findings agree with those of previous reports, suggesting that nonmultiresistant MRSA is emerging as an important pathogen in the community $(29,72$, 105).

\subsection{HORIZONTAL TRANSFER OF MEC DNA}

According to the present study, horizontal transfer of mec DNA has partly influenced the epidemiology of MRSA in Finland. This is supported by several findings.

First, we found that similar MRSA genotypes had different mec DNA, as assessed by mec hypervariable region hybridization and PCR analysis of the mec-regulatory region. These results are in line with previous findings $(74,75,198)$ and suggest that representatives of similar genotypes may have acquired the mec DNA from different donors. 
Second, HVR type A was found in many different genotypes, most often in those with a multisensitive antimicrobial resistance pattern, but also in some isolates of Iberian, New York, and UK EMRSA-16 clones. Other HVR types were restricted to a few clones: HVR $\mathrm{B}$ in one, $\mathrm{C}$ in two, and $\mathrm{D}$ in one clone. These results suggest that HVR A mec may transfer more easily than others. It has been suggested that one mec type (mecSCC IV) can spread to most, if not all, $S$. aureus genotypes (5). The small size of SCCmec IV may explain its enhanced transfer capacity. Although it remains to be clarified whether different HVR types are associated with specific SCCmec types, our data suggest that HVR type A may be similar to SCCmec IV $(158,198)$

Third, two common clones of MRSA in Finland, the Mikkeli and Joensuu clones, expressed MLST sequence types usually found in methicillin-sensitive strains (http:// www.mlst.net). These MRSA clones, and the Helsinki VIII strain, which is a triple allele variant of the Joensuu clone, are multisensitive, express HVR type A, and are associated with community acquisition. Furthermore, methicillin-sensitive $S$. aureus strains with PFGE types related to the Mikkeli and Joensuu clones are common in Finland. International community-acquired MRSA strains have been shown to harbor a type of mec DNA, which lacks resistance determinants other than the mecA gene, and regions known to contain mutated or partially deleted elements. This type of mec DNA has also been encountered in coagulase negative staphylococci (109), and it may be more capable than other mec DNAs of confering beta lactam resistance to community strains of $S$. aureus $(11,158)$. Our results support this hypothesis.

Emergence of new MRSA clones has also been encountered in Germany (305). Furthermore, strains resistant to fewer antimicrobial groups than before have also been encountered in France, and these strains have progressively replaced previous genetically different, multiresistant MRSA clones $(83,148,149)$.

The $m e c A$ gene is widely distributed among different species of coagulase negative staphylococci (214, 274), and such strains have been detected in both nosocomial infections and healthy carriers $(55,66)$. Thus, donors of mec DNA may be available both in nosocomial and community settings.

Overall, it seems evident that the increase in the number of MRSA is not exclusively due to clonal dissemination, but that emergence of de novo MRSA through horizontal transfer of mec DNA occurs occasionally. 


\section{CONCLUSIONS AND CON- SIDERATIONS FOR THE FU- TURE}

A suitable typing scheme for continuous nationwide MRSA surveillance was established. In a low prevalence country, comprehensive molecular typing, verification of methicillin resistance and S. aureus species, as well as antimicrobial susceptibility testing of all new isolates is feasible. Continuous feedback to laboratories and infection control nurses is provided.

MRSA trend in Finland is increasing. However, the incidence of MRSA is still low as compared with that in many other European countries and the USA. The proportion of MRSA isolated from persons without hospital contacts was surprisingly high, one fifth of all isolates.

Two epidemiologically distinct MRSA populations were found. The first population consisted of global MRSA strains, which mainly spread within and between hospitals through clonal dissemination. The second population consisted of strains genotypically related to MSSA. Some of these strains may emerge through horizontal transfer of mec DNA. Subsequent clonal dissemination may occur, often locally in susceptible environments, such as long-term care facilities. Some of these strains were associated with community acquisition.

The two MRSA populations may require different infection control measures. The control of global MRSA in Finland has been quite successful, as exemplified by the decline of such isolates in the largest hospital district. In contrast, increasing problems are encountered with the MRSA population consisting of strains genotypically related to MSSA. Although easier to treat, they may be more difficult to diagnose because of their low oxacillin MICs and heteroresistance. Factors influencing the emergence of such strains are unknown, but antibiotic selection pressure may play a role. If the emergence of such strains cannot be hindered, efforts should be aimed at the prevention of secondary transmission.

This study brought up several items which call for more precise research in the future. Further clinical information should be collected on persons with community-acquired MRSA in order to develop a hypothesis on risk factors specific for community acquisition. Association of HVRtypes with different SCCmec types should be addressed. Many open questions related to the horizontal transfer of mec DNA remain to be elucidated. Is HVR type A associated with community acquisition? Does mec DNA characterized by HVR type A transfer more easily than do other mec DNA types? Are the mec-integration areas different between isolates showing MLST STs common to both MRSA and MSSA as compared with those of MSSA exclusively? Furthermore, the SCCmec-types in coagulase negative staphylococci should be studied in more detail.

The near future will provide new techniques for typing and for predict- 
ing the epidemic capacity or pathogenicity of MRSA strains. Both structural and transcriptional differences in genomes can be revealed using microarray hybridizations. PCR or sequencing approaches may be developed for the allotyping of already identified genomic islands. The availability of complete genome sequences of several strains will result in identification of new areas important for the understanding of the adaptive fitness of MRSA strains found in different environments. 


\section{ACKNOWLEDGEMENTS}

This work was carried out in the Department of Microbiology, National Public Health Institute, Helsinki. I thank Professor Jussi Huttunen, Head of the Institute, for providing excellent research facilities.

Professor Tapani Hovi, Head of Department, and Professors Martti Vaara and Pirjo Mäkelä, former Heads of Department (Department of Bacteriology at that time) are thanked for their interest in and encouragement regarding my study.

I extend my deepest gratitude to my supervisor, Docent Jaana VuopioVarkila, for continuous support, discussions, and guidance throughout this work. Without Jaana's optimistic attitude and understanding this work would not have been completed.

I am most grateful to Docent Outi Lyytikäinen for valuable discussions, advice, co-operation, and especially for patience and guidance in my process of learning scientific writing. I wish to thank the other co-authors for their excellent collaboration and fruitful discussions. I also thank the members of the Harmony group, whose contribution and discussions greatly influenced my work.

The official reviewers, Docent Pentti Kuusela and Docent Mikael Skurnik, are thanked for their constructive criticism and valuable advice.

I thank everyone in the Laboratory of Hospital Bacteriology for their friendship, understanding, and help in every possible (and impossible) situ- ation that we have encountered together. I, especially, thank Elina and Ritva for sharing both good and bad moments with me throughout these years. Aila and Merja brought jokes and action to the lab, and Salha gave us perspective. During the past year, Tuula has been there, ready to answer any question, scientific or other, whenever necessary. I have had the opportunity to work with many other people in our lab, for shorter or longer periods. This has been an enjoyable and interesting part of my work.

I thank all the "Bakt-people" in the Department of Microbiology. You have created a warm atmosphere where working is fun and coffeebreaks are lively. I thank in particular Kaija Helisjoki and Ritva Marizu for everyday help, Carina Bergsten for rapid help with computer problems, Ritva Taipalinen for countless different things we have somehow ended up doing together, and Susanna and Joanna for their friendship and listening.

Thanks to all my friends, especially Janet, Kirsi, and Päivi (my friends since long ago), and Anne and Juha (from recent years) for providing me with and reminding me of "real life". I thank Taimi and Erkki for their help in daily affairs. Whenever we need something, Taimi's kitchen is open.

I warmly thank my parents, Anneli and Erkki, for their constant support of and belief in me in all aspects of life, and my brother, Samu, for countless short but efficient discussions and moments of fun. If I ever 
need an honest opinion, I will get it from Samu.

I thank Semi and Aaro for their love, and for bringing me the joy of life (almost) every day.

October 2002

furhenen

64 


\section{REFERENCES}

1. 2001. National Nosocomial Infections Surveillance (NNIS) System Report, Data Summary from January 1992-June 2001, issued August 2001. Am J Infect Control 29:404-21.

2. Aavitsland, P., M. Stormark, and A. Lystad. 1992. Hospitalacquired infections in Norway: a national prevalence survey in 1991. Scand J Infect Dis 24:47783.

3. Abi-Hanna, P., A. L. Frank, J. P. Quinn, S. Kelkar, P. C. Schreckenberger, M. K. Hayden, and J. F. Marcinak. 2000. Clonal features of community-acquired methicillin-resistant Staphylococcus aureus in children. Clin Infect Dis 30:630-1.

4. Abudu, L., I. Blair, A. Fraise, and K. K. Cheng. 2001. Methicillinresistant Staphylococcus aureus (MRSA): a community-based prevalence survey. Epidemiol Infect 126:351-6.

5. Ala'Aldeen, D. 2002. A nonmultiresistant community MRSA exposes its genome. Lancet 359:1791-2.

6. Anthony, B. F., and H. R. Hill. 1988. Gram-positive bacteria: an overview and summary of session. Rev Infect Dis 10:S345-50.

7. Aries de Sousa, M., H. de Lencastre, I. Santos Sanches, K. Kikuchi, K. Totsuka, and A. Tomasz. 2000. Similarity of antibiotic resistance patterns and molecular typing properties of methicillin-resistant

Staphylococcus aureus isolates widely spread in hospitals in New York City and in a hospital in Tokyo, Japan. Microb Drug Resist 6:253-8.
8. Arvidson, S., and K. Tegmark. 2001. Regulation of virulence determinants in Staphylococcus aureus. Int J Med Microbiol 291:159-70.

9. Aubry-Damon, H., C. J. Soussy, and P. Courvalin. 1998.

Characterization of mutations in the $r p o B$ gene that confer rifampin resistance in Staphylococcus aureus. Antimicrob Agents Chemother 42:2590-4.

10. Aucken, H. M., and K. Westwell. 2002. Reaction difference rule for phage typing of Staphylococcus aureus at 100 times the routine test dilution. J Clin Microbiol 40:2923.

11. Baba, T., F. Takeuchi, M. Kuroda, H. Yuzawa, K. Aoki, A. Oguchi, Y. Nagai, N. Iwama, K. Asano, T. Naimi, H. Kuroda, L. Cui, K. Yamamoto, and K. Hiramatsu. 2002. Genome and virulence determinants of high virulence community-acquired MRSA. Lancet 359:1819-27.

12. Baddiley, J. 1989. Bacterial cell walls and membranes. Discovery of the teichoic acids. Bioessays 10:207-10.

13. Bax, R., R. Bywater, G. Cornaglia, H. Goossens, P. Hunter, V. Isham, V. Jarlier, R. Jones, I. Phillips, D. Sahm, S. Senn, M. Struelens, D. Taylor, and A. White. 2001. Surveillance of antimicrobial resistance-what, how and whither? Clin Microbiol Infect 7:316-25.

14. Beck, W. D., B. Berger-Bachi, and F. H. Kayser. 1986. Additional DNA in methicillin-resistant Staphylococcus aureus and molecular cloning of mec-specific DNA. J Bacteriol 165:373-8.

15. Berger-Bachi, B. 1999. Genetic basis of methicillin resistance in 
Staphylococcus aureus. Cell Mol

Life Sci 56:764-70.

16. Berger-Bachi, B., A. Strassle, J. E. Gustafson, and F. H. Kayser.

1992. Mapping and

characterization of multiple

chromosomal factors involved in

methicillin resistance in

Staphylococcus aureus.

Antimicrob Agents Chemother

36:1367-73.

17. Bernander, S., A. Hambraeus, K.

E. Myrback, B. Nystrom, and B.

Sundelof. 1978. Prevalence of hospital-associated infections in

five Swedish hospitals in

November 1975. Scand J Infect

Dis 10:66-70.

18. Beveridge, T. J. 1999. Structures of gram-negative cell walls and their derived membrane vesicles. $\mathbf{J}$

Bacteriol 181:4725-33.

19. Bhakdi, S., and J. Tranum-Jensen. 1991. Alpha-toxin of

Staphylococcus aureus. Microbiol Rev 55:733-51.

20. Blanc, D., D. Pittet, C. Ruef, A. Widmer, K. Muhlemann, C.

Petignat, S. Harbarth, R. Auckenthaler, J. Bille, R. Frei, R. Zbinden, R. Peduzzi, V. Gaia, H. Khamis, E. Bernasconi, and

P. Francioli. 2002. Epidemiology of methicillin-resistant

Staphylococcus aureus: results of a nation-wide survey in Switzerland. Swiss Med Wkly 132:223-229.

21. Blevins, J. S., K. E. Beenken, M. O. Elasri, B. K. Hurlburt, and M. S. Smeltzer. 2002. Straindependent differences in the regulatory roles of sarA and agr in Staphylococcus aureus. Infect Immun 70:470-80.

22. Boyce, J. M. 1998. Are the epidemiology and microbiology of methicillin-resistant
Staphylococcus aureus changing? Jama 279:623-4.

23. Bradley, S. F. 1999. Methicillinresistant Staphylococcus aureus: long-term care concerns. Am J Med 106:2S-10S; discussion 48S$52 \mathrm{~S}$.

24. Brakstad, O. G., K. Aasbakk, and J. A. Maeland. 1992. Detection of Staphylococcus aureus by polymerase chain reaction amplification of the nuc gene. $\mathbf{J}$ Clin Microbiol 30:1654-60.

25. Brosius, T., A. Ullrich, M. Raker, A. Gray, T. Dull, R. Gutell, and H. Noller. 1981. Construction and fine mapping of recombinant plasmids containing the $r r n B$ ribosomal operon of E.coli. Plasmid 6:112-118.

26. Brown, D. F., and P. E. Reynolds. 1980. Intrinsic resistance to betalactam antibiotics in Staphylococcus aureus. FEBS Lett 122:275-8.

27. Bukharie, H. A., and M. S.

Abdelhadi. 2001. The epidemiology of methicillinresistant Staphylococcus aureus at a Saudi university hospital. Microb Drug Resist 7:413-6.

28. Byrne, M. E., M. T. Gillespie, and R. A. Skurray. 1991. 4',4'" adenyltransferase activity on conjugative plasmids isolated from Staphylococcus aureus is encoded on an integrated copy of pUB110. Plasmid 25:70-5.

29. CDC. 1998. Four pediatric deaths from community-acquired methicillin-resistant Staphylococcus aureus -Minnesota and North Dakoda, 1997-1999. JAMA 272829:1123-1125.

30. CDC. 1991. Nosocomial infection rates for interhospital comparison: limitations and possible solutions. A Report from the National Nosocomial Infections 
Surveillance (NNIS) System. Infect Control Hosp Epidemiol 12:609-21.

31. CDC. 2002. Staphylococcus aureus resistant to vancomycin, United States, 2002. Morbidity and Mortality Weekly Report 51:565567.

32. Cefai, C., S. Ashurst, and C. Owens. 1994. Human carriage of methicillin-resistant

Staphylococcus aureus linked with pet dog. Lancet 344:539-40.

33. Chamberlain, N. R., and B.

Imanoel. 1996. Genetic regulation of fatty acid modifying enzyme from Staphylococcus aureus. J Med Microbiol 44:125-9.

34. Chambers, H. F. 1997. Methicillin resistance in staphylococci: molecular and biochemical basis and clinical implications. Clin Microbiol Rev 10:781-91.

35. Chambers, H. F., G. Archer, and M. Matsuhashi. 1989. Low-level methicillin resistance in strains of Staphylococcus aureus. Antimicrob Agents Chemother 33:424-8.

36. Chambers, H. F., and M.

Sachdeva. 1990. Binding of betalactam antibiotics to penicillinbinding proteins in methicillinresistant Staphylococcus aureus. J Infect Dis 161:1170-6.

37. Chang, S.-C., C.-C. Sun, L.-S. Yang, K.-T. Luh, and W.-C. Hsieh. 1997. Increasing nosocomial infections of methicillin-resistant Staphylococcus aureus in a teaching hospital in Taiwan. International Journal of Antimicrobial Agents 8:109-114.

38. Charlebois, E. D., D. R. Bangsberg, N. J. Moss, M. R. Moore, A. R. Moss, H. F. Chambers, and F. PerdreauRemington. 2002. Population- based community prevalence of methicillin-resistant

Staphylococcus aureus in the urban poor of San Francisco. Clin Infect Dis 34:425-33.

39. Chavakis, T., M. Hussain, S. M. Kanse, G. Peters, R. G. Bretzel, J. I. Flock, M. Herrmann, and K. T. Preissner. 2002. Staphylococcus aureus extracellular adherence protein serves as anti-inflammatory factor by inhibiting the recruitment of host leukocytes. Nat Med 8:68793.

40. Cheung, A. I., S. J. Projan, R. E. Edelstein, and V. A. Fischetti. 1995. Cloning, expression, and nucleotide sequence of a Staphylococcus aureus gene $(f b p A)$ encoding a fibrinogenbinding protein. Infect Immun 63:1914-20.

41. Cheung, A. L., Y. T. Chien, and A. S. Bayer. 1999. Hyperproduction of alpha-hemolysin in a $\operatorname{sig} B$ mutant is associated with elevated SarA expression in Staphylococcus aureus. Infect Immun 67:1331-7.

42. Cheung, A. L., K. Eberhardt, and J. H. Heinrichs. 1997. Regulation of protein A synthesis by the sar and agr loci of Staphylococcus aureus. Infect Immun 65:2243-9.

43. Chien, Y., and A. L. Cheung. 1998. Molecular interactions between two global regulators, sar and agr, in Staphylococcus aureus. J Biol Chem 273:2645-52.

44. Chikramane, S. G., P. R. Matthews, W. C. Noble, P. R. Stewart, and D. T. Dubin. 1991. Tn554 inserts in methicillinresistant Staphylococcus aureus from Australia and England: comparison with an American methicillin-resistant group. J Gen Microbiol 137:1303-11. 
45. Cho, S. H., I. Strickland, M. Boguniewicz, and D. Y. Leung. 2001. Fibronectin and fibrinogen contribute to the enhanced binding of Staphylococcus aureus to atopic skin. J Allergy Clin Immunol 108:269-74.

46. Chung, M., H. de Lencastre, $\mathbf{P}$. Matthews, A. Tomasz, I. Adamsson, M. Aries de Sousa, T. Camou, C. Cocuzza, A. Corso, I. Couto, A. Dominguez, M. Gniadkowski, R. Goering, A. Gomes, K. Kikuchi, A. Marchese, R. Mato, O. Melter, D. Oliveira, R. Palacio, R. SaLeao, I. Santos Sanches, J. H. Song, P. T. Tassios, and P. Villari. 2000. Molecular typing of methicillin-resistant

Staphylococcus aureus by pulsedfield gel electrophoresis: comparison of results obtained in a multilaboratory effort using identical protocols and MRSA strains. Microb Drug Resist 6:18998.

47. Coello, R., J. R. Glynn, C. Gaspar, J. J. Picazo, and J. Fereres. 1997. Risk factors for developing clinical infection with methicillinresistant Staphylococcus aureus (MRSA) amongst hospital patients initially only colonized with MRSA. J Hosp Infect 37:39-46.

48. Cookson, B. D. 2000. Methicillinresistant Staphylococcus aureus in the community: new battlefronts, or are the battles lost? Infect Control Hosp Epidemiol 21:398403.

49. Couto, I., H. de Lencastre, E. Severina, W. Kloos, J. A. Webster, R. J. Hubner, I. S. Sanches, and A. Tomasz. 1996. Ubiquitous presence of a $m e c A$ homologue in natural isolates of Staphylococcus sciuri. Microb Drug Resist 2:377-91.
50. Cox, R. A., and P. E. Bowie. 1999. Methicillin-resistant

Staphylococcus aureus colonization in nursing home residents: a prevalence study in Northamptonshire. J Hosp Infect 43:115-22.

51. Crisostomo, M. I., H. Westh, A. Tomasz, M. Chung, D. C. Oliveira, and $H$. de Lencastre. 2001. The evolution of methicillin resistance in Staphylococcus aureus: similarity of genetic backgrounds in historically early methicillin-susceptible and resistant isolates and contemporary epidemic clones. Proc Natl Acad Sci U S A 98:9865-70.

52. Cui, L., H. Murakami, K. Kuwahara-Arai, H. Hanaki, and K. Hiramatsu. 2000. Contribution of a thickened cell wall and its glutamine nonamidated component to the vancomycin resistance expressed by Staphylococcus aureus Mu50. Antimicrob Agents Chemother 44:2276-85.

53. Davies, H. G., and D. R. Martin. 1987. Heat shocking as a useful adjunct to routine phage typing of Staphylococcus aureus. J Hosp Infect 10:4-9.

54. Day, N. P., C. E. Moore, M. C. Enright, A. R. Berendt, J. M. Smith, M. F. Murphy, S. J. Peacock, B. G. Spratt, and E. J. Feil. 2001. A link between virulence and ecological abundance in natural populations of Staphylococcus aureus. Science 292:114-6.

55. De Giusti, M., L. Pacifico, D. Tufi, A. Panero, A. Boccia, and C. Chiesa. 1999. Phenotypic detection of nosocomial mecApositive coagulase-negative 
staphylococci from neonates. J

Antimicrob Chemother 44:351-8.

56. de Lencastre, H., and A. Tomasz.

1994. Reassessment of the number

of auxiliary genes essential for

expression of high-level

methicillin resistance in

Staphylococcus aureus.

Antimicrob Agents Chemother

38:2590-8.

57. De Lencastre, H., S. W. Wu, M. G. Pinho, A. M. Ludovice, S. Filipe, S. Gardete, R. Sobral, S. Gill, M. Chung, and A. Tomasz. 1999.

Antibiotic resistance as a stress response: complete sequencing of a large number of chromosomal loci in Staphylococcus aureus strain COL that impact on the expression of resistance to methicillin. Microb Drug Resist 5:163-75.

58. de Sousa, M. A., I. S. Sanches, M. L. Ferro, M. J. Vaz, Z. Saraiva, T. Tendeiro, J. Serra, and H. de Lencastre. 1998. Intercontinental spread of a multidrug-resistant methicillin-resistant

Staphylococcus aureus clone. J Clin Microbiol 36:2590-6.

59. Del Vecchio, V. G., J. M.

Petroziello, M. J. Gress, F. K. McCleskey, G. P. Melcher, H. K. Crouch, and J. R. Lupski. 1995.

Molecular genotyping of methicillin-resistant

Staphylococcus aureus via fluorophore-enhanced repetitivesequence PCR. J Clin Microbiol 33:2141-4.

60. Deplano, A., W. Witte, W. J. van Leeuwen, Y. Brun, and M. J. Struelens. 2000. Clonal dissemination of epidemic methicillin-resistant Staphylococcus aureus in Belgium and neighboring countries. Clin Microbiol Infect 6:239-45.
61. Dickinson, R. B., J. A. Nagel, D. McDevitt, T. J. Foster, R. A. Proctor, and S. L. Cooper. 1995. Quantitative comparison of clumping factor- and coagulasemediated Staphylococcus aureus adhesion to surface-bound fibrinogen under flow. Infect Immun 63:3143-50.

62. Diekema, D. J., M. A. Pfaller, J. Turnidge, J. Verhoef, J. Bell, A. C. Fluit, G. V. Doern, and R. N. Jones. 2000. Genetic relatedness of multidrug-resistant, methicillin (oxacillin)-resistant

Staphylococcus aureus bloodstream isolates from SENTRY Antimicrobial Resistance Surveillance Centers worldwide, 1998. Microb Drug Resist 6:213-21.

63. Dinges, M. M., P. M. Orwin, and P. M. Schlievert. 2000. Exotoxins of Staphylococcus aureus. Clin Microbiol Rev 13:16-34, table of contents.

64. Doebbeling, B. N. 1995. The epidemiology of methicillinresistant Staphylococcus aureus colonisation and infection. $\mathrm{J}$ Chemother 7:99-103.

65. Doebbeling, B. N. 1994. Nasal and hand carriage of Staphylococcus aureus in healthcare workers. J Chemother 6:11-7.

66. Dominguez, E., M. Zarazaga, and C. Torres. 2002. Antibiotic resistance in Staphylococcus isolates obtained from fecal samples of healthy children. J Clin Microbiol 40:2638-41.

67. Duckworth, G., B. Cookson, H. Humphreys, and R. Heathcock. 1998. Revised guidelines for the control of methicillin-resistant Staphylococcus aureus infection in hospitals. Journal of Hospital Infection 39:250-290. 
68. Dziekan, G., A. Hahn, K. Thune, G. Schwarzer, K. Schafer, F. D. Daschner, and H. Grundmann. 2000. Methicillin-resistant Staphylococcus aureus in a teaching hospital: investigation of nosocomial transmission using a matched case-control study. J Hosp Infect 46:263-70.

69. Edmond, M. B., S. E. Wallace, D. K. McClish, M. A. Pfaller, R. N. Jones, and R. P. Wenzel. 1999.

Nosocomial bloodstream infections in United States hospitals: a three-year analysis. Clin Infect Dis 29:239-44.

70. Ellingsen, E., S. Morath, T. Flo, A. Schromm, T. Hartung, C. Thiemermann, T. Espevik, D. Golenbock, D. Foster, R. Solberg, A. Aasen, and J. Wang. 2002. Induction of cytokine production in human $\mathrm{T}$ cells and monocytes by highly purified lipoteichoic acid: involvement of Toll-like receptors and CD14. Med Sci Monit 8:BR149-56.

71. Elliott, T. S., and M. H. Faroqui. 1992. Infections and intravascular devices. Br J Hosp Med 48:496-7, 500-3.

72. Embil, J., K. Ramotar, L. Romance, M. Alfa, J. Conly, S. Cronk, G. Taylor, B. Sutherland, T. Louie, E. Henderson, and et al. 1994. Methicillin-resistant Staphylococcus aureus in tertiary care institutions on the Canadian prairies 1990-1992. Infect Control Hosp Epidemiol 15:646-51.

73. Enright, M. C., N. P. Day, C. E. Davies, S. J. Peacock, and B. G. Spratt. 2000. Multilocus sequence typing for characterization of methicillin-resistant and methicillin-susceptible clones of Staphylococcus aureus. J Clin Microbiol 38:1008-15.
74. Enright, M. C., D. A. Robinson, G. Randle, E. J. Feil, H.

Grundmann, and B. G. Spratt. 2002. The evolutionary history of methicillin-resistant

Staphylococcus aureus (MRSA). Proc Natl Acad Sci U S A 99:7687-92.

75. Fitzgerald, J. R., D. E. Sturdevant, S. M. Mackie, S. R. Gill, and J. M. Musser. 2001. Evolutionary genomics of Staphylococcus aureus: insights into the origin of methicillin-resistant strains and the toxic shock syndrome epidemic. Proc Natl Acad Sci U S A 98:8821-6.

76. Fluit, A. C., C. L. Wielders, J. Verhoef, and F. J. Schmitz. 2001. Epidemiology and susceptibility of 3,051 Staphylococcus aureus isolates from 25 university hospitals participating in the European SENTRY study. J Clin Microbiol 39:3727-32.

77. Foster, T. J., and M. Hook. 1998. Surface protein adhesins of Staphylococcus aureus. Trends Microbiol 6:484-8.

78. Fournier, B., A. Klier, and G. Rapoport. 2001. The twocomponent system ArlS-ArlR is a regulator of virulence gene expression in Staphylococcus aureus. Mol Microbiol 41:247-61.

79. Fraise, A. P., K. Mitchell, S. J. O'Brien, K. Oldfield, and R. Wise. 1997. Methicillin-resistant Staphylococcus aureus (MRSA) in nursing homes in a major UK city: an anonymized point prevalence survey. Epidemiol Infect 118:1-5.

80. Frenay, H. M., A. E. Bunschoten, L. M. Schouls, W. J. van Leeuwen, C. M. VandenbrouckeGrauls, J. Verhoef, and F. R. Mooi. 1996. Molecular typing of methicillin-resistant Staphylococcus aureus on the 
basis of protein A gene

polymorphism. Eur J Clin

Microbiol Infect Dis 15:60-4.

81. Frenay, H. M., J. P. Theelen, L. M. Schouls, C. M. VandenbrouckeGrauls, J. Verhoef, W. J. van Leeuwen, and F. R. Mooi. 1994. Discrimination of epidemic and nonepidemic methicillin-resistant Staphylococcus aureus strains on the basis of protein A gene polymorphism. J Clin Microbiol 32:846-7.

82. Frimodt-Moller, N., F. Espersen, P. Skinhoj, and V. T. Rosdahl. 1997. Epidemiology of Staphylococcus aureus bacteremia in Denmark from 1957 to 1990. Clin Microbiol Infect 3:297-305.

83. Galdbart, J. O., A. Morvan, and N. El Solh. 2000. Phenotypic and molecular typing of nosocomial methicillin-resistant

Staphylococcus aureus strains susceptible to gentamicin isolated in france from 1995 to $1997 . \mathrm{J}$ Clin Microbiol 38:185-90.

84. Garner, J. S., W. R. Jarvis, T. G. Emori, T. C. Horan, and J. M. Hughes. 1988. CDC definitions for nosocomial infections, 1988. Am J Infect Control 16:128-40.

85. Geyid, A., and Y. Lemeneh. 1991. The incidence of methicillin resistant $S$. aureus strains in clinical specimens in relation to their beta-lactamase producing and multiple-drug resistance properties in Addis Abeba. Ethiop Med J 29:149-61.

86. Giesbrecht, P., T. Kersten, H. Maidhof, and J. Wecke. 1998. Staphylococcal cell wall: morphogenesis and fatal variations in the presence of penicillin. Microbiol Mol Biol Rev 62:1371414.

87. Giraudo, A. T., A. L. Cheung, and R. Nagel. 1997. The sae locus of
Staphylococcus aureus controls exoprotein synthesis at the transcriptional level. Arch Microbiol 168:53-8.

88. Goering, R. 2000. The molucal epidemiology of nosocomial infection: past, present and future. Reviews in Medical Microbiology 11:145-152.

89. Goering, R. V., and T. D. Duensing. 1990. Rapid field inversion gel electrophoresis in combination with an rRNA gene probe in the epidemiological evaluation of staphylococci. J Clin Microbiol 28:426-9.

90. Goettsch, W., S. L. Bronzwaer, A. J. de Neeling, M. C. Wale, $H$. Aubry-Damon, B. OlssonLiljequist, M. J. Sprenger, and J. E. Degener. 2000. Standardization and quality assurance for antimicrobial resistance surveillance of Streptococcus pneumoniae and Staphylococcus aureus within the European Antimicrobial Resistance Surveillance System (EARSS). Clin Microbiol Infect 6:59-63.

91. Goffin, C., and J. M. Ghuysen. 1998. Multimodular penicillinbinding proteins: an enigmatic family of orthologs and paralogs. Microbiol Mol Biol Rev 62:107993.

92. Goh, S. H., S. K. Byrne, J. L. Zhang, and A. W. Chow. 1992. Molecular typing of

Staphylococcus aureus on the basis of coagulase gene polymorphisms. J Clin Microbiol 30:1642-5.

93. Gomes, A. R., I. S. Sanches, M. Aires de Sousa, E. Castaneda, and H. de Lencastre. 2001. Molecular epidemiology of methicillin-resistant Staphylococcus aureus in Colombian hospitals: dominance 
of a single unique multidrugresistant clone. Microb Drug Resist 7:23-32.

94. Grimont, F., and P. Grimont. 1995. Determination of $r R N A$ gene restriction patterns, p. 181-200. In J. Howard and D. Whitecombe (ed.), Diagnostic bacteriology protocols. Humana Press, Totowa.

95. Groom, A. V., D. H. Wolsey, T. S. Naimi, K. Smith, S. Johnson, D. Boxrud, K. A. Moore, and J. E. Cheek. 2001. Communityacquired methicillin-resistant Staphylococcus aureus in a rural American Indian community. Jama 286:1201-5.

96. Grundmann, H., S. Hori, B. Winter, A. Tami, and D. J. Austin. 2002. Risk factors for the transmission of methicillinresistant Staphylococcus aureus in an adult intensive care unit: fitting a model to the data. J Infect Dis 185:481-8.

97. Gustafson, J., A. Strassle, H. Hachler, F. H. Kayser, and B. Berger-Bachi. 1994. The femC locus of Staphylococcus aureus required for methicillin resistance includes the glutamine synthetase operon. J Bacteriol 176:1460-7.

98. Hackbarth, C. J., and H. F. Chambers. 1993. blaI and blaRI regulate beta-lactamase and PBP 2a production in methicillinresistant Staphylococcus aureus. Antimicrob Agents Chemother 37:1144-9.

99. Haley, R. W., D. H. Culver, J. W. White, W. M. Morgan, T. G. Emori, V. P. Munn, and T. M. Hooton. 1985. The efficacy of infection surveillance and control programs in preventing nosocomial infections in US hospitals. Am J Epidemiol 121:182-205.
100. Haley, R. W., A. W. Hightower, R. F. Khabbaz, C. Thornsberry, W. J. Martone, J. R. Allen, and J. M. Hughes. 1982. The emergence of methicillin-resistant Staphylococcus aureus infections in United States hospitals. Possible role of the house staff-patient transfer circuit. Ann Intern Med 97:297-308.

101. Hallanvuo, S., M. Skurnik, K. Asplund, and A. Siitonen. 2002.

Detection of a novel repeated sequence useful for epidemiological typing of pathogenic Yersinia enterocolitica. International Journal of Medical Microbiology In press.

102. Hamill, R. J., J. M. Vann, and R. A. Proctor. 1986. Phagocytosis of Staphylococcus aureus by cultured bovine aortic endothelial cells: model for postadherence events in endovascular infections. Infect Immun 54:833-6.

103. Hanaki, H., K. Kuwahara-Arai, S. Boyle-Vavra, R. S. Daum, H. Labischinski, and K. Hiramatsu. 1998. Activated cell-wall synthesis is associated with vancomycin resistance in methicillin-resistant Staphylococcus aureus clinical strains Mu3 and Mu50. J Antimicrob Chemother 42:199209.

104. Hartleib, J., N. Kohler, R. B. Dickinson, G. S. Chhatwal, J. J. Sixma, O. M. Hartford, T. J. Foster, G. Peters, B. E. Kehrel, and M. Herrmann. 2000. Protein A is the von Willebrand factor binding protein on Staphylococcus aureus. Blood 96:2149-56.

105. Herold, B. C., L. C. Immergluck, M. C. Maranan, D. S. Lauderdale, R. E. Gaskin, S. Boyle-Vavra, C. D. Leitch, and R. S. Daum. 1998. Communityacquired methicillin-resistant 
Staphylococcus aureus in children with no identified predisposing risk. Jama 279:593-8.

106. Heumann, D., C. Barras, A. Severin, M. P. Glauser, and A. Tomasz. 1994. Gram-positive cell walls stimulate synthesis of tumor necrosis factor alpha and interleukin- 6 by human monocytes. Infect Immun 62:2715-21.

107. Hiramatsu, K. 1995. Molecular evolution of MRSA. Microbiol Immunol 39:531-43.

108. Hiramatsu, K. 2001. Vancomycinresistant Staphylococcus aureus: a new model of antibiotic resistance. Lancet Infect Dis 1:147-55.

109. Hiramatsu, K., L. Cui, M. Kuroda, and T. Ito. 2001. The emergence and evolution of methicillin-resistant Staphylococcus aureus. Trends Microbiol 9:486-93.

110. Hiramatsu, K., H. Hanaki, T. Ino, K. Yabuta, T. Oguri, and F. C. Tenover. 1997. Methicillinresistant Staphylococcus aureus clinical strain with reduced vancomycin susceptibility. $\mathrm{J}$ Antimicrob Chemother 40:135-6.

111. Hoefnagels-Schuermans, A., W. E. Peetermans, M. J. Struelens, S. Van Lierde, and J. Van Eldere. 1997. Clonal analysis and identification of epidemic strains of methicillin-resistant Staphylococcus aureus by antibiotyping and determination of protein A gene and coagulase gene polymorphisms. J Clin Microbiol 35:2514-20.

112. Holmberg, S. D., and P. A. Blake. 1984. Staphylococcal food poisoning in the United States. New facts and old misconceptions. Jama 251:487-9.

113. Huang, S. S., B. J. Labus, M. C. Samuel, D. T. Wan, and A. L.
Reingold. 2002. Antibiotic resistance patterns of bacterial isolates from blood in san francisco county, california, 19961999. Emerg Infect Dis 8:195201.

114. Huesca, M., R. Peralta, D. N. Sauder, A. E. Simor, and M. J. McGavin. 2002. Adhesion and virulence properties of epidemic Canadian methicillin-resistant Staphylococcus aureus strain 1: identification of novel adhesion functions associated with plasminsensitive surface protein. J Infect Dis 185:1285-96.

115. Hussain, M., M. Herrmann, C. von Eiff, F. PerdreauRemington, and G. Peters. 1997. A 140-kilodalton extracellular protein is essential for the accumulation of Staphylococcus epidermidis strains on surfaces. Infect Immun 65:519-24.

116. Iandolo, j. 2000. Genetic and physical mapping of Staphylococcus aureus 8325, p. 317-325. In V. A. Fischetti, R. P. Novick, J. Ferretti, D. Portnoy, and J. Rood (ed.), Gram-positive pathogens. ASM Press, Washington D.C.

117. Ito, T., Y. Katayama, K. Asada, N. Mori, K. Tsutsumimoto, C. Tiensasitorn, and K. Hiramatsu. 2001. Structural comparison of three types of staphylococcal cassette chromosome mec integrated in the chromosome in methicillin-resistant

Staphylococcus aureus. Antimicrob Agents Chemother 45:1323-36.

118. Ito, T., Y. Katayama, and K. Hiramatsu. 1999. Cloning and nucleotide sequence determination of the entire mec DNA of premethicillin-resistant Staphylococcus aureus N315. 
Antimicrob Agents Chemother 43:1449-58.

119. Itokazu, G. S., J. P. Quinn, C. Bell-Dixon, F. M. Kahan, and R.

A. Weinstein. 1996. Antimicrobial resistance rates among aerobic gram-negative bacilli recovered from patients in intensive care units: evaluation of a national postmarketing surveillance program. Clin Infect Dis 23:77984.

120. Ivert, T. S., W. E. Dismukes, C. G. Cobbs, E. H. Blackstone, J. W. Kirklin, and L. A. Bergdahl. 1984. Prosthetic valve endocarditis. Circulation 69:22332.

121. Jevons, M. 1961. Celbenin-resistant staphylococci. British Medical Journal 1:124-125.

122. Joh, D., E. R. Wann, B. Kreikemeyer, P. Speziale, and M. Hook. 1999. Role of fibronectin-binding MSCRAMMs in bacterial adherence and entry into mammalian cells. Matrix Biol 18:211-23.

123. Johnson, Z., P. Fitzpatrick, C. Hayes, G. Sayers, H. Pelly, B. McDonnell, L. Thornton, and J. Buttimer. 1997. National survey of MRSA: Ireland, 1995. J Hosp Infect 35:175-84.

124. Jolly, L., S. Wu, J. van Heijenoort, H. de Lencastre, D. MenginLecreulx, and A. Tomasz. 1997. The femR315 gene from Staphylococcus aureus, the interruption of which results in reduced methicillin resistance, encodes a phosphoglucosamine mutase. J Bacteriol 179:5321-5.

125. Jones, T. F., M. E. Kellum, S. S. Porter, M. Bell, and W. Schaffner. 2002. An outbreak of community-acquired foodborne illness caused by methicillin- resistant Staphylococcus aureus.

Emerg Infect Dis 8:82-4.

126. Kaatz, G. W., S. M. Seo, and C. A.

Ruble. 1991. Mechanisms of

fluoroquinolone resistance in Staphylococcus aureus. J Infect

Dis 163:1080-6.

127. Karlsson, A., P. Saravia-Otten, K. Tegmark, E. Morfeldt, and S. Arvidson. 2001. Decreased amounts of cell wall-associated protein A and fibronectin-binding proteins in Staphylococcus aureus sarA mutants due to up-regulation of extracellular proteases. Infect Immun 69:4742-8.

128. Katayama, Y., T. Ito, and K.

Hiramatsu. 2000. A new class of genetic element, staphylococcus cassette chromosome mec, encodes methicillin resistance in Staphylococcus aureus.

Antimicrob Agents Chemother 44:1549-55.

129. Khan, S. A., and R. P. Novick. 1983. Complete nucleotide sequence of pT181, a tetracyclineresistance plasmid from

Staphylococcus aureus. Plasmid 10:251-9.

130. Kloos, W., and T. Bannerman. 1999. Staphylococcus and Micrococcus, p. 264-282. In P. Murray, E. Baron, M. A. Pfaller, F. Tenover, and R. Yolken (ed.), Manual of clinical microbiology. ASM Press, Washington D.C.

131. Kluytmans, J., A. van Belkum, and H. Verbrugh. 1997. Nasal carriage of Staphylococcus aureus: epidemiology, underlying mechanisms, and associated risks. Clin Microbiol Rev 10:505-20.

132. Kluytmans, J., A. Van Griethuysen, P. Willemse, and P. Van Keulen. 2002. Performance of CHROMagar Selective Medium and Oxacillin Resistance Screening Agar Base for 
Identifying Staphylococcus aureus and Detecting Methicillin

Resistance. J Clin Microbiol 40:2480-2.

133. Kobayashi, N., K. Taniguchi, and S. Urasawa. 1998. Analysis of diversity of mutations in the mecI gene and mecA promoter/operator region of methicillin-resistant Staphylococcus aureus and Staphylococcus epidermidis. Antimicrob Agents Chemother 42:717-20.

134. Kondo, N., K. Kuwahara-Arai, H. Kuroda-Murakami, E. TatedaSuzuki, and K. Hiramatsu. 2001. Eagle-type methicillin resistance: new phenotype of high methicillin resistance under mec regulator gene control. Antimicrob Agents Chemother 45:815-24.

135. Kreiswirth, B., J. Kornblum, R. D. Arbeit, W. Eisner, J. N. Maslow, A. McGeer, D. E. Low, and R. P. Novick. 1993. Evidence for a clonal origin of methicillin resistance in Staphylococcus aureus. Science 259:227-30.

136. Kropec, A., J. Huebner, M. Riffel, U. Bayer, A. Benzing, K. Geiger, and F. D. Daschner. 1993. Exogenous or endogenous reservoirs of nosocomial Pseudomonas aeruginosa and Staphylococcus aureus infections in a surgical intensive care unit. Intensive Care Med 19:161-5.

137. Kuhl, S. A., P. A. Pattee, and J. N. Baldwin. 1978. Chromosomal map location of the methicillin resistance determinant in Staphylococcus aureus. J Bacteriol 135:460-5.

138. Kullik, I., P. Giachino, and T. Fuchs. 1998. Deletion of the alternative sigma factor sigmaB in Staphylococcus aureus reveals its function as a global regulator of virulence genes. J Bacteriol 180:4814-20.

139. Kuroda, M., T. Ohta, I. Uchiyama, T. Baba, H. Yuzawa, I. Kobayashi, L. Cui, A. Oguchi, K. Aoki, Y. Nagai, J. Lian, T. Ito, M. Kanamori, H. Matsumaru, A. Maruyama, H. Murakami, A. Hosoyama, Y. Mizutani-Ui, N. K. Takahashi, T. Sawano, R. Inoue, C. Kaito, K. Sekimizu, H. Hirakawa, S. Kuhara, S. Goto, J. Yabuzaki, M. Kanehisa, A. Yamashita, K. Oshima, K. Furuya, C. Yoshino, T. Shiba, M. Hattori, N. Ogasawara, $H$. Hayashi, and K. Hiramatsu. 2001. Whole genome sequencing of meticillin-resistant Staphylococcus aureus. Lancet 357:1225-40.

140. Kuwahara-Arai, K., N. Kondo, S. Hori, E. Tateda-Suzuki, and K. Hiramatsu. 1996. Suppression of methicillin resistance in a $m e c A$ containing pre-methicillinresistant Staphylococcus aureus strain is caused by the mecImediated repression of PBP 2' production. Antimicrob Agents Chemother 40:2680-5.

141. Labischinski, H. 1992.

Consequences of the interaction of beta-lactam antibiotics with penicillin binding proteins from sensitive and resistant Staphylococcus aureus strains. Med Microbiol Immunol (Berl) 181:241-65.

142. Lacey, R. W., and J. Grinsted. 1973. Genetic analysis of methicillin-resistant strains of Staphylococcus aureus; evidence for their evolution from a single clone. J Med Microbiol 6:511-26.

143. Lachica, R. V., P. D. Hoeprich, and C. Genigeorgis. 1972. Metachromatic agar-diffusion microslide technique for detecting 
staphylococcal nuclease in foods. Appl Microbiol 23:168-9.

144. Ladhani, S., C. L. Joannou, D. P. Lochrie, R. W. Evans, and S. M. Poston. 1999. Clinical, microbial, and biochemical aspects of the exfoliative toxins causing staphylococcal scalded-skin syndrome. Clin Microbiol Rev 12:224-42.

145. Lahteenmaki, K., P. Kuusela, and T. K. Korhonen. 2001. Bacterial plasminogen activators and receptors. FEMS Microbiol Rev 25:531-52.

146. Lambert, P. A., I. C. Hancock, and J. Baddiley. 1977. Occurrence and function of membrane teichoic acids. Biochim Biophys Acta 472:1-12.

147. Layton, M. C., W. J. Hierholzer, Jr., and J. E. Patterson. 1995. The evolving epidemiology of methicillin-resistant Staphylococcus aureus at a university hospital. Infect Control Hosp Epidemiol 16:12-7.

148. Lelievre, H., G. Lina, M. E. Jones, C. Olive, F. Forey, M. RousselDelvallez, M. H. NicolasChanoine, C. M. Bebear, V. Jarlier, A. Andremont, F. Vandenesch, and J. Etienne. 1999. Emergence and spread in French hospitals of methicillinresistant Staphylococcus aureus with increasing susceptibility to gentamicin and other antibiotics. J Clin Microbiol 37:3452-7.

149. Lemaitre, N., W. Sougakoff, A. Masmoudi, M. H. Fievet, R. Bismuth, and V. Jarlier. 1998. Characterization of gentamicinsusceptible strains of methicillinresistant Staphylococcus aureus involved in nosocomial spread. J Clin Microbiol 36:81-5.

150. L'Heriteau, F., J. C. Lucet, A. Scanvic, and E. Bouvet. 1999.
Community-acquired methicillinresistant Staphylococcus aureus and familial transmission. Jama 282:1038-9.

151. Lilenbaum, W., E. L. Nunes, and M. A. Azeredo. 1998. Prevalence and antimicrobial susceptibility of staphylococci isolated from the skin surface of clinically normal cats. Lett Appl Microbiol 27:2248.

152. Lindenmayer, J. M., S. Schoenfeld, R. O'Grady, and J. K. Carney. 1998. Methicillinresistant Staphylococcus aureus in a high school wrestling team and the surrounding community. Arch Intern Med 158:895-9.

153. Lipsitch, M., and E. R. Moxon. 1997. Virulence and transmissibility of pathogens: what is the relationship? Trends Microbiol 5:31-7.

154. Lowy, F. D. 1998. Staphylococcus aureus infections. N Engl J Med 339:520-32.

155. Lumio, J. 1999.

Sairaalainfektioiden esiintyvyys ja sairaalahygienian merkitys, p. 1928. In P. Kujala, P. Grönroos, A. Rantala, 1. Tittanen, R. Vuento, and S. Hellsten (ed.), Infektioiden torjunta sairaalassa, vol. 4. Suomen kuntaliitto, Jyväskylä.

156. Luong, T. T., and C. Y. Lee. 2002. Overproduction of Type 8 Capsular Polysaccharide Augments Staphylococcus aureus Virulence. Infect Immun 70:338995.

157. Lyytikainen, O., J. Lumio, H. Sarkkinen, E. Kolho, A. Kostiala, and P. Ruutu. 2002. Nosocomial Bloodstream Infections in Finnish Hospitals during 1999-2000. Clin Infect Dis 35:E14-9.

158. Ma, X. X., T. Ito, C. Tiensasitorn, M. Jamklang, P. Chongtrakool, 
S. Boyle-Vavra, R. S. Daum, and

K. Hiramatsu. 2002. Novel Type

of Staphylococcal Cassette

Chromosome mec Identified in

Community-Acquired Methicillin-

Resistant Staphylococcus aureus

Strains. Antimicrob Agents

Chemother 46:1147-52.

159. Madani, T. A., N. A. Al-Abdullah, A. A. Al-Sanousi, T. M. Ghabrah, S. Z. Afandi, and $H$. A. Bajunid. 2001. Methicillinresistant Staphylococcus aureus in two tertiary-care centers in Jeddah, Saudi Arabia. Infect Control Hosp Epidemiol 22:211-6.

160. Maguire, G. P., A. D. Arthur, P. J. Boustead, B. Dwyer, and B. J.

Currie. 1996. Emerging epidemic of community-acquired methicillin-resistant

Staphylococcus aureus infection in the Northern Territory. Med J Aust 164:721-3.

161. Maiden, M. C., J. A. Bygraves, E. Feil, G. Morelli, J. E. Russell, R. Urwin, Q. Zhang, J. Zhou, K. Zurth, D. A. Caugant, I. M. Feavers, M. Achtman, and B. G. Spratt. 1998. Multilocus sequence typing: a portable approach to the identification of clones within populations of pathogenic microorganisms. Proc Natl Acad Sci U S A 95:3140-5.

162. Marchese, A., G. Balistreri, E. Tonoli, E. A. Debbia, and G. C. Schito. 2000. Heterogeneous vancomycin resistance in methicillin-resistant Staphylococcus aureus strains isolated in a large Italian hospital. J Clin Microbiol 38:866-9.

163. Marples, R. R., and E. M. Cooke. 1988. Current problems with methicillin-resistant Staphylococcus aureus. J Hosp Infect 11:381-92.
164. Marples, R. R., and V. T. Rosdahl. 1997. International quality control of phage typing of Staphylococcus aureus. International Union of Microbial Societies Subcommittee. J Med Microbiol 46:511-6.

165. Mato, R., I. Santos Sanches, M. Venditti, D. J. Platt, A. Brown, M. Chung, and H. de Lencastre. 1998. Spread of the multiresistant Iberian clone of methicillinresistant Staphylococcus aureus (MRSA) to Italy and Scotland. Microb Drug Resist 4:107-12.

166. Matthews, P., and P. Steward. 1984. Resistance heterogeneity in methicillin-resistant Staphylococcus aureus. FEMS Microbiology Letters 22:161-166.

167. Matthews, P. R., K. C. Reed, and

P. R. Stewart. 1987. The cloning of chromosomal DNA associated with methicillin and other resistances in Staphylococcus aureus. J Gen Microbiol 133:1919-29.

168. McDougal, L. K., and C. Thornsberry. 1986. The role of beta-lactamase in staphylococcal resistance to penicillinase-resistant penicillins and cephalosporins. J Clin Microbiol 23:832-9.

169. McGee, L., L. McDougal, J. Zhou, B. G. Spratt, F. C. Tenover, R. George, R. Hakenbeck, W. Hryniewicz, J. C. Lefevre, A. Tomasz, and K. P. Klugman. 2001. Nomenclature of major antimicrobial-resistant clones of Streptococcus pneumoniae defined by the pneumococcal molecular epidemiology network. J Clin Microbiol 39:2565-71.

170. MeNamara, P. J., and R. A. Proctor. 2000. Staphylococcus aureus small colony variants, electron transport and persistent infections. Int J Antimicrob Agents 14:117-22. 
171. Mehndiratta, P. L., S. Vidhani, and M. D. Mathur. 2001. A study on Staphylococcus aureus strains submitted to a reference laboratory. Indian J Med Res 114:90-4.

172. Mekalanos, J. J. 1992.

Environmental signals controlling expression of virulence determinants in bacteria. $\mathbf{J}$

Bacteriol 174:1-7.

173. Mongodin, E., O. Bajolet, J. Cutrona, N. Bonnet, F. Dupuit, E. Puchelle, and S. de Bentzmann. 2002. Fibronectinbinding proteins of

Staphylococcus aureus are involved in adherence to human airway epithelium. Infect Immun 70:620-30.

174. Moore, P. C., and J. A. Lindsay. 2002. Molecular characterisation of the dominant UK methicillinresistant Staphylococcus aureus strains, EMRSA-15 and EMRSA16. J Med Microbiol 51:516-21.

175. Moreillon, P., J. M. Entenza, P. Francioli, D. McDevitt, T. J. Foster, P. Francois, and P. Vaudaux. 1995. Role of Staphylococcus aureus coagulase and clumping factor in pathogenesis of experimental endocarditis. Infect Immun 63:4738-43.

176. Moreno, F., C. Crisp, J. H. Jorgensen, and J. E. Patterson. 1995. Methicillin-resistant Staphylococcus aureus as a community organism. Clin Infect Dis 21:1308-12.

177. Morfeldt, E., D. Taylor, A. von Gabain, and S. Arvidson. 1995. Activation of alpha-toxin translation in Staphylococcus aureus by the trans-encoded antisense RNA, RNAIII. Embo J 14:4569-77.
178. Mortensen, J. E., T. R. Shryock, and F. A. Kapral. 1992. Modification of bactericidal fatty acids by an enzyme of Staphylococcus aureus. J Med Microbiol 36:293-8.

179. Morton, T. M., J. L. Johnston, J. Patterson, and G. L. Archer. 1995. Characterization of a conjugative staphylococcal mupirocin resistance plasmid. Antimicrob Agents Chemother 39:1272-80.

180. Muller, E., S. Takeda, H. Shiro, D. Goldmann, and G. B. Pier. 1993. Occurrence of capsular polysaccharide/adhesin among clinical isolates of coagulasenegative staphylococci. J Infect Dis 168: 1211-8.

181. Murakami, K., T. Fujimura, and M. Doi. 1994. Nucleotide sequence of the structural gene for the penicillin-binding protein 2 of Staphylococcus aureus and the presence of a homologous gene in other staphylococci. FEMS Microbiol Lett 117:131-6.

182. Murakami, K., W. Minamide, K. Wada, E. Nakamura, $H$. Teraoka, and S. Watanabe. 1991. Identification of methicillinresistant strains of staphylococci by polymerase chain reaction. $\mathbf{J}$ Clin Microbiol 29:2240-4.

183. Musser, J. M., and V. Kapur. 1992. Clonal analysis of methicillinresistant Staphylococcus aureus strains from intercontinental sources: association of the mec gene with divergent phylogenetic lineages implies dissemination by horizontal transfer and recombination. J Clin Microbiol 30:2058-63.

184. Mylotte, J. M., S. Goodnough, and A. Tayara. 2001. Antibioticresistant organisms among longterm care facility residents on 
admission to an inpatient geriatrics

unit: Retrospective and

prospective surveillance. Am J

Infect Control 29:139-44.

185. Nahvi, M. D., J. E. Fitzgibbon, J.

F. John, and D. T. Dubin. 2001.

Sequence analysis of $d r u$ regions

from methicillin-resistant

Staphylococcus aureus and coagulase-negative staphylococcal isolates. Microb Drug Resist 7:112.

186. Namnyak, S., Z. Adhami, M.

Wilmore, H. Keynes, K.

Hampton, E. Mercieca, and K.

Roker. 1998. Methicillin-resistant

Staphylococcus aureus: a

questionnaire and microbiological survey of nursing and residential homes in Barking, Havering and

Brentwood. J Infect 36:67-72.

187. NCCLS. 1997. Methods for dilution antimicrobial susceptibility tests for bacteria that grow aerobically Approved Standard M7-A4. National Committee for Laboratory Standards.

188. NCCLS. 1997. Performance standards for disc antimicrobial susceptibility tests Approved Standard M2-A6. National Committee for Laboratory Standards.

189. Ng, E. Y., M. Trucksis, and D. C. Hooper. 1994. Quinolone resistance mediated by norA: physiologic characterization and relationship to $f l q B$, a quinolone resistance locus on the Staphylococcus aureus chromosome. Antimicrob Agents Chemother 38:1345-55.

190. Nichols, R. L. 1998. Postoperative infections in the age of drugresistant gram-positive bacteria. Am J Med 104:11S-16S.

191. Nishi, J., H. Miyanohara, T. Nakajima, I. Kitajima, M. Yoshinaga, I. Maruyama, and K.
Miyata. 1995. Molecular typing of the methicillin resistance determinant (mec) of clinical strains of Staphylococcus based on mec hypervariable region length polymorphisms. J Lab Clin Med 126:29-35.

192. Nouwen, J. L., A. van Belkum, and H. A. Verbrugh. 2001. Determinants of Staphylococcus aureus nasal carriage. Neth J Med 59:126-33.

193. Novick, R. P. 2000. pathogenicity factors and their regulation, $\mathrm{p}$. 392-407. In V. A. Fischetti, R. P. Novick, J. Ferretti, D. Portnoy, and J. Rood (ed.), Gram-positive pathogens. ASM Press, Washington D.C.

194. Novick, R. P., S. J. Projan, J. Kornblum, H. F. Ross, G. Ji, B. Kreiswirth, F. Vandenesch, and S. Moghazeh. 1995. The agr P2 operon: an autocatalytic sensory transduction system in Staphylococcus aureus. Mol Gen Genet 248:446-58.

195. Novick, R. P., H. F. Ross, S. J. Projan, J. Kornblum, B. Kreiswirth, and S. Moghazeh. 1993. Synthesis of staphylococcal virulence factors is controlled by a regulatory RNA molecule. Embo J 12:3967-75.

196. Ogawa, S. K., E. R. Yurberg, V. B. Hatcher, M. A. Levitt, and F. D. Lowy. 1985. Bacterial adherence to human endothelial cells in vitro. Infect Immun 50:218-24.

197. Oliveira, D. C., and H. Lencastre Hd. 2002. Multiplex PCR Strategy for Rapid Identification of Structural Types and Variants of the mec Element in MethicillinResistant Staphylococcus aureus. Antimicrob Agents Chemother 46:2155-61.

198. Oliveira, D. C., A. Tomasz, and H. de Lencastre. 2001. The evolution 
of pandemic clones of methicillinresistant Staphylococcus aureus: identification of two ancestral genetic backgrounds and the associated mec elements. Microb Drug Resist 7:349-61.

199. Oliveira, D. C., A. Tomasz, and H. de Lencastre. 2002. Secrets of success of a human pathogen: molecular evolution of pandemic clones of meticillin-resistant Staphylococcus aureus. Lancet Infect Dis 2:180-9.

200. Oliveira, D. C., S. W. Wu, and H. de Lencastre. 2000. Genetic organization of the downstream region of the mecA element in methicillin-resistant Staphylococcus aureus isolates carrying different polymorphisms of this region. Antimicrob Agents Chemother 44:1906-10.

201. Olmos, A., J. J. Camarena, J. M. Nogueira, J. C. Navarro, J. Risen, and R. Sanchez. 1998. Application of an optimized and highly discriminatory method based on arbitrarily primed PCR for epidemiologic analysis of methicillin-resistant Staphylococcus aureus nosocomial infections. J Clin Microbiol 36:1128-34.

202. Ornelas-Soares, A., H. de Lencastre, B. L. de Jonge, and A. Tomasz. 1994. Reduced methicillin resistance in a new Staphylococcus aureus transposon mutant that incorporates muramyl dipeptides into the cell wall peptidoglycan. J Biol Chem 269:27246-50.

203. O'Sullivan, N. P., and C. T. Keane. 2000. Risk factors for colonization with methicillin-resistant Staphylococcus aureus among nursing home residents. J Hosp Infect 45:206-10.
204. O'Sullivan, N. R., and C. T. Keane. 2000. The prevalence of methicillin-resistant Staphylococcus aureus among the residents of six nursing homes for the elderly. J Hosp Infect 45:3229.

205. Panlilio, A. L., D. H. Culver, R. P. Gaynes, S. Banerjee, T. S. Henderson, J. S. Tolson, and W. J. Martone. 1992. Methicillinresistant Staphylococcus aureus in U.S. hospitals, 1975-1991. Infect Control Hosp Epidemiol 13:582-6.

206. Papakyriacou, H., D. Vaz, A. Simor, M. Louie, and M. J. McGavin. 2000. Molecular analysis of the accessory gene regulator $(a g r)$ locus and balance of virulence factor expression in epidemic methicillin-resistant Staphylococcus aureus. J Infect Dis 181:990-1000.

207. Parker, M. 1972. Phage-typing of Staphylococcus aureus, vol. 7B. Academic Press, London.

208. Parker, M. 1983. The significance of phage-typing in Staphylococcus aureus. Academic Press, London.

209. Patel, A. H., T. J. Foster, and P. A. Pattee. 1989. Physical and genetic mapping of the protein A gene in the chromosome of Staphylococcus aureus 8325-4. J Gen Microbiol 135:1799-807.

210. Pattee, H., H.-C. Lee, and J. Bannantine. 1990. Genetic and physical mapping of Staphylococcus aureus, p. 41-58. In R. P. Novick (ed.), Molecular biology of staphylococci. VHC, New York.

211. Pattee, P. A., and D. S. Neveln. 1975. Transformation analysis of three linkage groups in Staphylococcus aureus. J Bacteriol 124:201-11.

212. Patti, J. M., B. L. Allen, M. J. McGavin, and M. Hook. 1994. 
MSCRAMM-mediated adherence of microorganisms to host tissues. Annu Rev Microbiol 48:585-617.

213. Perl, T. M., and M. C. Roy. 1995. Postoperative wound infections: risk factors and role of Staphylococcus aureus nasal carriage. J Chemother 7:29-35.

214. Petinaki, E., A. Arvaniti, G. Dimitracopoulos, and I. Spiliopoulou. 2001. Detection of $m e c A$, mecRl and mecI genes among clinical isolates of methicillin-resistant staphylococci by combined polymerase chain reactions. J Antimicrob Chemother 47:297-304.

215. Pinho, M. G., H. de Lencastre, and A. Tomasz. 2001. An acquired and a native penicillinbinding protein cooperate in building the cell wall of drugresistant staphylococci. Proc Natl Acad Sci U S A 98:10886-91.

216. Pinho, M. G., A. M. Ludovice, S. Wu, and H. De Lencastre. 1997. Massive reduction in methicillin resistance by transposon inactivation of the normal PBP2 in a methicillin-resistant strain of Staphylococcus aureus. Microb Drug Resist 3:409-13.

217. Piriz Duran, S., F. H. Kayser, and

B. Berger-Bachi. 1996. Impact of sar and $a g r$ on methicillin resistance in Staphylococcus aureus. FEMS Microbiol Lett 141:255-60.

218. Pitcher, D., N. Saunders, and R. Owen. 1989. Rapid extraction of bacterial genomic DNAwith guanidiumthiocyanate. Letters in Applied Microbiology 8:151-156.

219. Ploy, M. C., C. Grelaud, C. Martin, L. de Lumley, and F. Denis. 1998. First clinical isolate of vancomycin-intermediate Staphylococcus aureus in a French hospital. Lancet 351:1212.
220. Popescu, A., and R. J. Doyle. 1996. The Gram stain after more than a century. Biotech Histochem 71:145-51.

221. Popovic, T., I. K. Mazurova, A. Efstratiou, J. Vuopio-Varkila, M. W. Reeves, A. De Zoysa, T. Glushkevich, and P. Grimont. 2000. Molecular epidemiology of diphtheria. J Infect Dis 181:S16877.

222. Proctor, R. A., P. van Langevelde, M. Kristjansson, J. N. Maslow, and R. D. Arbeit. 1995. Persistent and relapsing infections associated with small-colony variants of Staphylococcus aureus. Clin Infect Dis 20:95-102.

223. Projan, S. J., and R. P. Novick. 1997. The Molecular Basis of pathogenicity, p. 55-81. In K. Crossley and G. Archer (ed.), The staphylococci in human disease. Churchill publications, new York.

224. Prokesova, L., B. Potuznikova, J. Potempa, J. Zikan, J. Radl, L. Hachova, K. Baran, Z. PorwitBobr, and C. John. 1992.

Cleavage of human immunoglobulins by serine proteinase from Staphylococcus aureus. Immunol Lett 31:259-65.

225. Pujol, M., C. Pena, R. Pallares, J. Ayats, J. Ariza, and F. Gudiol. 1994. Risk factors for nosocomial bacteremia due to methicillinresistant Staphylococcus aureus. Eur J Clin Microbiol Infect Dis 13:96-102.

226. Rampone, H., G. L. Martinez, A. T. Giraudo, A. Calzolari, and R. Nagel. 1996. In vivo expression of exoprotein synthesis with a Sae mutant of Staphylococcus aureus. Can J Vet Res 60:237-40.

227. Reagan, D. R., B. N. Doebbeling, M. A. Pfaller, C. T. Sheetz, A. K. Houston, R. J. Hollis, and R. P. Wenzel. 1991. Elimination of 
coincident Staphylococcus aureus nasal and hand carriage with intranasal application of mupirocin calcium ointment. Ann Intern Med 114:101-6.

228. Reynolds, P. E. 1986. Methicillinresistant strains of Staphylococcus aureus; presence of identical additional penicillin-binding protein in all strains examined. FEMS Microbiology Letters 33:251-254.

229. Roberts, R. B., A. de Lencastre, W. Eisner, E. P. Severina, B. Shopsin, B. N. Kreiswirth, and A. Tomasz. 1998. Molecular epidemiology of methicillinresistant Staphylococcus aureus in 12 New York hospitals. MRSA Collaborative Study Group. J Infect Dis 178: 164-71.

230. Rohrer, S., K. Ehlert, M.

Tschierske, H. Labischinski, and B. Berger-Bachi. 1999. The essential Staphylococcus aureus gene $f m h B$ is involved in the first step of peptidoglycan pentaglycine interpeptide formation. Proc Natl Acad Sci U S A 96:9351-6.

231. Rossney, A. S., D. C. Coleman, and C. T. Keane. 1994.

Evaluation of an antibiogramresistogram typing scheme for methicillin-resistant

Staphylococcus aureus. J Med Microbiol 41:441-7.

232. Rotun, S. S., V. McMath, D. J. Schoonmaker, P. S. Maupin, F. C. Tenover, B. C. Hill, and D. M. Ackman. 1999. Staphylococcus aureus with reduced susceptibility to vancomycin isolated from a patient with fatal bacteremia. Emerg Infect Dis 5:147-9.

233. Ryffel, C., R. Bucher, F. H. Kayser, and B. Berger-Bachi. 1991. The Staphylococcus aureus mec determinant comprises an unusual cluster of direct repeats and codes for a gene product similar to the Escherichia coli snglycerophosphoryl diester phosphodiesterase. J Bacteriol 173:7416-22.

234. Ryffel, C., A. Strassle, F. H. Kayser, and B. Berger-Bachi. 1994. Mechanisms of heteroresistance in methicillinresistant Staphylococcus aureus. Antimicrob Agents Chemother 38:724-8.

235. Sabath, L. D. 1977. Chemical and physical factors influencing methicillin resistance of Staphylococcus aureus and Staphylococcus epidermidis. J Antimicrob Chemother 3:47-51.

236. Safdar, N., and D. G. Maki. 2002. The commonality of risk factors for nosocomial colonization and infection with antimicrobialresistant Staphylococcus aureus, enterococcus, gram-negative bacilli, Clostridium difficile, and Candida. Ann Intern Med 136:834-44.

237. Sa-Leao, R., I. S. Sanches, I. Couto, C. R. Alves, and H. de Lencastre. 2001. Low prevalence of methicillin-resistant strains among Staphylococcus aureus colonizing young and healthy members of the community in Portugal. Microb Drug Resist 7:237-45.

238. Samad, A., D. Banerjee, N. Carbarns, and S. Ghosh. 2002. Prevalence of methicillin-resistant Staphylococcus aureus colonization in surgical patients, on admission to a Welsh hospital. J Hosp Infect 51:43-6.

239. Saravolatz, L. D., D. J. Pohlod, and L. M. Arking. 1982. Community-acquired methicillinresistant Staphylococcus aureus infections: a new source for 
nosocomial outbreaks. Ann Intern

Med 97:325-9.

240. Savolainen, K., L. Paulin, B.

Westerlund-Wikstrom, T. J.

Foster, T. K. Korhonen, and P.

Kuusela. 2001. Expression of pls, a gene closely associated with the $m e c A$ gene of methicillin-resistant Staphylococcus aureus, prevents bacterial adhesion in vitro. Infect Immun 69:3013-20.

241. Schmitz, F. J., A. C. Fluit, E. Lindenlauf, S. Scheuring, and K. Kohrer. 2000. Molecular analyses of possible mechanisms coding for low-level mupirocin resistance in clinical Staphylococcus aureus isolates. Eur J Clin Microbiol Infect Dis 19:649-50.

242. Schmitz, F. J., M. Steiert, H. V. Tichy, B. Hofmann, J. Verhoef, H. P. Heinz, K. Kohrer, and M. E. Jones. 1998. Typing of methicillin-resistant Staphylococcus aureus isolates from Dusseldorf by six genotypic methods. J Med Microbiol 47:34151.

243. Schwartz, D. C., and C. R. Cantor. 1984. Separation of yeast chromosome-sized DNAs by pulsed field gradient gel electrophoresis. Cell 37:67-75.

244. Seki, K., J. Sakurada, M. Murai, A. Usui, H. K. Seong, H. Jitsukawa, and S. Masuda. 1995. Auxiliary method for clonal identification of Staphylococcus aureus by protein band pattern of released proteins on SDSpolyacrylamide gel. Microbiol Immunol 39:615-7.

245. Selander, R. K., D. A. Caugant, H. Ochman, J. M. Musser, M. N. Gilmour, and T. S. Whittam. 1986. Methods of multilocus enzyme electrophoresis for bacterial population genetics and systematics. Appl Environ

Microbiol 51:873-84.

246. Senna, J. P., C. A. Pinto, L. P. Carvalho, and D. S. Santos. 2002. Comparison of Pulsed-Field Gel Electrophoresis and PCR Analysis of Polymorphisms on the mec Hypervariable Region for Typing Methicillin-Resistant Staphylococcus aureus. J Clin Microbiol 40:2254-6.

247. Shands, K. N., G. P. Schmid, B. B. Dan, D. Blum, R. J. Guidotti, N. T. Hargrett, R. L. Anderson, D. L. Hill, C. V. Broome, J. D. Band, and D. W. Fraser. 1980. Toxic-shock syndrome in menstruating women: association with tampon use and Staphylococcus aureus and clinical features in 52 cases. $\mathrm{N}$ Engl J Med 303:1436-42.

248. Sharma, V. K., C. J. Hackbarth, T. M. Dickinson, and G. L. Archer. 1998. Interaction of native and mutant MecI repressors with sequences that regulate $m e c A$, the gene encoding penicillin binding protein $2 \mathrm{a}$ in methicillin-resistant staphylococci. J Bacteriol 180:2160-6.

249. Shopsin, B., B. Mathema, X. Zhao, J. Martinez, J. Kornblum, and B. N. Kreiswirth. 2000. Resistance rather than virulence selects for the clonal spread of methicillin-resistant

Staphylococcus aureus: implications for MRSA transmission. Microb Drug Resist 6:239-44.

250. Siboo, I. R., A. L. Cheung, A. S. Bayer, and P. M. Sullam. 2001. Clumping factor A mediates binding of Staphylococcus aureus to human platelets. Infect Immun 69:3120-7.

251. Simor, A. E., M. Ofner-Agostini, E. Bryce, K. Green, A. McGeer, 
M. Mulvey, and S. Paton. 2001.

The evolution of methicillinresistant Staphylococcus aureus in Canadian hospitals: 5 years of national surveillance. CMAJ 165:21-6.

252. Sinha, B., P. Francois, Y. A. Que, M. Hussain, C. Heilmann, P. Moreillon, D. Lew, K. H. Krause, G. Peters, and M. Herrmann. 2000. Heterologously expressed Staphylococcus aureus fibronectin-binding proteins are sufficient for invasion of host cells. Infect Immun 68:6871-8.

253. Smith, T. L., M. L. Pearson, K. R. Wilcox, C. Cruz, M. V. Lancaster, B. Robinson-Dunn, F. C. Tenover, M. J. Zervos, J. D. Band, E. White, and W. R. Jarvis. 1999. Emergence of vancomycin resistance in Staphylococcus aureus. Glycopeptide-Intermediate Staphylococcus aureus Working Group. N Engl J Med 340:493501.

254. Solberg, C. O. 2000. Spread of Staphylococcus aureus in hospitals: causes and prevention. Scand J Infect Dis 32:587-95.

255. Song, M. D., M. Wachi, M. Doi, F. Ishino, and M. Matsuhashi. 1987. Evolution of an inducible penicillin-target protein in methicillin-resistant Staphylococcus aureus by gene fusion. FEBS Lett 221:167-71.

256. Stranden, A. M., K. Ehlert, H. Labischinski, and B. BergerBachi. 1997. Cell wall monoglycine cross-bridges and methicillin hypersusceptibility in a femAB null mutant of methicillinresistant Staphylococcus aureus. J Bacteriol 179:9-16.

257. Stranden, A. M., M. Roos, and B. Berger-Bachi. 1996. Glutamine synthetase and heteroresistance in methicillin-resistant

Staphylococcus aureus. Microb

Drug Resist 2:201-7.

258. Struelens, M. J., and R. Mertens.

1994. National survey of

methicillin-resistant

Staphylococcus aureus in Belgian

hospitals: detection methods,

prevalence trends and infection

control measures. The

Groupement pour le Depistage,

l'Etude et la Prevention des

Infections Hospitalieres. Eur J

Clin Microbiol Infect Dis 13:56-

63.

259. Suntharam, N., D. Hacek, and L.

R. Peterson. 2001. Low

Prevalence of Community-

Acquired Methicillin-Resistant

Staphylococcus aureus in Adults

at a University Hospital in the

Central United States. J Clin

Microbiol 39:1669-71.

260. Suzuki, E., K. Kuwahara-Arai, J.

F. Richardson, and $K$.

Hiramatsu. 1993. Distribution of mec regulator genes in methicillinresistant Staphylococcus clinical strains. Antimicrob Agents

Chemother 37:1219-26.

261. Tenover, F. C., R. Arbeit, G. Archer, J. Biddle, S. Byrne, R. Goering, G. Hancock, G. A. Hebert, B. Hill, R. Hollis, and et al. 1994. Comparison of traditional and molecular methods of typing isolates of Staphylococcus aureus. J Clin Microbiol 32:407-15.

262. Tenover, F. C., R. D. Arbeit, R. V. Goering, P. A. Mickelsen, B. E. Murray, D. H. Persing, and B. Swaminathan. 1995. Interpreting chromosomal DNA restriction patterns produced by pulsed-field gel electrophoresis: criteria for bacterial strain typing. J Clin Microbiol 33:2233-9. 
263. Tesch, W., C. Ryffel, A. Strassle, F. H. Kayser, and B. Berger-Bachi. 1990. Evidence of a novel staphylococcal mec-encoded element (mecR) controlling expression of penicillin-binding protein 2'. Antimicrob Agents Chemother 34:1703-6.

264. Thakker, M., J. S. Park, V. Carey, and J. C. Lee. 1998.

Staphylococcus aureus serotype 5 capsular polysaccharide is antiphagocytic and enhances bacterial virulence in a murine bacteremia model. Infect Immun 66:5183-9.

265. Thakker-Varia, S., W. D. Jenssen, L. Moon-McDermott, M. P. Weinstein, and D. T. Dubin. 1987. Molecular epidemiology of macrolides-lincosamidesstreptogramin B resistance in Staphylococcus aureus and coagulase-negative staphylococci. Antimicrob Agents Chemother 31:735-43.

266. Thanh, T., and C. Y. Lee. 2002. Overproduction of type 8 capsular polysaccharide augments Staphylococcus aureus virulence. Infection and Immunity 70:33893395.

267. Thevanesam, V., W. L. Wijeyawardana, and E. W. Ekanayake. 1994. Methicillin resistant Staphylococcus aureus: the scale of the problem in a Shri Lankan hospital. J Hosp Infect 26:123-7.

268. Todd, J., M. Fishaut, F. Kapral, and T. Welch. 1978. Toxic-shock syndrome associated with phagegroup-I Staphylococci. Lancet 2:1116-8.

269. Tomasz, A., H. B. Drugeon, H. M. de Lencastre, D. Jabes, L. McDougall, and J. Bille. 1989. New mechanism for methicillin resistance in Staphylococcus aureus: clinical isolates that lack the PBP 2a gene and contain normal penicillin-binding proteins with modified penicillin-binding capacity. Antimicrob Agents Chemother 33:1869-74.

270. Townsend, D. E., N. Ashdown, J. M. Bradley, J. W. Pearman, and W. B. Grubb. 1984. "Australian" methicillin-resistant

Staphylococcus aureus in a London hospital? Med J Aust 141:339-40.

271. Trick, W. E., R. A. Weinstein, P. L. DeMarais, M. J. Kuehnert, W. Tomaska, C. Nathan, T. W. Rice, S. K. McAllister, L. A. Carson, and W. R. Jarvis. 2001. Colonization of skilled-care facility residents with antimicrobial-resistant pathogens. J Am Geriatr Soc 49:270-6.

272. Turnidge, J. D., and J. M. Bell. 2000. Methicillin-resistant Staphylococcal aureus evolution in Australia over 35 years. Microb Drug Resist 6:223-9.

273. Tyler, K. D., G. Wang, S. D. Tyler, and W. M. Johnson. 1997.

Factors affecting reliability and reproducibility of amplificationbased DNA fingerprinting of representative bacterial pathogens. J Clin Microbiol 35:339-46.

274. Ubukata, K., R. Nonoguchi, M. D. Song, M. Matsuhashi, and M. Konno. 1990. Homology of mecA gene in methicillin-resistant Staphylococcus haemolyticus and Staphylococcus simulans to that of Staphylococcus aureus. Antimicrob Agents Chemother 34:170-2.

275. Ubukata, K., N. Yamashita, and M. Konno. 1985. Occurrence of a beta-lactam-inducible penicillinbinding protein in methicillinresistant staphylococci. 
Antimicrob Agents Chemother 27:851-7.

276. Udo, E. E., L. E. Jacob, and B. Mathew. 2001. Genetic analysis of methicillin-resistant

Staphylococcus aureus expressing high- and low-level mupirocin resistance. J Med Microbiol 50:909-15.

277. Uhlen, M., B. Guss, B. Nilsson, S. Gatenbeck, L. Philipson, and M. Lindberg. 1984. Complete sequence of the staphylococcal gene encoding protein A. A gene evolved through multiple duplications. J Biol Chem 259:1695-702.

278. van Belkum, A. 2000. Molecular epidemiology of methicillinresistant Staphylococcus aureus strains: state of affairs and tomorrow' s possibilities. Microb Drug Resist 6:173-88.

279. Van Belkum, A., N. H. Riewarts Eriksen, M. Sijmons, W. Van Leeuwen, M. Van den Bergh, J. Kluytmans, F. Espersen, and $\mathbf{H}$. Verbrugh. 1997. Coagulase and protein A polymorphisms do not contribute to persistence of nasal colonisation by Staphylococcus aureus. J Med Microbiol 46:22232.

280. van Belkum, A., N. Riewerts Eriksen, M. Sijmons, W. van Leeuwen, M. VandenBergh, J. Kluytmans, F. Espersen, and $H$. Verbrugh. 1996. Are variable repeats in the spa gene suitable targets for epidemiological studies of methicillin-resistant

Staphylococcus aureus strains? Eur J Clin Microbiol Infect Dis 15:768-70.

281. van Belkum, A., W. van Leeuwen, M. E. Kaufmann, B. Cookson, F. Forey, J. Etienne, R. Goering, F. Tenover, C. Steward, F. O'Brien, W. Grubb, P. Tassios, N.
Legakis, A. Morvan, N. El Solh, R. de Ryck, M. Struelens, S. Salmenlinna, J. Vuopio-Varkila, M. Kooistra, A. Talens, W. Witte, and H. Verbrugh. 1998. Assessment of resolution and intercenter reproducibility of results of genotyping Staphylococcus aureus by pulsedfield gel electrophoresis of SmaI macrorestriction fragments: a multicenter study. J Clin Microbiol 36:1653-9.

282. van Belkum, A., W. van Leeuwen, R. Verkooyen, S. C. Sacilik, C. Cokmus, and H. Verbrugh. 1997. Dissemination of a single clone of methicillin-resistant Staphylococcus aureus among Turkish hospitals. J Clin Microbiol 35:978-81.

283. van Leeuwen, N. 2002. Binary typing of Staphyloccus aureus. Erasmus university, Rotterdam.

284. van Leeuwen, W., C. Libregts, M. Schalk, J. Veuskens, H. Verbrugh, and A. van Belkum. 2001. Binary typing of Staphylococcus aureus strains through reversed hybridization using digoxigenin-universal linkage system-labeled bacterial genomic DNA. J Clin Microbiol 39:328-31.

285. van Leeuwen, W., M. Sijmons, J. Sluijs, H. Verbrugh, and A. van Belkum. 1996. On the nature and use of randomly amplified DNA from Staphylococcus aureus. J Clin Microbiol 34:2770-7.

286. van Leeuwen, W., A. van Belkum, $B$. Kreiswirth, and $H$. Verbrugh. 1998. Genetic diversification of methicillin-resistant Staphylococcus aureus as a function of prolonged geographic dissemination and as measured by binary typing and other 
genotyping methods. Res

Microbiol 149:497-507.

287. van Wely, K. H., J. Swaving, R.

Freudl, and A. J. Driessen. 2001.

Translocation of proteins across

the cell envelope of Gram-positive

bacteria. FEMS Microbiol Rev

25:437-54.

288. Verdrengh, M., and A. Tarkowski. 1997. Role of neutrophils in experimental septicemia and septic arthritis induced by

Staphylococcus aureus. Infect

Immun 65:2517-21.

289. Verhoef, J., D. Beaujean, H. Blok, A. Baars, A. Meyler, C. van der Werken, and A. Weersink. 1999. A Dutch approach to methicillinresistant Staphylococcus aureus. Eur J Clin Microbiol Infect Dis 18:461-6.

290. von Eiff, C., K. Becker, K. Machka, H. Stammer, and G. Peters. 2001. Nasal carriage as a source of Staphylococcus aureus bacteremia. Study Group. N Engl J Med 344:11-6.

291. von Eiff, C., C. Heilmann, R. A. Proctor, C. Woltz, G. Peters, and F. Gotz. 1997. A site-directed Staphylococcus aureus hemB mutant is a small-colony variant which persists intracellularly. $\mathrm{J}$ Bacteriol 179:4706-12.

292. Vos, P., R. Hogers, M. Bleeker, M. Reijans, T. van de Lee, $M$. Hornes, A. Frijters, J. Pot, J. Peleman, M. Kuiper, and et al. 1995. AFLP: a new technique for DNA fingerprinting. Nucleic Acids Res 23:4407-14.

293. Voss, A., D. Milatovic, C. Wallrauch-Schwarz, V. T. Rosdahl, and I. Braveny. 1994. Methicillin-resistant Staphylococcus aureus in Europe. Eur J Clin Microbiol Infect Dis 13:50-5.
294. Vuopio-Varkila, J., P. Kotilainen, P. Kujala, J. Lumio, M. Ristola, K. Sammalkorpi, and L. Tiittanen. 1995. Ohje metisilliiniresistenttien Staphylococcus aureusten torjunnasta C1/1995. Kansanterveyslaitos.

295. Wada, A., H. Ohta, K. Kulthanan, and K. Hiramatsu. 1993.

Molecular cloning and mapping of 16S-23S rRNA gene complexes of Staphylococcus aureus. J Bacteriol 175:7483-7.

296. Wagenvoort, J. H., W. Sluijsmans, and R. J. Penders. 2000. Better environmental survival of outbreak vs. sporadic MRSA isolates. J Hosp Infect 45:231-4.

297. Waldvogel, F. A. 2000.

Staphylococcus aureus (including staphylococcal toxic shock), p. 2069-2092. In G. Mandell, J. Bennett, and R. Dolin (ed.), Principles and practise of infectious diseaseases, vol. 2. Churchill Livingstone, Philadelphia.

298. Waldvogel, F. A., and P. S. Papageorgiou. 1980. Osteomyelitis: the past decade. $\mathrm{N}$ Engl J Med 303:360-70.

299. Waxman, D. J., and J. L. Strominger. 1983. Penicillinbinding proteins and the mechanism of action of betalactam antibiotics. Annu Rev Biochem 52:825-69.

300. Wehrli, W. 1983. Rifampin: mechanisms of action and resistance. Rev Infect Dis 5:S40711.

301. Weinstein, M. P., M. L. Towns, S. M. Quartey, S. Mirrett, L. G. Reimer, G. Parmigiani, and L. B. Reller. 1997. The clinical significance of positive blood cultures in the 1990s: a prospective comprehensive 
evaluation of the microbiology, epidemiology, and outcome of bacteremia and fungemia in adults. Clin Infect Dis 24:584-602.

302. Weist, K., K. Pollege, I. Schulz, H. Ruden, and P. Gastmeier. 2002. How many nosocomial infections are associated with crosstransmission? A prospective cohort study in a surgical intensive care unit. Infect Control Hosp Epidemiol 23:127-32.

303. Westh, H., J. O. Jarlov, H. Kjersem, and V. T. Rosdahl. 1992. The disappearance of multiresistant Staphylococcus aureus in Denmark: changes in strains of the 83A complex between 1969 and 1989. Clin Infect Dis 14:1186-94.

304. Wieneke, A. A., D. Roberts, and R. J. Gilbert. 1993. Staphylococcal food poisoning in the United Kingdom, 1969-90. Epidemiol Infect 110:519-31.

305. Witte, W., C. Braulke, D. Heuck, and C. Cuny. 2000. Methicillinresistant Staphylococcus aureus in German hospitals develop narrower patterns of antimicrobial resistance. Eurosurveillance 5:3134.

306. Witte, W., C. Cuny, C. Braulke, D. Heuck, and I. Klare. 1997. Widespread dissemination of epidemic MRSA in German hospitals. Eurosurveillance 2:2529.

307. Witte, W., M. Kresken, C. Braulke, and C. Cuny. 1997. Increasing incidence and widespread dissemination of methicillin-resistant Staphylococcus aureus (MRSA) in hospitals in central Europe, with special reference to German hospitals. Clin Microbiol Infect 3:414-422.
308. Witte, W., G. Werner, and C. Cuny. 2001. Subtyping of MRSA isolates belonging to a widely disseminated clonal group by polymorphism of the $d r u$ sequences in mec-associated DNA. Int J Med Microbiol 291:57-62.

309. Wu, S., C. Piscitelli, H. de Lencastre, and A. Tomasz. 1996. Tracking the evolutionary origin of the methicillin resistance gene: cloning and sequencing of a homologue of mecA from a methicillin susceptible strain of Staphylococcus sciuri. Microb Drug Resist 2:435-41.

310. Yarwood, J. M., J. K. McCormick, and P. M. Schlievert. 2001. Identification of a novel twocomponent regulatory system that acts in global regulation of virulence factors of Staphylococcus aureus. J Bacteriol 183:1113-23. 
10. ORIGINAL PUBLICATIONS 